Een methode ter bepaling van kostenefficiënte inspectiestrategieën in multistadia-productiesystemen

\title{
A Method for Determining Cost-Efficient Inspection Strategies in Multistage Production Systems
}

Sofie Van Volsem

Promotoren: prof. dr. ir. H. Van Landeghem, prof. dr. C. Van Mechelen

Proefschrift ingediend tot het behalen van de graad van

Doctor in de Ingenieurswetenschappen

Vakgroep Technische Bedrijfsvoering

Voorzitter: prof. dr. ir. H. Van Landeghem

Faculteit Ingenieurswetenschappen

Academiejaar 2005 - 2006

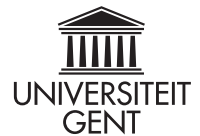


ISBN 90-8578-055- I

NUR 957, 804

Wettelijk depot: D/2006// 0.500// 3 
To the true cynic nothing is ever revealed

Oscar Wilde 



\section{Dankwoord}

\section{(Acknowledgement)}

Gedurende het voorbereiden en totstandkomen van deze thesis hebben velen mijn pad gekruist, en zo, direct of indirect, hun invloed gehad op dit werk.

Het is een onmogelijke taak iedereen persoonlijk te vermelden in deze korte tekst. In elk geval wil ik allen die een steentje hebben bijgedragen via deze weg zeggen: dank je, zonder jou was het dit niet geworden.

Voorop in de rij van personen naar wie mijn bijzondere dank uitgaat staan de professoren:

Peter Vanrolleghem -als copromotor van mijn ingenieursthesis- was de eerste die erin geloofde dat ik (en ik citeer) "het in me had om te doctoreren". Peter, bedankt voor het vertrouwen.

Rik Van Landeghem aanvaardde de niet-evidente opdracht om mijn promotor te worden en gaf me zo de gelegenheid en de ruimte om dit onderzoekswerk aan de UGent te doen, vanuit mijn UA thuisbasis. Rik, bedankt voor de samenwerking. Je geduld, je steun en je blijvende enthousiasme, ondanks onze lange-afstandsrelatie, waren inspirerend.

Claude Van Mechelen die het copromotorschap op zich heeft genomen. Claude, bedankt voor het belangstellend opvolgen van de vorderingen en de nuttige commentaren.

Herbert Peremans, voor de fijne samenwerking, de waardevolle opmerkingen na het kritisch nalezen, de hulp met MatLab.

Peter Ottoy, als commissielid en begeleider, ook steeds bereid me bij te staan ondanks de afstand en de beperkte tijd. 
El-Houssaine Aghezzaf en Frank Devlieghere, leden van de jury, voor het zorgvuldig nalezen en de opmerkingen die daaruit voortvloeiden.

Wout Dullaert was er van in het prille begin bij om samen "de wereld te veroveren" vanop de vijfde verdieping (waar is de tijd...?). Merci maat, je hulp was van onschatbare waarde, je vriendschap een bonus!

Karel Soudan mijn "baas" op het UA-(onderwijs)front. Je creëerde het flexibele klimaat dat de combinatie UA/UGent/thuiswerk mogelijk maakte; mijn oprechte erkentelijkheid daarvoor.

Johan Springael, voor het onuitputtelijke enthousiasme.

Verder een hele grote "dankoewel" voor een hele bende toffe collega's. Bedankt voor jullie steun, jullie luisterend oor, jullie praktische hulp, jullie tijd, kortom: bedankt voor jullie vriendschap! Voor de meesten die hieronder vermeld staan is de vriendschap zelfs "extra muros" geworden; dat het zo mag blijven!

Mike, dat je naam vooraan in dit rijtje komt zal niemand verbazen. Merci voor het delen van hectoliters koffie en bijhorende babbels, de ontelbare onnozele mailtjes over en weer, het badminton als sportieve uitlaatklep. Je blijft, behalve uiteraard mijn vriend, ook mijn grote voorbeeld als Rustige Mens ;-) : geen zorgen, geen stress, niet druk-druk-druk maar gewoon rustig voortdoen!

Amaryllis, we deelden minder koffie maar zeker evenveel babbels, minder mailtjes maar meer (soms zelfs een beetje te veel ;-) ...) telefoontjes. Je was als ex-lotgenootje en ex-bureaugenootje een uitstekend klankbord en dito steun... en ook een voorbeeld voor wat betreft het combineren van een jong gezin met een doctoraat.

Sigrid, Patsy, Martine, Hilde: onze professionele wegen zijn al een tijdje gescheiden, hopelijk blijven onze persoonlijke wegen kruisen.

Birger, op het Gentse front: het programmeerwerk, en het immer grappige gezever zullen niet licht vergeten worden.

.iv $\cdots$ 
Tom, Carlos en co: fifth floor forever! Tot in de Ardennen!

Kenneth, Nico, Gensy, Katja: als huidige- en ex-bureaugenoten de eerste uitlaatklep op de mindere momenten: bedankt voor alle peptalk en het verdragen van mijn kuren. Het was tijdens de laatste schrijfdagen ook bijzonder handig om Kenneth als $\mathrm{AT}_{\mathrm{E}} \mathrm{X}$-expert in de buurt te hebben, en Nico en Katja als spellingscheckers...

de resto-groep: voor het delen van bokes, soep, en op tijd en stond een portie frieten; uiteraard steeds overgoten met de beste saus: een goed "klapke"!

alle MTT- en WIS-collegae: dank voor het delen van ups \& downs, voor de aanmoedigingen, voor de hulp ook bij de vervelendste integralen en statistische finesses.

\section{alle TW18 collegae}

De grootste dank gaat natuurlijk uit naar het thuisfront.

Bedankt vrienden en familie, om me regelmatig genoeg te herinneren aan alles wat het leven te bieden heeft buiten de werkuren en naast een doctoraat.

Bedankt mama en papa, mijn warme thuizen hebben ervoor gezorgd dat ik op een fijne manier mijn weg in het leven kon zoeken én vinden. Bedankt ook dat jullie me de kans hebben gegeven om te gaan studeren en bovendien het klimaat hebben gecreëerd waarin dat studeren tot een goed einde kon worden gebracht.

Bedankt Sven, voor onze eigen warme thuis, en voor 1001 overige redenen die ik hier niet zal vermelden, ik fluister ze wel eens in je oor... Bedankt kindjes, you are the reason. 



\section{Contents}

Acknowledgement

List of Figures xiii

List of Tables $\quad$ Xv

Dutch Summary xvii

Summary xxi

I Theoretical framework 1

1 A review on quality economics - techniques, models, and literature 3

1.0 Chapter purpose and outline ........... . 3

1.1 Introduction and a historical perspective on quality thinking 4

1.2 Quality economics: overview . . . . . . . . . 5 5

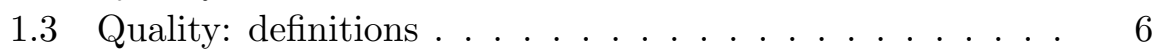

1.4 Quality costing ................ 7

1.4.1 Definitions . . . . . . . . . . . . 7

1.4.2 Quality cost models . . . . . . . . . . . . 9

1.4.3 QC model applications and field studies . . . . . . 13

1.4.4 Quality loss functions ............... 15

1.5 Designing and Manufacturing for Quality . . . . . . . . 15

1.5.1 Quality Function Deployment (QFD) . . . . . . 15

1.5 .2 Tolerancing . . . . . . . . . . . . . 17 
1.5.3 Process capability and loss functions: determining and quantifying variance . . . . . . . . . . . . 21

1.5.4 Optimal process level . . . . . . . . . . . . . . 28

1.5.5 Inspection and process control . . . . . . . . . 30

1.6 Inspection . . . . . . . . . . . . . . . . . 31

1.6.1 The basics of acceptance sampling . . . . . . . . 33

1.6.2 Single sampling . . . . . . . . . . . . . . . . 34

1.6.3 Discriminatory power of a sampling plan . . . . . . 36

1.7 Process control . . . . . . . . . . . . . . 36

2 Quality inspection in multistage production systems - literature review 39

2.0 Chapter purpose and outline . . . . . . . . . . . 39

2.1 Introduction . . . . . . . . . . . . . . . . . . 39

2.2 Separate optimization . . . . . . . . . . . . . 41

2.2.1 Inspection allocation . . . . . . . . . . . . . 41

2.2.2 Sample size and sampling frequency . . . . . . . . 41

2.2.3 Acceptance limits, quality levels, specifications . . 42

2.3 Joint optimization . . . . . . . . . . . . . . . . 42

2.4 Concluding comment . . . . . . . . . . . . . . . 46

2.A A simple example of Chen's approach . . . . . . . 47

3 Solving the MSPS inspection optimization problem - an analytical approach 51

3.0 Chapter purpose and outline . . . . . . . . . . 51

3.1 Model formulation . . . . . . . . . . . . . . . . 51

3.1.1 The serial multistage production system . . . . . 51

3.1.2 Determination of the TIC . . . . . . . . . . 54

3.2 Analytical calculations for a three-stage example . . . . . 55

3.2 .1 The general case . . . . . . . . . . . . 58

3.2.2 The case of no inspection $(\mathrm{NNN}) \ldots \ldots \ldots$

3.2.3 The cases of full inspection in one of the three stages 60

3.2.4 The cases of full inspection in more than one of the three stages (NFF, FNF, FFN, FFF) . . . . . . 65

3.3 Limitations of an analytical approach . . . . . . . . 65

3.A General statistical notions . . . . . . . . . . . . . 65

-viii. . 
3.A.1 Common notations . . . . . . . . . . . 65

3.A.2 Confidence intervals . . . . . . . . . . 67

3.A.3 Linear combination of random variables . . . . . 68

3.A.4 Truncated normal distributions . . . . . . . . . 68

3.B Some integral calculus . . . . . . . . . . . . . 70

\section{Development and validation of a new solution method} for the MSPS inspection optimization problem

4 Solutions to the MSPS inspection optimization problem - a metaheuristic approach: an Evolutionary Algorithm and Simulation $\quad \mathbf{7 5}$

4.0 Chapter purpose and outline . . . . . . . . . . . 75

4.1 Introduction . . . . . . . . . . . . . . 76

4.2 Mathematical preliminaries on optimization . . . . . . 77

4.2.1 Types of minima . . . . . . . . . . . . . . 77

4.2 .2 Optimality conditions . . . . . . . . . . . . . 79

4.3 Optimization methods: a brief overview . . . . . . . . 80

4.3.1 Solution methods based on systematic search techniques . . . . . . . . . . . . . 80

4.3.2 Solution methods based on random search techniques 81

4.4 A metaheuristic solution approach . . . . . . . . . . 83

4.4.1 Monte Carlo simulation to calculate TIC . . . . . 83

4.4.2 An Evolutionary Algorithm to determine the optimal inspection strategy - first version $(\mathrm{EA} / 1)$. . . 84

4.4.3 An Evolutionary Algorithm to determine the optimal inspection strategy - second version $(\mathrm{EA} / 2) \quad$. $\quad 89$

4.5 Computational testing . . . . . . . . . . . . . . 90 $4.5 .1 \mathrm{EA} / 1 \ldots \ldots \ldots \ldots \ldots$

$4.5 .2 \mathrm{EA} / 2 \ldots \ldots \ldots \ldots \ldots$

4.6 Influence of the cost parameters on MSPS optimization . 98

4.6.1 Simulation: process and assumptions . . . . . . . . 98

4.6.2 Simulation modeling: program . . . . . . . . . . . 99

4.6.3 Influence of the cost parameters . . . . . . . . . 100

4.6 .4 Conclusions . . . . . . . . . . . . . . . . . 107 
4.A Metaheuristics: an overview . . . . . . . . . . . 107 4.A.1 Neighborhood-based metaheuristics . . . . . . . . . 108 4.A.2 Population-based metaheuristics . . . . . . . . . 111 4.A.3 Hybrid metaheuristics . . . . . . . . . . . . . 113

4.B Notes on statistical analysis of simulation output . . . . 113

$\begin{array}{ll}5 \text { A case study } & 117\end{array}$

5.0 Chapter purpose and outline . . . . . . . . . . . 117

5.126 cases . . . . . . . . . . . . . . . . . 117

5.2 Discussion . . . . . . . . . . . . . . . . . 121

5.2.1 The additive cases (A through J): general observations . . . . . . . . . . . . . . . . 121

5.2.2 Case A, the additive base case . . . . . . . . . 123

5.2.3 Comparison of case A to cases B and C . . . . . 123

5.2.4 Comparison of case A to cases D and E . . . . . 123

5.2.5 Comparison of cases F, G, H, I and J . . . . . . 123

5.2.6 The multiplicative cases ( $\mathrm{K}$ through $\mathrm{T}$ ): general observations . . . . . . . . . . . . . . 124

5.2.7 Comparison of cases K, L, M, N and O . . . . 125

5.2.8 Comparison of cases P, Q, R, S and T . . . . . 126

5.2.9 Comparison of cases U, V, W, X, Y, Z . . . . . . 127

5.3 Note on the statistical significance of the results . . . . . 127

6 Concluding comments \& suggestions for further research129

6.1 Concluding comments . . . . . . . . . . . . . . 129

6.2 Suggestions for further research . . . . . . . . . . . . 130

III Appendices

133

A EA2/stat output: an example 135

A.1 Results file: final generation . . . . . . . . . . . . 135

A.1.1 Example 1. . . . . . . . . . . . . . . . 135

A.1.2 Example 2. . . . . . . . . . . . . . . . . 144

A.2 Results file: statistical analysis . . . . . . . . . . . . . 148

A.2.1 Example 1. . . . . . . . . . . . . . . . . 148

A.2.2 Example 2. . . . . . . . . . . . . . . 150

$\cdot \mathrm{x} \cdot \cdot$ 
B Random number generation $\quad 151$

C Computational complexity theory: some definitions $\quad 155$

$\begin{array}{ll}\text { Bibliography } & 159\end{array}$ 



\section{List of Figures}

1.1 Conceptual difference between Total Quality Cost models 12

1.2 TQC evolution over time . . . . . . . . . . . . . . 13

1.3 Methodological areas in Designing and Manufacturing for Quality ..................... 16

1.4 House of Quality: general form . . . . . . . . . . . 17

1.5 House of Quality: example . . . . . . . . . . . . . 18

1.6 Calculation of $C_{p}$ and $C_{p k}$ indices: some examples . . . 24

1.7 Basic loss functions . . . . . . . . . . . . . . . . 27

1.8 Operating Characteristic curve: example . . . . . . . 35

2.1 A three part stack-up assembly . . . . . . . . . . . . 47

2.2 Decision tree . . . . . . . . . . . . . . . . 48

2.3 General evolution of total expected cost with inspection parameter $t_{01} \ldots \ldots \ldots \ldots \ldots \ldots$. . . . . . . 49

3.1 A serial n-stage MSPS . . . . . . . . . . . . . . 52

3.2 Inspection costs versus defect rate for different inspection options . . . . . . . . . . . . 57

4.1 Types of minima . . . . . . . . . . . . . 78

4.2 Solution quality versus calculation time . . . . . . . 82

4.3 OC curves for single sampling schemes with various parameters . . . . . . . . . . . . . . 90

4.4 TIC as a function of generation number, for 25 replications

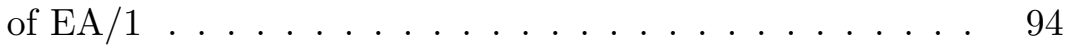

4.5 TIC versus multiplication factor $a$ for NNN, FFF and cost optimal inspection strategies . . . . . . . . . . 104 
4.6 Schematic operating principle of Tabu Search Algorithms 110

4.7 Schematic operating principle of Genetic and Evolutionary Algorithms . . . . . . . . . . . . . . . . 113

5.1 Paired mean differences between solutions, and their confidence intervals: case B . . . . . . . . . . . . . . 128

5.2 Paired mean differences between solutions, and their confidence intervals: case P . . . . . . . . . . . . 128

$\cdot x i v \cdot \cdots$ 


\section{List of Tables}

1.1 Determination of single sampling parameters for given $\alpha$

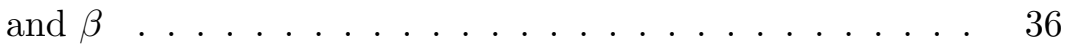

3.2 Example 1: process and inspection characteristics . . . . 56

3.3 Example 1: cost parameters . . . . . . . . . . . . 56

4.1 Taxonomy of optimization problems . . . . . . . . 77

4.2 Process characteristics . . . . . . . . . . . . . . . 92

4.3 Cost parameters . . . . . . . . . . . . . . . . 92

$4.4 \mathrm{EA} / 1$ Solutions . . . . . . . . . . . . . . . . . . 95

$4.5 \mathrm{EA} / 2$ Solutions . . . . . . . . . . . . . . 97

4.6 Process parameter settings for experiment series $1 \ldots 100$

4.7 Cost parameter settings for experiment series $1 \ldots$. . . . 101

4.8 Inspection parameter settings for experiment series 1 . . 102

4.9 Optimal inspection strategies for experiment series 1 . . 103

4.10 Cost parameter settings for experiment series $2 \ldots \ldots$. . 105

4.11 Cost parameter settings for experiment series $2 \ldots \ldots$. 106

5.1 Cases A through J, general setting . . . . . . . . . . 118

5.2 Cases A/B /C/D/E, specific setting . . . . . . . . 118

5.3 Cases $\mathrm{F} / \mathrm{G} / \mathrm{H} / \mathrm{I} / \mathrm{J}$, specific setting . . . . . . . . . . 119

5.4 Cases K through $\mathrm{O}$, general setting . . . . . . . . . . . 119

5.5 Cases K/L/M/N/O, specific setting . . . . . . . . . 119

5.6 Cases $\mathrm{P}$ through $\mathrm{T}$, general setting . . . . . . . . . . . 119

5.7 Cases $\mathrm{P} / \mathrm{Q} / \mathrm{R} / \mathrm{S} / \mathrm{T}$, specific setting . . . . . . . . 120

5.8 Cases U through Z, general setting . . . . . . . . . . 120

5.9 Cases U/V/W, specific setting . . . . . . . . . . 120 
5.10 Cases X/Y/Z, specific setting . . . . . . . . . . . 120

5.11 Fixed parameters for all cases . . . . . . . . . . . . 121

5.12 Winners ... . . . . . . . . . . . . . . 122

$\cdot x v i \cdot \cdots$ 


\section{Samenvatting}

Efficiënte kwaliteitscontroles zijn van het grootste belang in elke productieomgeving. Voor veel bedrijven is kwaliteit immers, in het huidige geglobaliseerde ondernemingsklimaat, een strategisch element in de continue strijd om verbetering van winstgevendheid, marktaandeel en competitiviteit. Het bereiken van kwaliteit vereist een geïntegreerde aanpak van verschillende aspecten (wat verschillende studiedomeinen met zich meebrengt): kwaliteitsbewust ontwerpen, kwaliteitsbewust produceren, kwaliteit in dienstverlening, en het beheer van kwaliteit en kwaliteitssystemen (kwaliteitsmanagement).

In deze dissertatie wordt gewerkt rond een specifiek instrument voor het bereiken van kwaliteit in een productie-omgeving, namelijk kwaliteitsinspecties. Kwaliteitsinspecties worden gebruikt om productkwaliteitskarakteristieken te beoordelen, mogelijk in verschillende stadia van het productieproces. Indien een geïnspecteerd product, of onderdeel, van een (te) lage kwaliteit blijkt te zijn, kan het ofwel herwerkt worden, ofwel uit het productieproces verwijderd worden. In het domein van economisch kwaliteitsbeheer worden de kosten en baten gerelateerd aan het bereiken van kwaliteit in een productie- of dienstenomgeving bestudeerd.

De meeste productieprocessen bestaan uit een sequentie van productiestadia. Elk productiestadium (uitgezonderd het laatste) produceert zo de toevoer (input) voor het daaropvolgend stadium. Omdat de productieprocessen van nature stochastisch zijn, zullen er afwijkingen van de productspecificaties optreden, die, zonder interventie, zullen accumuleren in de loop van de productieketen. Daarom zou het uitvoeren van kwaliteitsinspectie enkel aan het einde van de productieketen, kunnen resulteren in een hoog aantal producten van ontoereikende kwaliteit, en navenant hoge kosten voor het herwerken of vernietigen van deze de- 
fecte producten.

Een (kosten)optimale inspectiestrategie voor een zogenaamd multistadia-productiesysteem (MSPS) zal daarom moeten beslissen over het geheel van (i) het aantal inspectiestations en hun lokatie in het productieproces, (ii) de grootte van de productiefractie die aan inspectie onderworpen zal worden (staalnamegrootte) en (iii) de gestrengheid van de inspectie (aanvaardingsgrenzen) bij elk inspectiestation, met het oog op het minimaliseren van de totale verwachte inspectiekost.

Vereenvoudigd gesteld zal meer en strengere inspectie normaalgezien leiden tot hogere productkwaliteit, maar ook tot hogere kosten voor het inspecteren, herwerken en vernietigen. Het kwantificeren van deze wisselwerking in het algemeen, en het vinden van het economisch optimum in het bijzonder, vormt de kern van dit onderzoek.

Naar ons beste weten bevat dit doctoraal proefschrift de eerste methode voor het gezamenlijk optimaliseren van (i), (ii) en (iii), i.e. het aantal inspectiestations en hun lokatie, en hun respectieve inspectiemodi, inspectielimieten en staalnameparameters.

Hiertoe is het proefschrift als volgt ingedeeld: in Hoofdstuk 1 wordt het globale domein van economisch kwaliteitsbeheer geschetst, teneinde het doctoraatsproject te situeren in zijn onderzoeksomgeving. Het eigenlijke onderwerp van deze thesis, met name het kostenefficiënt ontwerpen van kwaliteitsinspectiestrategieën voor multistadia-productiesystemen, is gestoeld op de technieken aangereikt in dit inleidende Hoofdstuk.

Het MSPS-inspectie-optimalisatieprobleem zelf, de probleemspecifieke kwesties en de literatuur erover worden besproken in Hoofdstuk 2. Over het basisprobleem van inspectie-allocatie, zijnde de beslissing over plaatsing (aantal en lokatie) van inspectiestations in multistadia productieketens, werd reeds een veelheid aan theoretisch werk gepubliceerd; enkele van de besproken oorspronkelijke publicaties dateren uit de jaren ' 60 .

Ook het verdelen van toleranties of het afzonderlijk optimaliseren van inspectielimieten kreeg in de literatuur al veel aandacht, net zoals het economisch ontwerp van staalnameschema's en controlekaarten. Bij het literatuuronderzoek blijkt er echter een leemte waar het het gezamenlijk optimaliseren van alle aspecten van inspectiestrategiebepaling voor MSPSen betreft.

Hoofdstuk 3 onderzoekt analytische oplossingen voor het MSPS-in$\cdot x$ viii $\cdots$ 
spectie-optimalisatieprobleem. Eerst wordt het in dit werk gebruikte MSPS model voorgesteld. Vervolgens worden analytische berekeningen uitgevoerd voor enkele voorbeeldgevallen, met het oog op het verwerven van inzicht in de mogelijkheden tot analytisch oplossen van het MSPSinspectie-optimalisatieprobleem. Ten slotte wordt er licht geworpen op de limitaties van een analytische aanpak.

De metaheuristische oplossingsmethode voor het MSPS-inspectie-optimalisatieprobleem voorgesteld in deze thesis, vormt het onderwerp van Hoofdstuk 4.

Daartoe start dit Hoofdstuk met een inleiding tot, de voorwaarden voor, en een overzicht van mathematisch optimaliseren. Er wordt een overzicht gegeven van zoekmethodes gebaseerd op systematische of deterministische algoritmes. Vervolgens worden methoden gebaseerd op toevallige of stochastische zoektechnieken overlopen.

Eén van deze heuristieken, namelijk een evolutionair algoritme, is de basis voor de voorgestelde oplossingsmethode. De techniek bestaat in essentie uit een evolutionair algoritme gecombineerd met simulatie. Simulatie wordt gebruikt om het MSPS onderworpen aan inspectie te modelleren en de resulterende inspectiekosten te berekenen, het evolutionair algoritme optimaliseert de eigenlijke inspectiestrategie. De aanpak wordt geschetst en berekeningsvoorbeelden, indicatief voor het potentieel van deze metaheuristiek in de optimalisatie van kwaliteitsinspectie, worden gegeven. Vervolgens wordt geillustreerd wat effect is van de (exogene) kostparameters op de uitkomst van de MSPS inspectie-optimalisatie.

Het Hoofdstuk bevat ook twee Appendices; de eerste bespreekt kort de beginselen van enkele andere frequent gebruikte metaheuristieken en motiveert tevens de keuze voor een evolutionair algoritme. De tweede Appendix is gewijd aan het bespreken van statistische analyses (betrouwbaarheid en betrouwaarheidsintervallen) van simulatie-uitkomsten.

In Hoofdstuk 5 wordt een gevalstudie opgezet om de karakteristieken, mogelijkheden en beperkingen van de voorgestelde metaheuristiek te verkennen. Eerst worden de gevallen voorgedragen. Met het oog op het verwerven van inzicht in de mogelijkheden van de metaheuristiek in verschillende situaties, werden 26 verschillende -doch vergelijkbare- gevallen geselecteerd, met verscheiden proces- en kostparameters. Daarna volgt een bespreking van de berekende resultaten. 
Tot slot worden besluiten en suggesties voor verder onderzoek aangegeven in Hoofdstuk 6. 


\section{Summary}

Efficient production quality control is a major issue to manufacturers. After all, cost-efficiently improving the quality of products, processes and services is -in the present global business environment- a key focus point of many organizations in their struggle to improve their profitability, market share and competitiveness. The achievement of quality involves many different aspects, yielding different fields of study: designing quality, manufacturing quality, servicing quality and managing quality.

In this thesis, focus is on a specific tool for achieving high manufacturing quality: quality inspections. Quality inspections are used to evaluate the quality characteristics of a product, possibly at several phases in its production process. If an inspected product (or product part) is found to be of a (too) low quality, it can either be reworked or rejected. The domain of quality economics studies the costs and benefits related to these efforts for achieving manufacturing or service quality.

Most production processes consist of a sequence of production stages. Each stage (but the last) produces input for the next production stage. As the production processes at each stage are generally stochastic in nature, deviations from expected product specifications occur, which, without intervention, will accumulate in the course of the production process. Quality inspection only at the last stage could therefore result in a large number of faulty products and high rework and scrap costs.

An optimal inspection strategy for a so-called serial multistage production system (MSPS) therefore has to decide on (i) the number and location of inspection stations, (ii) the size of the production fraction subject to inspection (sample size) and (iii) the rigor of the inspections (acceptance limits) at each inspection station, in order to minimize total expected inspection costs. 
Simplified, more and tighter inspection will normally induce a higher product quality -in terms of meeting product specifications- but will also result in higher costs of inspection, scrap and rework. Quantifying this trade-off and thus establishing ways of finding an economic optimum is at the heart of this research.

To our best of knowledge, this dissertation contains the first method for jointly optimizing the number and location of inspection stations, their inspection type, inspection limits and inspection sampling parameters.

Thereto, the dissertation is organized as follows: in Chapter 1 a sketch of the general domain of quality economics is drawn, in order to situate the thesis project in its research environment. The actual subject of this thesis, economic design of quality inspection strategies for multistage processes, builds on the techniques presented in this introductory Chapter.

The MSPS inspection optimization problem itself, with the problemspecific issues and the literature on it, are discussed separately, in Chapter 2. A variety of theoretical work has been published on the subject of optimal inspection allocation for multistage process chains, i.e. on the decision of where to place inspection stations in multistage processes. Some of the seminal papers that are discussed date back to the 60 's.

Tolerancing, or the separate optimization of inspection limits, has also received a lot of attention in the literature, as has the economic design of sampling schemes and control charts. However, the literature review reveals a void where jointly looking into all aspects of inspection policy setting for MSPS'es is concerned.

Chapter 3 investigates analytical solutions to the MSPS inspection optimization problem. First, the MSPS modeling framework used in this thesis, is introduced. Thereupon, analytical calculations for some examples cases are proposed, with an eye to gain an insight into the possibilities of tackling the MSPS inspection optimization problem analytically. Finally, some light is shed on the limitations of an analytical approach.

The metaheuristic solution method for the MSPS inspection optimization proposed in this thesis, is presented in Chapter 4.

Thereto, the Chapter starts with an introduction to, preliminaries for, and an overview of mathematical optimization. An overview of methods based on systematic or deterministic search techniques is introduced. Subsequently, an overview of methods based on random or stochastic $\cdot x x i i \cdot \cdots$ 
search techniques is proposed.

One of these techniques, namely evolutionary algorithms, is the basis for the suggested solution method. The solution technique essentially consists of combining an evolutionary algorithm with simulation.

Simulation is used to model the MSPS subject to inspection and to calculate the resulting inspection costs, an evolutionary algorithm is proposed to optimize the inspection strategies. The solution approach is outlined and examples are computed, indicating the potential of the metaheuristic for optimizing quality inspection. Subsequently, the influence of the (exogenous) cost parameters on the outcome of the MSPS inspection optimization problem is illustrated.

The Chapter also contains two Appendices. The first is concerned with reviewing some of the other frequently used metaheuristics; and it is discussed why preference was given to an EA to tackle the MSPS inspection optimization problem. The second Appendix is devoted to a discussion on statistical analysis (reliability and confidence intervals) of simulation output.

In Chapter 5, a case study is built to explore the characteristics, possibilities and limitations of the proposed metaheuristic solution technique. First the cases are presented; 26 different -yet comparable- cases were selected, each with distinct process and cost characteristics, in order to gain insight in the possibilities of the metaheuristic in various situations. Consecutively, the computational results are discussed.

Concluding comments, and suggestions for further research are presented in Chapter 6. 

Part I

theoretical framework 



\section{Chapter 1}

\section{a review on quality economics - techniques, models, and literature}

\subsection{Chapter purpose and outline}

It is not the intention of this Chapter to provide in-depth details on the techniques and models discussed, but rather to introduce some of the ideas used throughout this thesis, and to situate the thesis subject in its research environment. The reader is referred to some standard textbooks on each specific subject if and where appropriate.

After a general introduction and a historical perspective on quality thinking in Section 1.1, a brief overview on quality economics in Section 1.2, and a tour on definitions of quality in Section 1.3, different quality economics techniques and models are discussed. The overview begins with the topic of quality costing, with its definitions, models, relevance, applications and shortcomings, in Section 1.4. Then Section 1.5 touches the broad domain of designing and manufacturing for quality, both in product development and in quality control. It includes an introduction in the basics of tolerancing, process capabilities, optimal process levels, process control, inspection (sampling and sampling plans); as well as an outline of the literature on these subjects. Given their relative importance, the topics on inspection and process control are more amply discussed in Sections 1.6 and 1.7.

The subject of this dissertation, economic design of quality inspection 
strategies for multistage processes, builds on the techniques presented in Sections 1.5, 1.6 and 1.7. The problem itself, the problem-specific issues and literature are discussed separately in Chapter 2.

\subsection{Introduction and a historical perspective on quality thinking}

Although quality thinking has "boomed and bloomed" significantly over the last few decades, in practice as well as in literature, it is of course by no means new. A law in the codex of the Babylonian king Hammurabi (1800 b.C.) is frequently cited as a first example of quality control and product liability: "The mason who builds a house that collapses and thereby wounds or kills the inhabitants will be executed".

Inspection and product control exist since men started to barter. The idea of a uniform production goes back to the Egyptian pharaohs, when pyramid bricks were produced to a standard size, with an amazing accuracy and precision. In the Middle Ages, craftsmen were united in guilds, institutions that controlled the admittance to the trade, to guarantee among other things- a certain quality standard of that trade or profession.

Fundamental changes were brought about by the second industrial revolution (1789-1914), with e.g. the introduction of an industrially useable steam engine by Watt; and revolutions in industrial chemistry such as the full-scale ammonia synthesis process by Kellogg. Mass production was brought on by the use of steam engine drives that allowed a scaleup from domestic industry to factories. The need for standardization (exchangeable components instead of individual, unique tools; factory laborers instead of craftsmen) originated from this concept of mass production. This new way of producing goods necessitated quality control as a separate task next to the actual production, as it became impossible for individual workers-executers to have an overview of the entire production process or to be aware of the customers' product expectations. Work instructions were introduced as well as controllers and inspectors, the quality of execution of each task measured and compared to standards. The (quality) controller became the factory policeman, the workers' involvement and motivation minimal. These principles of early mass production (a.k.a. Taylorism or scientific management) would rule industry roughly

$.4 \cdot$ 
till mid-20th century.

In the interbellum, Dodge and Romig's acceptance sampling techniques and Shewhart's control charts were developed at the heart of the Bell Telephone Laboratories. World War II, or more precisely the war industry behind it, made quality inspection and the application of these techniques leap forward. The American military had trained a lot of personnel in these quality techniques during the war. From these people, the ASQC (American Society for Quality Control) was founded after the war. But the Americans were initially very focussed on inspection only, which caused quality gurus Deming and Juran to turn to Japan to develop and implement their more comprehensive ideas on quality and quality management. As a result, important parts of modern quality thinking, and a lot of quality (management) tools, originated in Japan.

From the eighties on, quality awareness has flourished worldwide, in industry as well as in science. New management concepts on quality, as well as new diagnostic (statistical) tools and techniques, found their way into industrial and research entities. In the new millennium, the strategic importance of total quality management has become generally accepted. Improving the quality of products, processes and services is nowadays a key focus point of many organizations in their struggle to improve -or at least maintain- their profitability, market share and competitiveness. Therefore, there has been much interest in the so-called economics of quality. In the remains of this Chapter, an overview of the main research lines in this broad field will be given.

\subsection{Quality economics: overview}

Quality economics might be defined as the study of costs and benefits related to the achievement of manufacturing or service quality (Clark and Tannock, 1999). Thus, the two main constituting elements of quality economics comprised in this definition are (i) the study of costs and benefits and (ii) the achievement of quality.

(i) Before the costs can be studied, they have to be collected in some systematic way: hence the existence of quality costing systems. In Section 1.4 some general ideas on quality costing are summarized. 
(ii) The achievement of quality involves different aspects, yielding different fields of study. Contributions in this area fall into four basic categories: designing for quality, manufacturing for quality, servicing for quality and managing for quality. The latter two fields fall outside the scope of this thesis and thus will not be discussed in this literature review.

One could say that designing for quality (DfQ) is making sure the right things are done, while manufacturing for quality (MfQ) is making sure things are done right.

Concepts and techniques on DfQ and MfQ will be discussed in Section 1.5 .

\subsection{Quality: definitions}

But now what is quality? Definitions are as manifold as authors. A useful categorization of different definitions is proposed by Demeulemeester and Callewier (1997) based on the seminal paper by Garvin (1984). Five groups of quality definitions are identified:

\section{Transcendent definitions}

In this vision quality is synonymous with "innate excellence", absolute and universally recognizable. It is the philosopher's point of view, and in this approach quality is not tangible nor analyzable, comparable to the abstract and subjective notion of "beauty".

\section{Product-based definitions}

In this vision the starting point is quite the opposite: quality is viewed as a precise and measurable variable. It is the economist's point of view: differences in quality reflect differences in attributes possessed by products.

\section{User-based definitions}

The premise here is that quality lies in the eyes of the beholder. The viewpoint is market-oriented, and thus this type of quality definitions is subjective, as the customers' individual wishes can be 
interpreted in different ways. Quality can stand for "fitness for use", or meeting consumer's "needs", "expectations" or "goals".

4. Manufacturing-based definitions

Starting point for this group of definitions is not the user/customer (demand), but the engineering and production practice (supply). Quality is defined as (the rate of) conformity to specifications, leading to objective measures of quality in terms of these specifications (target value and tolerances).

5. Value-based definitions

This approach defines quality in terms of costs and benefits: this point of view links product performance to an "affordable" price (demand side), or production conformance to an "acceptable" cost (supply side).

These different views on quality co-exist; according to the situation or the problem studied, one will be more appropriate than another. For example, in a design or production setting, the value-based and manufacturing-based definitions will prevail, while in a marketing environment the user-based definitions will dominate.

As this thesis is concerned with cost optimal inspection strategies, the supply side value-based definition: production conformance at "acceptable" cost will be used implicitly throughout, unless mentioned otherwise.

\subsection{Quality costing}

\subsubsection{Definitions}

Quality cost measurement originated in the 1950s, and has since been studied by numerous authors, resulting in numerous definitions. This lack of true standard definitions remains an important impediment to assessing quality costs. Thus, given the impossibility of compiling a complete overview of definitions used in literature, only a selection is put together below.

Following British Standard 6143: Part 2 (1990), quality cost is 
The cost in insuring and assuring quality as well as loss incurred when quality is not achieved.

Juran, one of the "gurus" of quality thinking, states that quality is customer satisfaction (Juran and Gryna, 1993). His definition of quality costs (Juran, 1980):

Quality costs are the sum of all costs that would disappear if there were no quality problems.

and (Juran and Gryna, 1993):

Quality has two components: product features and freedom from deficiencies. Product features affect sales income, freedom from deficiencies affects costs.

According to Clark and Tannock (1999):

Quality costing is [...] a method designed to report to management the quality performance of the company in monetary terms.

Sandoval-Chavez and Beruvides (1998) define the costs of quality (COQ) as

$C O Q=$ the cost of deviations from the perfect process state.

A formulation derived directly from the philosophy of Crosby, another "guru", by Hwang and Aspinwall (1999):

The cost of quality (COQ) is determined as the sum of the cost of conformance $(\mathrm{COC})$ and the cost of non-conformance $(C O N C)$, therefore $C O Q=C O C+C O N C$.

These examples illustrate the lack of specificity in defining the cost of quality as well as the different viewpoints towards quality in general. $\cdot 8 \cdot \cdots$ 


\subsubsection{Quality cost models}

Many different approaches to quality costing and quality cost models exist. In the following, only the two most widespread, namely the PAF approach and the process approach, are discussed, and some general remarks are formulated.

\section{The PAF approach to quality costing}

In the PAF approach to quality costing, quality related costs are collected and fit into different categories. The three main categories: Prevention costs, Appraisal costs, Failure costs, were first introduced by Feigenbaum (1956), and have been widely accepted since. Subdividing failure costs in internal and external failure costs, acknowledges four major categories of quality costs (QC):

Prevention costs: The costs of all activities specifically designed to prevent poor quality in products or services. Examples are:

- New product review

- Quality planning

- Supplier capability surveys

- Process capability evaluations

- Quality improvement team meetings

- Quality improvement projects

- Quality education and training

Appraisal costs: The costs associated with measuring, evaluating or auditing products or services to assure conformance to quality standards and performance requirements. These include:

- Incoming and source inspection/test of purchased material

- In-process and final inspection/test Product, process or service audits

- Calibration of measuring and test equipment

- Associated supplies and materials 
Internal failure costs: The costs resulting from products or services not conforming to requirements or customer/user needs, more specifically those failure costs occurring prior to delivery or shipment of the product, or the furnishing of a service, to the customer. Examples are:

- Scrap

- Rework

- Re-inspection

- Re-testing

- Material review

- Downgrading

External failure costs: The costs resulting from products or services not conforming to requirements or customer/user needs, more specifically those failure costs occurring after delivery or shipment of the product - and during or after furnishing of a service - to the customer. Examples are:

- Processing customer complaints

- Customer returns

- Warranty claims

- Product recalls

The above terminology has been adopted by the American Society for Quality Control; reference is made to Campanella and the ASQC Quality Costs Committee (1990).

The last of the above cited categories, external failure costs, presents a fundamental problem in the collecting of accurate $\mathrm{QC}$ data. Apart from the quite easily quantifiable matters such as warranty claims, the external failure costs are extremely difficult to estimate. Delivery of an unsatisfactory or defective product to a customer may indeed result in loss of reputation and future orders, which are extremely difficult, if not impossible, to quantify. It is therefore quite common to arbitrarily ${ }^{1}$ set

\footnotetext{
${ }^{1} \mathrm{~A}$ (non-exhaustive) literature search yielded external/internal failure cost ratios varying between 2.5 (Burgess, 1996) and 10 (Tannock, 1995).
} 
external failure costs as an order of magnitude higher than their internal counterparts.

In spite of its shortcomings, the PAF QC model has established itself as a common framework for discussing quality costs. There are, however, many alternative models and model expansions in which the quality costs are categorized under different headings. Some models categorize the costs according to their nature, e.g. they discriminate between passive vs. active, direct vs. indirect, discretionary vs. consequential, controllable vs. uncontrollable costs. Other models utilize an activity based categorization approach and thus allocate the different quality costs to the various functional parts of the (production) process.

These different categorizations are not necessarily contradictory; Arnheiter and Giglio (1998) for example state that prevention and appraisal costs are discretionary and failure costs are consequential. In the model proposed by Wasserman (1996), the different approaches are used complementarily, to result in seven QC categories: the internal and external failure costs are both subdivided in passive and active failure costs, while prevention costs are split in capital and expense prevention costs. As Arnheiter and Giglio (1998) point out, this overlap between models is in fact not at all remarkable considering that -bottom line- it all relates to the same costs being collected.

\section{The process approach to quality costing}

As the name suggests, the process approach to QC focusses on processes rather than products. Let "process" be defined as a unique combination of machines, tools, methods, materials and people that attains an output in goods, software or services (Juran and Gryna, 1993). In the process approach to quality costing, the total process quality cost (PQC) is regarded as being the sum of the cost of conformance (COC) and the cost of non-conformance (CONC). The COC is the whole of process costs made when producing "first time right" product (i.e. no rework or other non-standard operations are necessary to make the product conforming to specifications). The CONC are all costs associated with a process operated under other conditions than those required to produce right first time products.

A general advantage of this approach over the PAF approach is its 
apparent simplicity. Assigning costs to one of the three PAF categories is indeed not straightforward. For instance: test costs can be appraisal costs as well as prevention costs. Testing can even be a built-in production activity, so that in the PAF approach it might not even be captured as a quality cost, but merely as a standard operational cost. In the PQC approach, it is not necessary to assess whether or not this testing cost is specifically quality related or not, only its relevance in the production of a right first time product has to be considered.

\section{General QC concepts}

Whatever the categorization used, a conceptual difference exists between (total) QC models showing an economic optimal quality level (minimal total quality cost) at a product conformance level of less than $100 \%$ conformance, and models that assume the economical optimum to occur at the $100 \%$ conformance level (see Figure 4.5). The former concept prevailed widely from the beginning of quality awareness in production environments till the eighties. The latter concept represents the quality thinking that evolved in the late twentieth century: new technologies and automated production and inspection should result in the possibility of achieving perfect quality (i.e. 100\% conformance) at a finite cost.
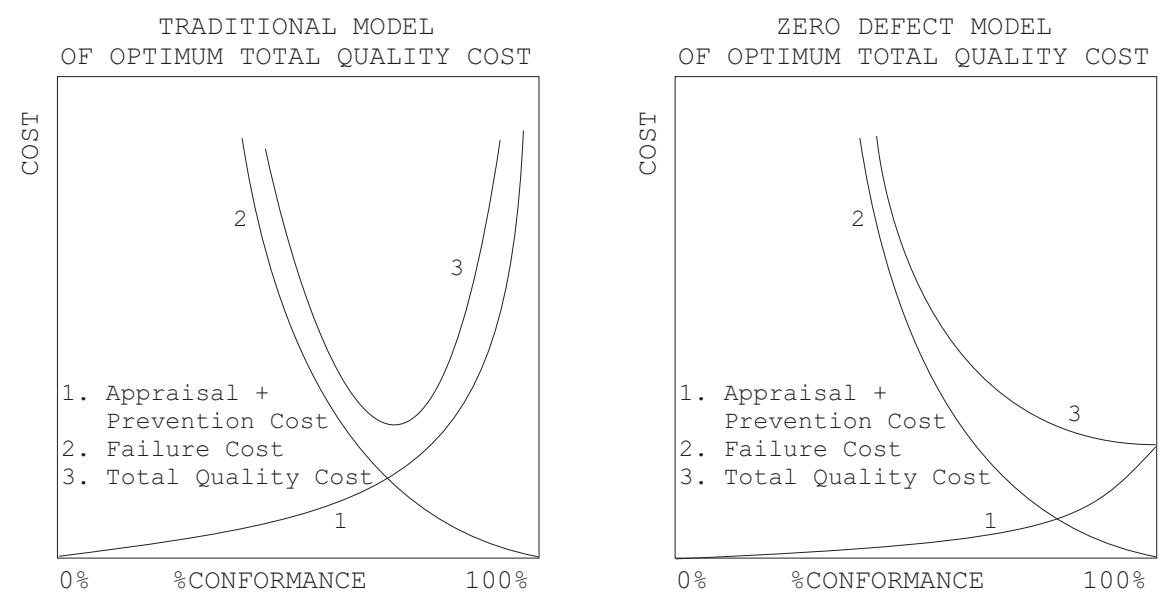

Figure 1.1: Conceptual difference between Total Quality Cost models 
However, as Juran and Gryna (1993) explain, while perfection is the ultimate goal, it does not automatically follow that perfection is the most economical goal for the short run. Wasserman and Lindland (1994) therefore propose a dynamic quality cost model (see Figure 1.2), where the economical goal can shift over time from less than $100 \%$ conformance to $100 \%$ conformance.

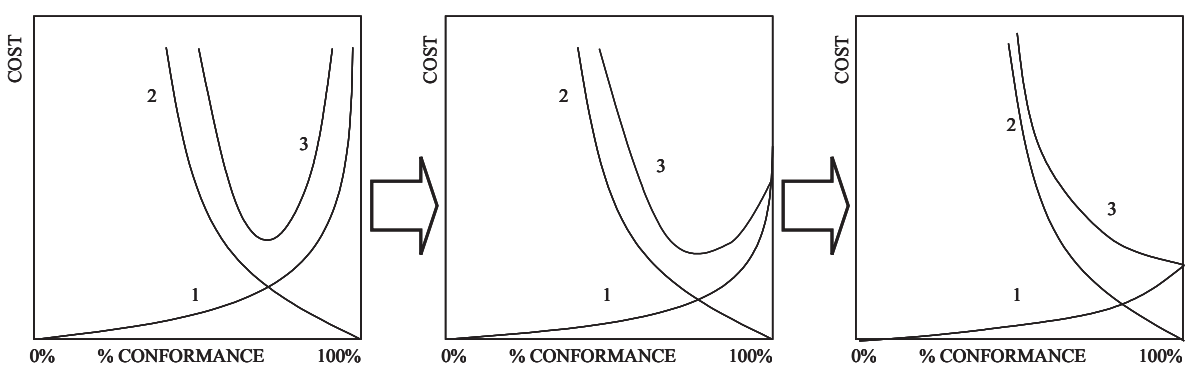

Figure 1.2: TQC evolution over time (adapted from Wasserman and Lindland (1994))

\subsubsection{QC model applications and field studies}

In spite of the multitude of different theoretical QC models that have been developed, the number of examples to validate them remains quite limited. Most models are process- or company-specific, due to their embedding in company-specific costing structures, and therefore hard to compare with or transfer to other applications. Another problem originates from the nature of accounting systems and methods of cost collection and allocation: traditional accounting systems make no discrimination between doing something and doing something over (Moen, 1998).

Dale and Plunkett (1991) state that much of what has been written on quality costs is of a qualitative nature and that, with few exceptions, the quantitative data are broad and unqualified. Indeed, the inherent confidentiality of cost data hampers the collection and publication of reliable data, and one finds that a lot of published data are either fictitious or deliberately kept vague.

Field studies reporting on QC fall into one of three categories: intracompany quality cost reports, comparative inter-company quality cost 
reports, or macro-economic QC studies. The first category prevails in number of publications, but most of their research conclusions are limited in generalizability, due to the company-specificity. Some fairly recent examples: Barber et al. (2000); Cayer and Puddicombe (2000); Ovretveit (2000); Curkovic et al. (2000); Krishnan et al. (2000).

QC models may not be very rewarding research subjects, their practical applications are countless. Indeed the use of a sound QC system can be a powerful management tool. Some examples of the use of QC systems and COQ data (e.g. Clark and Tannock, 1999; Porter and Rayner, 1992):

- guiding of quality improvement efforts (see e.g. Czuchry et al. (1999)):

- budgeting and setting improvement goals

- highlighting areas for improvement

- estimating benefits ${ }^{2}$ from quality improvement projects

- monitoring trends

- assisting with strategic decisions - focussing management attention

- comparing performances amongst divisions

- supplier control or supplier rating

- provide cost information for motivational purposes at different company levels

\section{Quality Cost performance measures}

Since the volume of business in total will vary in time, the cost of quality can best be measured in relation to some appropriate base. Relating quality costs to a relevant base results in indices which can be compared and analyzed over time. For long-range analyses, net sales is the base most often used for presentations to top management (Campanella and the ASQC Quality Costs Committee, 1990). For short-range use, the best

\footnotetext{
${ }^{2}$ not only cost reductions, but possibly also higher market share, premium prices for higher quality, ...
} 
bases are generally those which are already key performance indicators, as they are easily available and already known and understood by the personnel involved. Typical examples (Dale and Plunkett, 1991) are total or direct labor costs and the actual average cost of delivered product or service. For effective use of a quality costing system as a management tool, it may be preferable to use more than one base.

\subsubsection{Quality loss functions}

A quality loss function is a mathematical function describing the (monetary) loss to society that occurs whenever a product or a component quality characteristic does not meet its specifications. Different types of loss functions exist, with different costing consequences. More details on loss functions are provided in Section 1.5.3.

\subsection{Designing and Manufacturing for Quality}

This Section is concerned with reviewing various techniques that allow designing for quality (DfQ) and manufacturing for quality (MfQ). There is no sharp line dividing DfQ from MfQ, so both are treated in one Section. Basic steps in DfQ and MfQ methodology are represented in Figure 1.3. This scheme is by no means exhaustive, other or analogous methodologies exist next to the represented ones, but it is a useful starting point to outline this Section.

\subsubsection{Quality Function Deployment (QFD)}

In the field of product development, several methodologies, formal procedures and tools for product design and development have been formulated. In the following, one of these tools, QFD, will be presented.

In the product development process there is a sequence of transformations, such as requirements to specification, specification to design, design to fabrication, specification to tests, etc. It is easy for the customer requirements to become lost in these chains. Quality Function Deployment (or QFD) addresses this problem. QFD is a methodology that originated in Mitsubishi's Kobe Shipyards and was developed and extended by Toyota (Clark and Wheelwright, 1993). There is a large and 


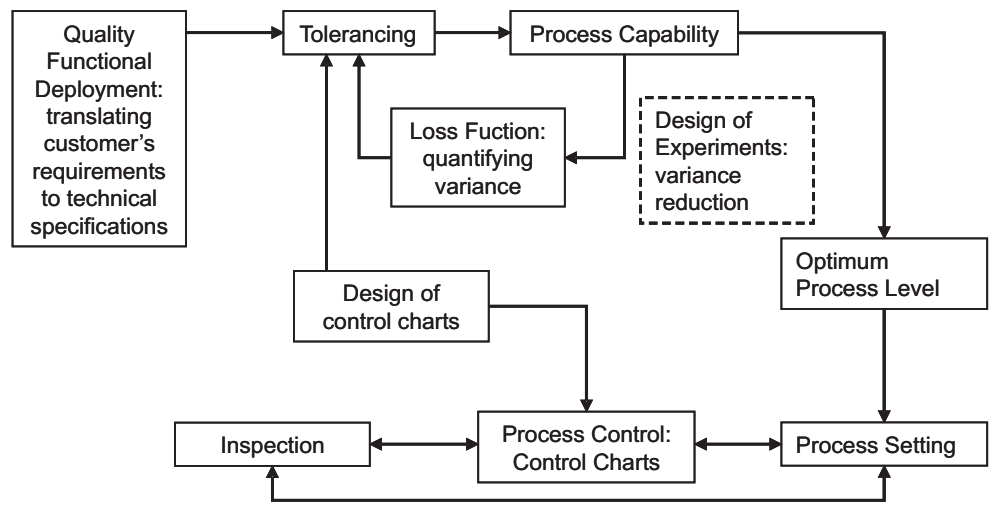

Figure 1.3: Methodological areas in Designing and Manufacturing for Quality (adapted from Chandra (2001))

growing literature on QFD, the basic framework is laid out in Hauser and Clausing (1988). The QFD method is used to identify (critical) product attributes and to "translate" these attributes to design parameters, both in a systematic way, by using matrix-like planning tools.

The matrix used typically maps customer needs (the "what") to the function or process that provides the need (the "how"). This is achieved by representing the product attributes in rows, and the design parameters in columns. Once the rows and columns are established (steps one and two in the QFD process), the third step is to fill in the matrix, as each element in this matrix now represents a potential link between a product attribute and a design parameter. Numbers, symbols or very specific values may be assigned, to establish the direction and strength of the relationship between attribute and parameter.

After the body of the matrix is filled in in this way, two additional structures are added to complete the "house of quality". Correlation between the whats and the hows, and between the hows themselves, adds a "roof" to the matrix, representing the interaction between design parameters. The second addition is added to the right of the central matrix and is concerned with comparing the product (perception) to competitors' analogous products. It becomes the "right wing" of the house.

When the construction and analysis of such a "house of quality" is fin- 


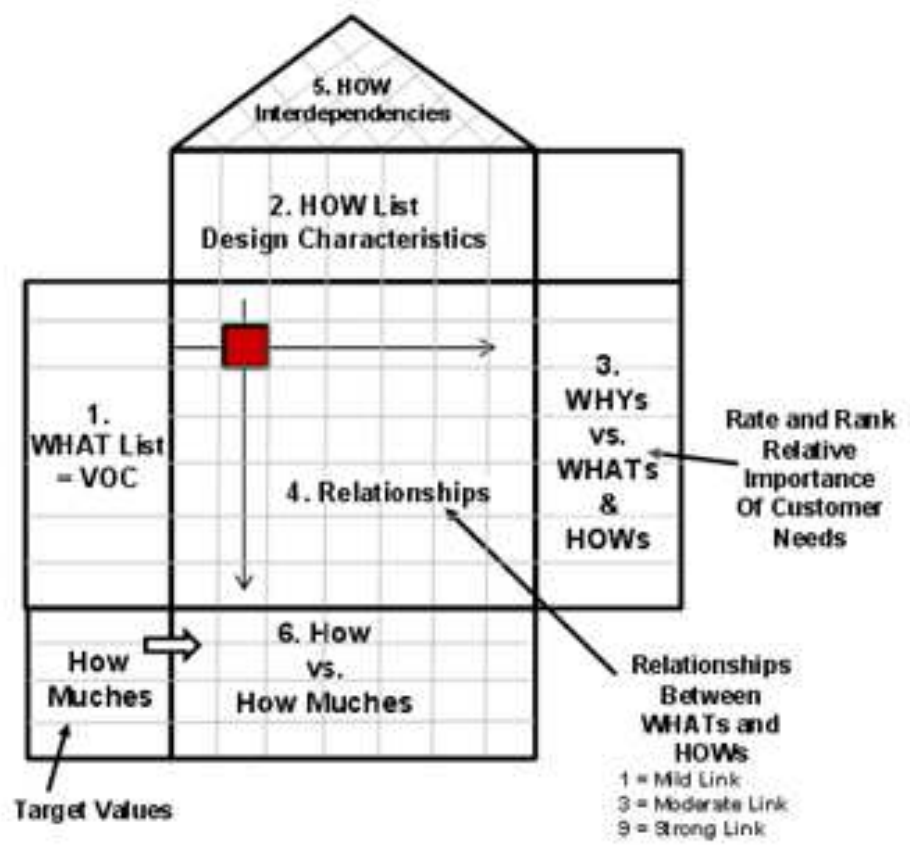

Figure 1.4: House of Quality: general form

ished, the development team should have a clear vision on and a schematic summary of (critical) product attributes (rows), the design parameters connected to these attributes (columns), the interaction pattern among these design parameters (roof), and the product's competitive position (right wing).

\subsubsection{Tolerancing}

A QFD or similar exercise should have yielded the product or assembly tolerances, i.e. the maximum allowable variations in (mass) production of each component so that they remain interchangeable while assembling them ${ }^{3}$. The next step is to allocate these tolerances among the quality

\footnotetext{
${ }^{3}$ The conceptions "component" and "assembly" should be interpreted in a broad way, i.e. the term component can represent a tangible part of an actual assembly (e.g.
} 


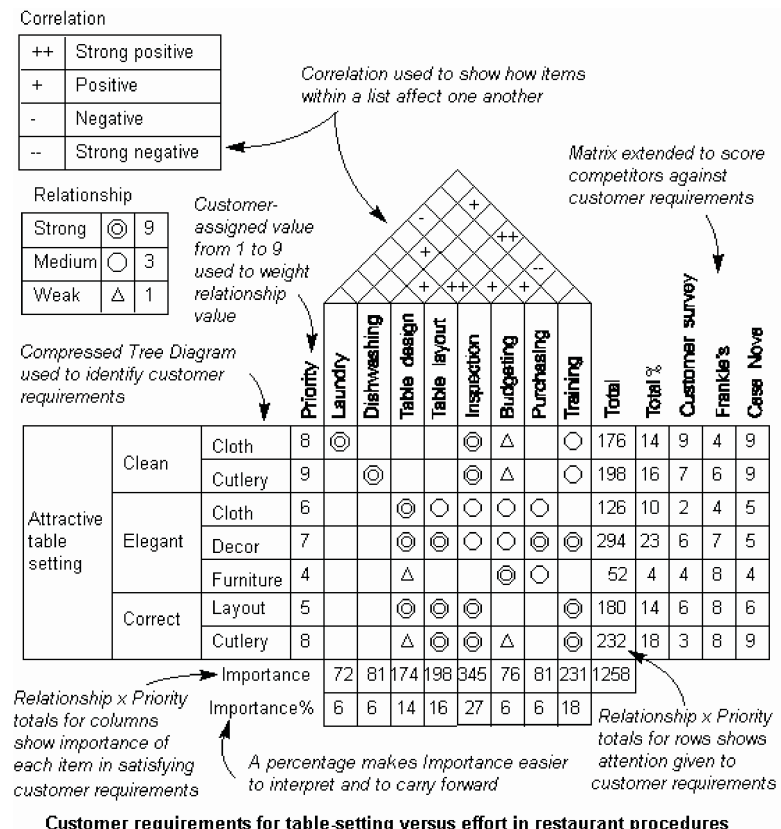

Figure 1.5: House of Quality: example

characteristics of the components of the assembly. This Section provides the basics of tolerance allocation (after Chandra (2001)), and an introduction in literature dealing with more advanced tolerancing techniques.

\section{The basics of tolerance allocation}

Assemblies consisting of $k$ components $(k \geq 2)$ will be considered. Let each component $i$ have a single critical quality characteristic $X_{i}$, and that the assembly has a single critical quality characteristic $X$. The latter is a function of the former, that is,

$$
X=f\left(X_{1}, X_{2}, \ldots, X_{k}\right)
$$

The upper and lower specification limits of $X$ and $X_{i}$ will be denoted as $U S L / L S L$, and $U S L_{i} / L S L_{i}$ respectively.

machine), but also an ingredient in a (chemical) formulation. 
Let the tolerance of $X_{i}$ be $T_{i}$, and let the tolerance of the assembly quality characteristic $X$ be $T$. Then,

$$
\begin{aligned}
T_{i} & =U S L_{i}-L S L_{i} \\
T & =U S L-L S L
\end{aligned}
$$

Tolerances can be allocated using additive or probabilistic relationships. For linear functions,

$$
X=X_{1} \pm X_{2} \pm \ldots \pm X_{k}
$$

straightforward equations can be derived. With an additive relationship

$$
T=T_{1}+T_{2}+\ldots+T_{k},
$$

for a given $T$, tolerances $T_{i}$ can be allocated among the $k$ components. Using a probabilistic relationship slightly complicates the exercise, necessitating assumptions regarding the probabilistic properties of the characteristics $X_{i}$. Classical assumptions made are

1. The $X_{i}$ 's are independent.

2. Components for assembly are randomly picked.

3. The mean $\mu_{i}$ of the distribution of $X_{i}$, is equal to the nominal value of $X_{i}$, denoted by $E_{i}$, which is also the midpoint of the tolerance region $T_{i}=U S L_{i}-L S L_{i}$. So,

$$
\mu_{i}=E_{i}=\frac{U S L_{i}+L S L_{i}}{2}
$$

4. The standard deviation $\sigma_{i}$ of $X_{i}$ is such that $T_{i}=U S L_{i}-L S L_{i}=$ $n \sigma_{i}$

( $n$ often equals 6, see Section 1.5.3).

With these assumptions, for any linear function $X=X_{1} \pm X_{2} \pm \ldots \pm X_{k}$, it can be stated that

$$
\begin{aligned}
\mu & =\mu_{1} \pm \mu_{2} \pm \ldots \pm \mu_{k} \\
\sigma^{2} & =\sigma_{1}^{2}+\sigma_{2}^{2}+\ldots+\sigma_{k}^{2}
\end{aligned}
$$


with $\mu$ and $\sigma$ the mean and variance, respectively, of $X$. Let now $T=$ $U S L-L S L=n \sigma$, then

$$
\begin{aligned}
\sigma_{i}{ }^{2} & =\left(\frac{T_{i}}{n}\right)^{2} \\
\sigma^{2} & =\left(\frac{T}{n}\right)^{2}
\end{aligned}
$$

so

$$
\left(\frac{T}{n}\right)^{2}=\left(\frac{T_{1}}{n}\right)^{2}+\left(\frac{T_{2}}{n}\right)^{2}+\ldots+\left(\frac{T_{k}}{n}\right)^{2}
$$

or

$$
T=\sqrt{T_{1}^{2}+T_{2}^{2}+\ldots+T_{k}^{2}}
$$

\section{Tolerancing beyond the basics}

From the basics described in the previous Section, all sorts of extensions are possible: other than normal distributions for the $X_{i}$, other than linear functions $X=f\left(X_{1}, X_{2}, \ldots, X_{k}\right)$, more than one quality characteristic $X$, asymmetric specification limits $\left(\mu_{i}=E_{i} \neq \frac{U S L_{i}+L S L_{i}}{2}\right)$, multi-step assemblies, and so on. The mathematics for these extended cases rapidly become very complicated and cumbersome, making an analytical approach impossible for most cases. Numerous approximate solution procedures and heuristics are then called upon.

Depending on the goal of the tolerance allocation exercise, different objective functions for the heuristic procedures will be defined. An important group are least-cost tolerances. The basic problem was laid out by Bennett and Gupta $(1969,1970)$. The objective function is to minimize the total manufacturing cost $C$ using $T_{1}, T_{2}, \ldots, T_{k}$ as the decision variables:

$$
\begin{gathered}
\operatorname{minimize} \quad C=\sum_{i=1}^{k} h_{i} T_{i}^{\alpha_{i}} \quad \text { subject to } \\
\sum_{i=1}^{k} N_{i} T_{i}=T \text { and } \\
T_{i} \geq 0, \forall i
\end{gathered}
$$


This is a standard nonlinear programming problem that can be solved using the method of Lagrange multipliers. To that end, the constrained optimization problem is transformed to its unconstrained equivalent, namely

$$
\operatorname{minimize} \quad C^{\prime}=\sum_{i=1}^{k} h_{i} T_{i}^{\alpha_{i}}+\lambda\left(\sum_{i=1}^{k} N_{i} T_{i}-T\right)
$$

Finding the optimal values of $T_{i}$ and $\lambda$ now comes down to differentiating $C^{\prime}$ with respect to the $T_{i}$ and $\lambda$ and equaling the derivatives to 0 .

Literature on these and other tolerancing techniques is concisely reviewed by Zhang and Huq (1992). A more recent contribution is e.g. the work of Fraticelli et al. (1997), in which sequential tolerance control is introduced, suitable for components moving through a sequence of $n$ operations. The approach uses realtime measurement information at the completion of stage $j$ to reposition the set point for operations $j+1$ tot $n$.

Another fairly recent field of study is tolerancing under uncertainty, with contributions from among others Gerth and Pfeifer (2000). They propose a method combining classical minimum cost tolerancing methods with design of experiments, to determine which features are critical or non-critical early in the design phase - when cost information is uncertain. Maghsoodloo and Li (2000) comprehensively address the problem of asymmetric tolerances, while the work of Moskowitz et al. (2001) deals with multivariate tolerance design.

\subsubsection{Process capability and loss functions: determining and quantifying variance}

Process capability ratios compare the process' performance in terms of variance to the specification or tolerance interval for a given quality characteristic. Three types of quality characteristics exist:

N-type: nominal-the-best. In this case, the closer the quality characteristic approximates its expected value, the better. This is the most common type of characteristic for component dimensions: if a component is either too large or too small, it will not fit the assembly. 
S-type: smaller-the-better. For this type only an upper specification limit $(U S L)$ exists, and the lower the quality characteristic remains under this limit, the better. This type of characteristic is used e.g. for the setting of maximum contamination levels.

L-type: larger-the-better. Here only a lower specification limit $(L S L)$ appears, and the more the quality characteristic exceeds this value, the better. Such type characteristics are used e.g. when a minimum purity is required.

Besides comparing the process' ability to meet specifications, process capability information serves multiple purposes (Juran and Gryna, 1993):

1. Predicting the extent of variability that processes will exhibit. Such information is important in setting realistic specification limits.

2. Choosing from competing processes that which is most appropriate for the tolerances to be met.

3. Planning the interrelationship of sequential processes.

4. Providing a quantified basis for establishing a schedule of periodic process control checks and readjustments.

5. Testing theories of causes of defects during quality improvement programs.

6. Serving as a basis for specifying the quality performance requirements for purchased equipment.

\section{Capability ratios}

For N-type quality characteristics following a normal distribution, it has been the convention to take the interval from $\mu-3 \sigma$ to $\mu+3 \sigma$ as the benchmark against which to measure the process capability. This is known as the six-sigma-spread, which indicates the width of this interval. For a normal distribution, $99.73 \%$ of the values lie within this interval.

The ratio of the specification interval $U S L-L S L$ to this six-sigmaspread, is known as the process capability ratio $C_{p}$.

$$
C_{p}=\frac{U S L-L S L}{6 \sigma}
$$


This implies that if the process' $C_{p}=1,99.73 \%$ of the values of the quality characteristic fall within the limits of the tolerance interval, assuming the process is centered, i.e. the mean of the distribution of the characteristic is equal to the nominal size or the mid-point of the tolerance interval.

A major reason for quantifying process capability is to compute the process' ability to hold product tolerances. For processes that are in a state of statistical control (see Section 1.7), a comparison of the variation spread of $6 \sigma$ to the tolerance limits permits straightforward calculation of the percentage defective material. A centered process that is just meeting specification limits has thus a $C_{p}$ of 1 . A $C_{p}$ value of 1.33 is often cited as adequate, the extra 0.33 "margin" dictated by the criticality of many applications and the reality that the process will not remain centered. For a centered process, a defect rate of $1 \mathrm{ppm}$ requires a process capability ratio of about 1.63 .

To overcome the limitations attached to the rather daring assumption of centered processes, the $C_{p k}$ index was proposed. It is defined as

$$
C_{p k}=\frac{\operatorname{minimum}[(\mu-L S L),(U S L-\mu)]}{3 \sigma}
$$

and thus also takes into account deviations of the mean from the nominal value. Only for perfectly centered processes the indices $C_{p}$ and $C_{p k}$ will be equal, and in any case $C_{p k} \leq C_{p}$. For some examples on the calculation of $C_{p}$ and $C_{p k}$ indices for N-type characteristics, see Figure 1.6.

For S- and L-type characteristics, the definitions for $C_{p}$ and $C_{p k}$ always coincide.

$$
\begin{array}{ll}
C_{p}=C_{p k}=\frac{U S L-\mu}{3 \sigma} & \text { (S-type) } \\
C_{p}=C_{p k}=\frac{\mu-L S L}{3 \sigma} & \text { (L-type) }
\end{array}
$$

The main limitation of the $C_{p k}$ index is the normality assumption of the characteristics. Moreover, for computing the indices $C_{p}$ and $C_{p k}$, usually the estimate of the variation used will only consider the so called "short-term" variability, because typically data from one batch or one production cycle will be used. This estimate is usually smaller than the estimate of the total variation (including "long-term" variability), so that 


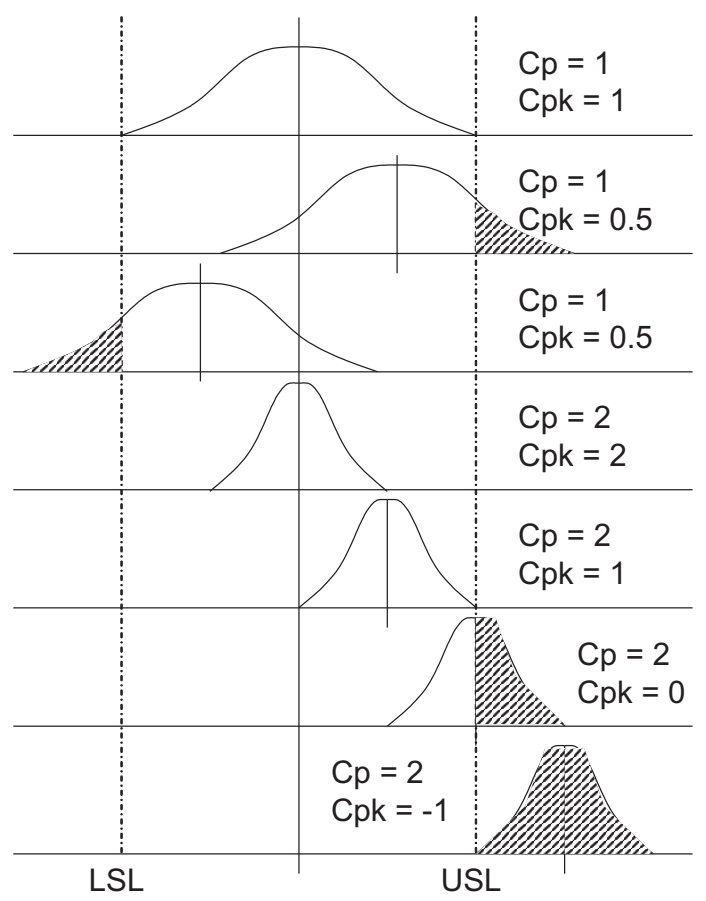

Figure 1.6: Calculation of $C_{p}$ and $C_{p k}$ indices: some examples

$C_{p}$ and $C_{p k}$ will overestimate the process capability and underestimate the proportion of defectives, long-term. New indices $P_{p}$ and $P_{p k}$ were introduced to address this problem. The formulas for computing them are similar:

$$
\begin{aligned}
P_{p} & =\frac{U S L-L S L}{6 \sigma_{L T}} \quad(\mathrm{~N} \text {-type }) \\
P_{p k} & =\frac{\operatorname{minimum}[\mu-L S L),(U S L-\mu)]}{3 \sigma_{L T}} \quad \text { (N-type) } \\
P_{p} & =P_{p k}=\frac{U S L-\mu}{3 \sigma_{L T}} \quad(\text { S-type }) \\
P_{p} & =P_{p k}=\frac{\mu-L S L}{3 \sigma_{L T}} \quad \text { (L-type) }
\end{aligned}
$$

but in all these forms $\sigma_{L T}$ will be estimated by the long-term standard deviation. 
For all practical purposes, estimators for the parameters of the probability distribution of the characteristics will be used. Hence, only estimators of process capability indices can be calculated. For N-type characteristics, with $s$-the sample standard deviation- as estimate for $\sigma$, and $\bar{x}$-the sample mean- as estimate for $\mu$ :

$$
\begin{aligned}
\hat{C}_{p} & =\frac{U S L-L S L}{6 s} \\
\hat{C}_{p k} & =\frac{\operatorname{minimum}[(\bar{x}-L S L),(U S L-\bar{x})]}{3 s}
\end{aligned}
$$

Extensions to S- and L-type characteristics are straightforward.

For non-normal distributions of the quality characteristic under consideration, researchers have suggested using modified formulas after transforming the data to appropriate distributions. Another approach is to transform the data, to convert them from non-normal to normal. A review of this line of work is not included here, as many of the proposed methods are quite specific, and the intent of this Chapter is to provide a general introduction. Worth mentioning is the work of English and Taylor (1993), where the robustness of the process capability indices for nonnormal distributions was studied. Another interesting topic, addressed by among others Chen et al. (2001) and Plante (2001), is process capability analysis for multistage processes. The conventional indices restrict the application to single-process products; methods to overcome this are proposed and applied.

Chan et al. (1988) have developed another capability index, the $C_{p m}$ index. It is used for N-type characteristics. The numerator is the range of the tolerance interval $(U S L-L S L)$; the denominator is a combined measure of the standard deviation and the deviation of the mean from the target value $X_{t v}$ :

$$
C_{p m}=\frac{U S L-L S L}{6 \sqrt{\sigma^{2}+\left(\mu-X_{t v}\right)^{2}}}
$$

The expression $\sigma^{2}+\left(\mu-X_{t v}\right)^{2}$ (or the mean squared error, MSE) is related to Taguchi's loss function, discussed in Section 1.5.3.

\section{Loss functions}

Three main approaches can be distinguished (see Figure 1.7): 
Step type loss functions This type of loss function is connected with the product-based quality definition of meeting specifications. It is stated that no loss is incurred as long as the product or part meets its specifications, and that a constant loss occurs if the product or part does not meet its specifications. This constant loss corresponds to the cost of the "bad" product. Besides naked costs such as material and production cost of this bad product, the total constant loss can include a rework cost (to make the bad product good again), or a scrap cost (to dispose of the bad product), or even a failure cost (if the bad product is sent to a customer).

Taguchi type loss functions It is shown (Taguchi et al., 1989) that products with quality characteristics following normal distributions result in less failures compared to products with quality characteristics following a uniform distribution, even though the range of this uniform distribution is within the tolerance range, theoretically resulting in zero defectives. This is because the uniform distribution has a larger variance than a (truncated) normal distribution with the same range. Taguchi therefore dismisses the idea of constant loss and instead proposes a quadratic loss function: loss is incurred from the very moment a product or part characteristic deviates from its (ideal, desired) target value, even when well within specification. The further away from the target value, the higher the cost incurred, represented mathematically by a quadratic function (parabola), with a minimum of zero at the target value. Taguchi thus introduces the notion of a variability cost: he stresses the importance of variability reduction as a tool to improve quality. In his view, variability inevitably causes quality loss, and the loss increases more than proportionally with deviation from target value, hence the proposition of a quadratic loss function.

Combined loss functions A commonly used combination of the previous loss functions: within the tolerance range the quality loss is calculated following Taguchi's quadratic loss function, outside the tolerance range the quality loss is constant, as in the step function.

Variations on these basic approaches are manifold, but a lot of them problem-specific. For instance, Kros and Mastrangelo (1998) introduce 

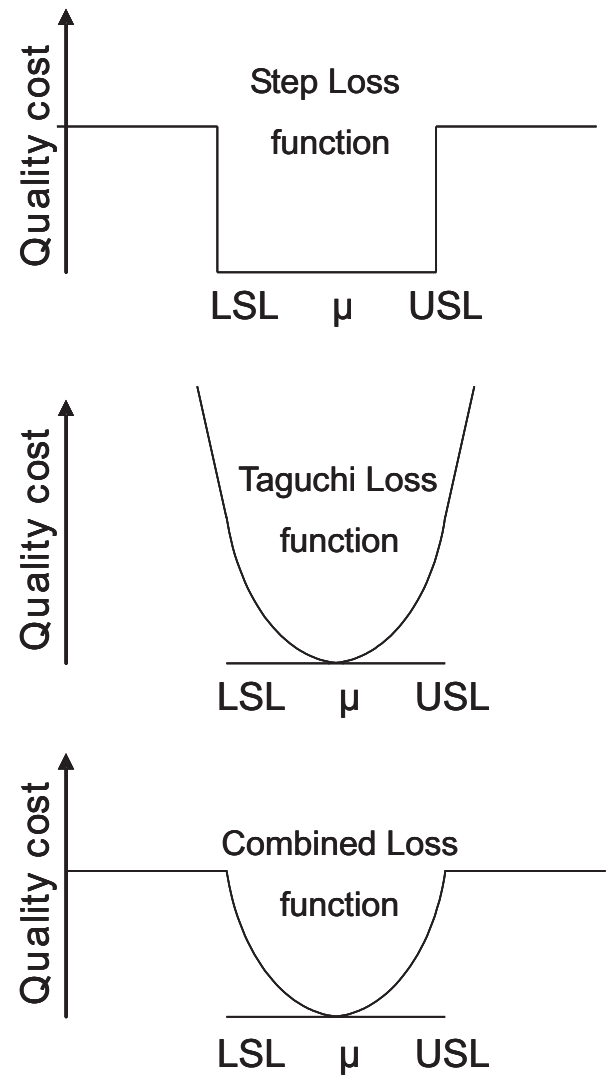

Figure 1.7: Basic loss functions

nonquadratic loss functions into Taguchi's methodology.

Taguchi's loss function $L(X)$ for a quality characteristic $X$ with a target value $X_{t v}$ was derived as follows. A general function $f(X)$ can, using Taylor series, be written as

$$
f(X)=f(a+X-a)=f(a)+\frac{(X-a)}{1 !} f^{\prime}(a)+\frac{(X-a)^{2}}{2 !} f^{\prime \prime}(a)+\ldots
$$

with $f^{\prime}(a)$ and $f^{\prime \prime}(a)$ the first and second order derivatives of $f(X)$ respectively, evaluated at $a$. For $L(X)=L\left(X_{t v}+X-X_{t v}\right)$ this becomes

$$
L(X)=L\left(X_{t v}\right)+\left(X-X_{t v}\right) L^{\prime}\left(X_{t v}\right)+\frac{\left(X-X_{t v}\right)^{2}}{2} L^{\prime \prime}\left(X_{t v}\right)+\ldots
$$


There is no loss when the quality characteristic $X$ is equal to its target value $X_{t v}$, so $L\left(X_{t v}\right)=0$. Also, as the function $L(X)$ attains its minimum when $X=X_{t v}$, its first derivative $L^{\prime}$ evaluated at $X_{t v}$ is zero: $L^{\prime}\left(X_{t v}\right)=0$. Neglecting the third and higher order terms of the Taylor series expansion, equation (1.29) becomes

$$
L(X)=\frac{1}{2} L^{\prime \prime}\left(X_{t v}\right)\left(X-X_{t v}\right)^{2}
$$

or

$$
L(X)=k\left(X-X_{t v}\right)^{2} \quad \text { for } \quad L S L \leq X \leq U S L
$$

with $k=0.5 L^{\prime \prime}\left(X_{t v}\right)$, Taguchi's proportionality constant. Furthermore, it can be derived that the expected value of Taguchi's loss function, $E[L(X)]$, is given by

$$
E[L(X)]=k\left[\sigma^{2}+\left(\mu-X_{t v}\right)^{2}\right]
$$

Process capability indices and process expected loss are, together with process yield, the basic means that are widely applied in measuring production performance. Examples of such performance evaluations in the area of multistage production are e.g. Angell and Chandra (2001); Lee et al. (1997); Maghsoodloo and Huang (1997); Morris and Watson (1997); Troutt et al. (2001).

\subsubsection{Optimal process level}

As discussed in the previous Section, the variance of the probability distribution of the quality characteristic is inherent in the process generating that characteristic. But the other parameter of this distribution, the process mean, is user-determined. This means that an optimal value of the process mean, i.e. the value that optimizes some to be determined objective function, can be found. In this Section, some commonly used objective functions will be outlined.

\section{Optimal process levels to minimize costs}

This type of optimal process value determination is concerned with finding the process value for a quality characteristic $X$ that minimizes the total 
expected production cost $T C$. Let $C_{U S L}$ be the cost due to manufacturing a product with a quality characteristic above the $U S L$, and $C_{L S L}$ the cost incurred when the characteristic is below the $L S L$, then the exercise is to minimize an objective function like

$$
T C=E\left[C_{U S L}\right]+E\left[C_{L S L}\right]
$$

The specific form of the objective function is dependant on the type of characteristic.

For an N-type characteristic, it is intuitive to set the optimal process level, denoted $\mu_{o}$, equal to the mid-point of the tolerance interval. However, in the case where $C_{U S L}$ is not equal to $C_{L S L}$, this mid-point will not be the optimal process setting. First, the following assumptions are made:

1. The quality characteristic $X$ follows a unimodal probability density function $f(x)$, with a mean $\mu$ (unknown) and a variance $\sigma^{2}$ (known).

2. There are minimum and maximum values $X_{\min }$ and $X_{\max }$ for $X$. Then, equation (1.33) becomes

$$
T C=C_{U S L} \cdot P[X>U S L]+C_{L S L} \cdot P[X<L S L]
$$

or, with the use of the pdf $f(x)$

$$
T C=C_{U S L} \int_{U S L}^{X_{\max }} f(x) d x+C_{L S L} \int_{X_{\min }}^{L S L} f(x) d x
$$

This is a function of the decision variable $\mu$ (as $\mu$ is a parameter in $f(x)$ ). It is possible to prove that this problem has a unique optimal solution, i.e. the function $T C(\mu)$ has a unique minimum value, corresponding to the optimal process level $\mu_{o}$. Moreover, the minimum and maximum values for $X$ may be equal to $-\infty$ and $\infty$, respectively.

Analogous systems of assumptions and equations can be constructed for L-type and S-type characteristics. A striking example of this sort is the so-called canning problem, where cans are filled with some product. Because of the operating nature of a filling machine, with its inherent variation, the amount of product per can is a random variable. It is up to 
the manufacturer to guarantee that the amount of product in each can is at least a certain specified value. Yet, as cans are sold at a fixed price per can, all product filled in a can above this value is loss. Hence, there must be an optimal setting for the mean of the distribution of the amount of product in a can. The problem is described and solved by Golhar and Pollock (1988), it is a joint optimization problem of finding the optimal values of the mean and the upper limit.

\section{Optimal process levels without considering cost}

There are applications in which the objective is not to minimize the expected cost or to maximize the expected profit, but to satisfy some regulations. For instance, manufacturers of food products need to satisfy requirements specified by official agencies or legislators. This will of course result in other, case-specific, optimal process levels.

\subsubsection{Inspection and process control}

According to an oldish but insightful taxonomy of economically based quality control procedures by Menipaz (1978), there are two basic categories of operational quality control procedures to be considered:

1. sorting procedures, i.e. procedures for sampling, the design of sampling plans or a sequence of sampling plans, intended to separate between good and defective products.

2. process control procedures, i.e. procedures intended to maintain the quality level of a process. This definition of process control is perhaps somewhat outdated, modern views would suggest something like secure, monitor and improve the quality level of a process

Extending the first category beyond mere (acceptance) sampling to inspection in general, leads to the split suggested by the title of this Section: inspection and process control. Quality inspection and process control are an integral part of Manufacturing for Quality and thus of this Section, but given their relative importance in this work, both topics are treated in separate Sections, 1.6 and 1.7. 


\section{Attributes versus variables}

Both inspection and process control can be applied to either attribute data or variable data. Attribute data is concerned with counts of defects, product is graded as either conforming or non-conforming; whilst variable data is "a number on some scale of measurement" (Montgomery, 1991). For example, a quality characteristic such as the length of a part or the concentration of a chemical in a batch, can be measured as a variable, whilst the presence of a scratch on the part or the presence of a contaminant in the batch can be considered as attribute data, either pass or fail. But it is also possible to interpret variable data as attribute data by comparing the variable measurement to specifications and thus attributing a pass or a fail. Data acquired in this way are known as gauged variables.

Generally speaking, the use of variable data offers more information about a process, batch or part, but is usually more costly, as it is mostly more difficult or time-consuming to measure or ascertain. The use of attribute data offers the possibility of combining several quality characteristics into one pass or fail.

Let there be no confusion between this distinction (variable vs. attribute data) and the distinction between discrete and continuous data. Duncan (1986): "Discrete data necessarily vary in jumps. For example, data that arise from counting are discrete; in the counting of nonconformities, each non-conformity is an integral unit: it either exists or it does not. Continuous data refer to data that can potentially take on any value within a specified range. This means that within that range, there is no inherent restriction on the values that may be taken, the values are only restricted by the intrinsic limitations of measurement."

Mostly, but not necessarily, continuous data will be linked with variable data and discrete data with attribute data.

\subsection{Inspection}

In this Section the spotlights are on a specific tool for achieving (manufacturing) quality: quality inspections. Quality inspections are used to evaluate the quality of a product, possibly at several phases in its production process. If a product is found to be of a (too) low quality, it 
can either be reworked or rejected. Product can mean a discrete unit, a collection of discrete units (a lot), a bulk product, or a complex system.

Inspection and test typically include measurement of an output and comparison to specifications to determine conformity. Inspection is performed for a wide variety of purposes (Juran and Gryna, 1993):

- distinguishing between good and bad product

- determining if a process is changing

- measuring process capability

- rating product quality

- securing product design information

- rating the inspector's accuracy

- determining the precision of measurement instruments

Each of these purposes has its influence on the nature of the inspection and the manner of performing it. Of all these purposes, the most extensively used is product acceptance, i.e. determining whether a product conforms to a standard, and thereby whether this product should be accepted. There are three basic strategies for this evaluation:

1. No inspection

2. Sampling inspection

3. Full (100\%) inspection

An economic evaluation of the three strategies requires a comparison of total costs under each of the alternatives. This topic will be covered in Chapter 2.

The first and last strategy are straightforward to implement; for sampling inspection, the technique most commonly used is known as acceptance sampling. Its basics were developed by Dodge and Romig in their work at Bell Laboratories. The trade-off is between erroneously accepting a bad lot (a.k.a. a type II error, or the consumer's risk, typically associated with a probability $\beta$ of committing this error) and erroneously 
rejecting a good lot (a.k.a. a type I error, or the producer's risk, typically associated with a probability $\alpha$ ) in answering the question: "what is the smallest amount of evidence needed in order to make a rational decision about whether or not to use this lot?". The main advantage of sampling is of course the economic advantage of inspecting only part of the lot (smaller inspection staff and/or less tools for automated inspection required, shorter inspection time). But other reasons for using sampling exist, e.g. under the following conditions acceptance sampling is likely to be used (Duncan, 1986):

- When the cost of inspection is high compared to the loss arising from the passing of a non-conforming unit (the "lower limit" of this case is of course to perform no inspection).

- When $100 \%$ inspection is difficult (demanding, fatiguing, ..), risking high inspector fallibility, so that a carefully worked out sampling plan will produce at least as good results.

- When inspection or testing is destructive.

On the other hand, sampling is unacceptable when it is potentially dangerous or harmful to pass defectives (e.g. in safety critical products, critical pharmaceuticals,...).

\subsubsection{The basics of acceptance sampling}

There are many different types of acceptance sampling plans, applying to both attribute and variable data. Most common and easiest to understand and implement are single sampling plans, but there exist also double and multiple sampling plans, chain sampling, sequential sampling and adaptive sampling plans. It is to be emphasized that the purpose of acceptance sampling is to determine a course of action and not to estimate or control quality. Acceptance sampling merely provides a procedure that will yield a specified risk of accepting some predetermined quality. The basics of it will be outlined in the following Sections, 1.6.2 to 1.6.3. 


\subsubsection{Single sampling}

A simple single sampling plan is defined by two parameters, the sample size and the acceptance number. An example might be that from a lot of 1000 items, 67 items are sampled and the lot is accepted if 3 or fewer items are defective in this sample (thus, for this example the sample size is 67 and the acceptance number is 3 ). If more than 3 defective items are detected in the sample, the whole lot of 1000 items will be rejected (the lot can be either returned to the supplier (or previous process step) or subjected to full inspection to remove further defectives).

\section{Operating Characteristic Curve}

Any (single) sampling plan is determined by its so called operating characteristic curve (OC curve). The curve basically shows how the probability of accepting a lot varies with the quality of the lots submitted to inspection. Assume a process operating in a random (but stable) manner, with a defect rate of 100.p\% non-conforming material. Then, for lots of size $N$, the fractions non-conforming of these lots will follow a binomial distribution. If each lot is submitted to sampling inspection with sample size $n$ and acceptance number $c$, then the probability of accepting a lot will equal the proportion of lots that will be accepted under the plan in the long (theoretically infinite) run. Hence, this probability of lot acceptance can be calculated from the binomial distribution. The OC curve now shows how this probability of acceptance varies with $p$. The computation of such curves is a relatively simple matter, based on straightforward statistics, amply described in various textbooks (Montgomery, 1991; Duncan, 1986). Figure 1.8 shows an example of an OC curve for a single sampling plan with $n=100, c=2$.

An OC curve unambiguously describes the sampling plan and all its consequences. In fact, two points on the OC curve suffice to design a single sampling plan, i.e. to establish values for the sample size $n$ and the threshold $c$. Commonly, two characteristic points are chosen, based on the concepts of the producer's risk or the consumer's risk associated with the sampling plan. The producer's risk refers to the probability of rejection of a good lot, while the consumer's risk corresponds with the probability of accepting a bad lot. 


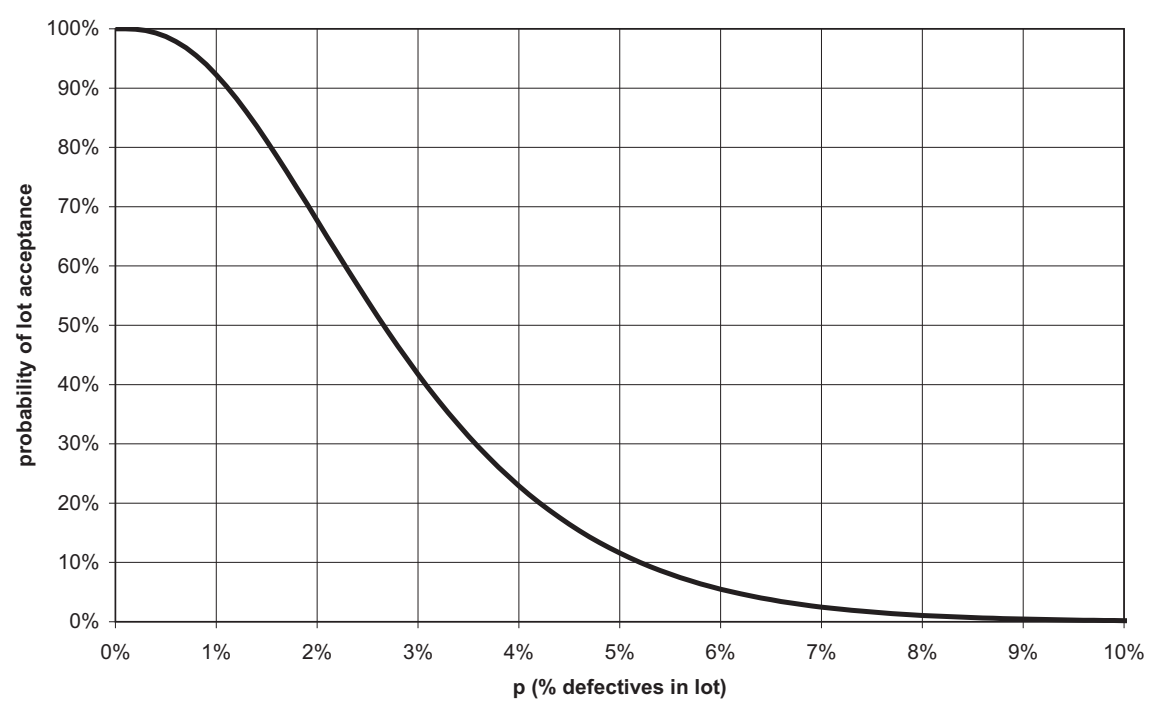

Figure 1.8: Operating Characteristic curve: example

These concepts are similar to the so-called type I and type II errors in statistical hypothesis testing. A type I error occurs when the hypothesis $H_{0}$ is wrongfully rejected, a type II error occurs when the hypothesis $H_{0}$ is wrongfully accepted. The probabilities of occurrence of these errors are commonly designated with $\alpha$ for a type I error and $\beta$ for a type II error.

To illustrate the use of $\alpha$ and $\beta$, suppose that the desired single sampling plan should not accept, more than $10 \%$ of the time, lots with $8 \%$ or more non-conformities. Also, the plan should accept lots with no more than $1 \%$ non-conformities at least $95 \%$ of the time. In other words, the plan should have an $\alpha$ value of 0.05 and a $\beta$ value of 0.10 corresponding with defect rates of 0.01 and 0.08 respectively. The appropriate $n$ and $c$ can now be calculated, or rather, approximated (since $n$ and $c$ must be integers). Results are given in Table 1.1.

The inspection planner must decide whether it is more important to hold on to the $\alpha$ (holding on to the desired consumer protection, plans $\mathrm{B}$ 
Table 1.1: Determination of single sampling parameters for given $\alpha$ and $\beta$

\begin{tabular}{|c|c|c|c|c|}
\hline Plan & $n$ & $c$ & $\alpha$ & $\beta$ \\
\hline A & 49 & 1 & 0.08 & $\mathbf{0 . 1 0}$ \\
B & 36 & 1 & $\mathbf{0 . 0 5}$ & 0.23 \\
C & 67 & 2 & 0.03 & $\mathbf{0 . 1 0}$ \\
D & 82 & 2 & $\mathbf{0 . 0 5}$ & 0.04 \\
\hline
\end{tabular}

and $\mathrm{D}$ ) or to the $\beta$ (keeping fixed the desired producer risk, plans $\mathrm{A}$ and C). Subsequently he has to pick $c=1$ (the more "conservative" plans A and $\mathrm{B}$ ) or $c=2$ (the more "liberal" plans $\mathrm{C}$ and $\mathrm{D}$ ).

\subsubsection{Discriminatory power of a sampling plan}

Perfect discrimination between good and bad lots can, alas, only be achieved through perfect, $100 \%$ inspection. The discriminatory power of sampling plans decreases with decreasing sample sizes. Thus, the "best" sample size to use is a trade-off between the higher precision of larger samples and their higher cost.

Sampling plans can, as is clear, also be "tightened" by decreasing the value of $c$ without changing $n$.

\section{Further reading}

In the remainder of this work, when referred to "sampling inspection", single sampling plans are assumed. Duncan (1986) provides the interested reader with a comprehensive overview of the other types of sampling plans, each with their own OC curves, their raison d'être and their practical use.

\subsection{Process control}

Once the optimal process levels are determined and set (see 1.5.4), they have to be maintained. Process control techniques are there to check whether the processes operate within their settings. Statistical process control or SPC is defined as the application of statistical methods to the 
measurement and analysis of variation in any process (Juran and Gryna, 1993). Process variations are traceable to two kinds of causes: (i) common causes (or random or chance), which are inherent in the process (unavoidable), and (ii) special (or assignable) causes, which cause excessive (avoidable) variation. Ideally, only common causes should be present in a process because then the process is stable and variation is minimal. A process that is operating without special causes of variation is said to be "in a state of statistical control".

A control chart is a statistical test, in a graphical form, to determine whether or not a process is operating in this statistical control state. The chart is a (graphic) comparison of process performance data to computed "statistical control limits", drawn as limit lines on the chart. The control chart for an "in-control" process has its data points within these limits. Through its choice of control limits, the chart can distinguish between common and special causes of variation. This is in fact the statistical test that is behind the graphical representation. The control limits are calculated using the laws of probability in such a way that when variation exceeds the limits, it is a signal that special causes have entered the process. Random variation within the limits means that only common causes of variation are present. Of course, there is a (known) possibility of "false alarms" where a point will fall outside the control limits even when the process is in-control. Control chart design methods take this into account and will usually be intended to minimize this false alarm probability without reducing the ability of the chart to detect a real process shift.

Note that a control chart, when designed and used properly, can detect the presence of a special cause of variation but does not "find" the cause, this requires action from the process' operators, engineering or management. It should also be noted that out-of-control does not necessarily mean out-of-specification. Again, reference is made to textbooks such as Montgomery (1991) and Duncan (1986) for a detailed description of various types of control charts and their use. 


\section{Further reading}

Textbooks on quality control and statistical tools are manifold, rendering the exercise of compiling a list of "standard" textbooks impossible. Yet the following short list could serve as a useful starting point for the interested reader ${ }^{4}$.

- Campanella and the ASQC Quality Costs Committee (1990). Principles of Quality Costs

- Chandra (2001). Statistical Quality Control

- Dale and Plunkett (1990). Managing Quality

- Dale and Plunkett (1991). Quality Costing

- Demeulemeester and Callewier (1997). Integrale Kwaliteitszorg Concepten, methoden en technieken (in Dutch)

- Duncan (1986). Quality Control and Industrial Statistics

- Grant and Leavenworth (1972). Statistical Quality Control

- Juran and Gryna (1993). Quality Planning and Analysis

- Montgomery (1991). Introduction to Statistical Quality Control

- Wonnacott and Wonnacott (1990). Introductory Statistics for Business and Economics

\footnotetext{
${ }^{4}$ see bibliography for full references
} 


\section{Chapter 2}

\section{quality inspection in multistage production systems - literature review}

\subsection{Chapter purpose and outline}

In the previous Chapter, methodologies for tolerancing, process control and inspection were outlined. In this Chapter the literature on the proposed methods, applied in an economic design perspective, to determine optimal inspection strategies for the broad class of multistage production systems (MSPS) is reviewed. After an introduction in the following Section, literature on separate optimization is discussed in Section 2.2. Work on joint optimization is reviewed is Section 2.3. In Appendix 2.A, one particular example of joint optimization is elaborated upon.

\subsection{Introduction}

In a production environment, reducing variance is the major key to achieve conformance to specifications. It is pursued along different paths in design and operation of a production process. The implementation of an efficient inspection strategy is one of those paths. Efficient economic inspection strategies ensure the required output quality while minimizing the total inspection cost. Generally speaking, more and tighter inspec- 
tion will induce a higher product quality -in terms of meeting product specifications- but will also result in higher costs of inspection, scrap and rework. An economic inspection plan will balance these effects.

For a single stage production process, the extent of inspection refers to the number of inspections executed (sample size and sampling frequency) and to the rigor of the inspections (inspection acceptance limits). Thus, the problem facing the inspection planner consists of finding the combination of these inspection parameters that minimizes the total expected inspection cost TIC.

For multistage production processes, an additional set of decision variables is added to the problem: the number and location of inspection stations in the production process. For an $n$-stage process, it is to be decided for each of the $n$ stages whether or not inspection will be performed after that process stage, and if so, to what extent (i.e. which inspection parameters to be used).

Thus, in a multistage production system (MSPS) the inspection strategy addresses

1. the number and location of inspection stations;

2. the number of inspections executed (sample size - sampling frequency) for each inspection station;

3. the rigor of the inspections (acceptance limits) for each inspection station.

The optimization problem to economically design quality inspection strategies for multistage production systems, is at the heart of this thesis.

Determining the optimal inspection strategy in a MSPS involves the above cited three types of inspection decision variables to be considered together, resulting in a complex joint optimization problem. While separate optimization of each type of decision variable has been studied extensively and is well established in literature, the joint problem has not been subject to intense research. 


\subsection{Separate optimization}

\subsubsection{Inspection allocation}

A variety of theoretical work has been published on the subject of optimal inspection allocation for multistage process chains, i.e. on the decision of where to place inspection stations in multistage processes. Pioneers Lindsay and Bishop (1964) use a dynamic programming algorithm to determine optimal screening allocation along a single-line, multistage and constant rate process, assuming linear inspection and scrap costs, and a $100 \%$ efficient inspection. An important finding of theirs is that the total cost function will only be minimized by an extreme-point solution, such that, at each process stage, the cost optimal inspection level is either 0 (no inspection) or 1 (full inspection).

White (1969), adopting this conclusion and thus only considering allor-none inspection plans, developed two shortest route models for determining the optimal inspection allocation for some general cost structures. Britney (1972) has extended the Lindsay and Bishop approach to nonserial production systems, while Ballou and Pazer (1982) contributed by including the impact of inspection error. Imperfect inspection is also considered by Eppen and Hurst (1974): under the assumption that the inspection error probabilities are known at each stage, they prove that the expected total cost function is concave and piecewise linear.

\subsubsection{Sample size and sampling frequency}

Determining an optimal sample size and sampling frequency is an aspect of inspection strategy that has been exhaustively researched as part of SPC and its applications. Recent developments in the field are oriented towards quantification of the economic benefits of adaptive versus static control charting, and thus also towards adaptive sampling size and frequency. Contributors are e.g. Tagaras $(1996,1998)$, Keats et al. (1997), Montgomery et al. (1994), Del Castillo and Hurwitz (1997). 


\subsubsection{Acceptance limits, quality levels, specifications}

Kapur and Cho (1994) propose optimization models for the economic design and development of specifications: generic models for each type ${ }^{1}$ of quality characteristic are developed and substantiated by two case studies. Wei et al. (1999) propose a tolerance design model to minimize the overall scrap in a process chain.

\subsection{Joint optimization}

The optimization models discussed in the previous Sections are all limited to single-issue optimization. To optimize the entire inspection strategy along a multistage process chain, simultaneous or combined optimization approaches are necessary.

In the work of Tang (1991) the impact of the inspection policy on inspection and production capacities is accounted for; combined optimization of the integrated production-inspection model is performed, using elements of queueing theory and dynamic programming. The model can be used for budget planning: it enables trade-off analysis between the initial investment in the production-inspection system and the total operating cost. A major model limitation is that it doesn't allow rework nor recycle loops in the production process.

Another combined approach is proposed by Tannock $(1995,1997)$ : he compares the costs of different inspection strategies (100\% inspection, sampling inspection, no inspection), based on simulated quality data, for different values of the process capability indices $C_{p}$ and $C_{p k}$. This work however, is limited to single stage processes.

In the thesis by Chen (1999), two approaches are used to analyze the optimal inspection problem for a general multistage assembly process. First, analytical equations are proposed for the variation propagation through the system. Second, a simulation based optimization tool is developed and applied to a case study: assembly of an aircraft wing contour. The major limitation of this work is that it is only valid for linear dependencies of the critical quality characteristics. It is assumed that the $n_{k}$ critical quality characteristics $X_{k i},\left(i=1, \ldots, n_{k}\right)$ of stage $k,(k=1, \ldots, n)$

\footnotetext{
${ }^{1}$ S-type, L-type and N-type, see Section 1.5.3
} 
depend on the $n_{k-1}$ quality characteristics $X_{(k-1) i},\left(i=1, \ldots, n_{k-1}\right)$ of the previous stage $k-1$ through linear equations only:

$$
\begin{aligned}
X_{k i} & =a_{k i 1} X_{(k-1) 1}+a_{k i 2} X_{(k-1) 2}+\ldots+a_{k i n_{(k-1)}} X_{(k-1) n_{(k-1)}} \\
(i & \left.=1, \ldots, n_{k}\right) \\
(k & =1, \ldots, n)
\end{aligned}
$$

Chen's analytical approach is not valid for general relations between these consecutive quality characteristics, i.e. general functions like

$$
X_{k i}=f_{k i}\left(X_{(k-1) 1}, X_{(k-1) 2}, \ldots, X_{(k-1) n_{(k-1)}}\right)
$$

Besides the limitation to linear dependencies for the quality characteristics, another restriction of this work is that it assumes only serial processing, no recycle loops or parallel processing is possible.

The idea of variation propagation calculation for the linear relationships is as follows: for a $k$-stage process, assume a set of $n_{k}$ output quality characteristics, $X_{k 1}$ to $X_{k n_{k}}$. Further assume that in the last process stage (stage $n), n_{(n-1)}$ critical parameters $X_{(n-1) 1}$ to $X_{(n-1) n_{(n-1)}}$ influence the outcome value for $X_{n 1}$ to $X_{n n_{n}}$; in the last-but-one process stage (stage $n-1), n_{(n-2)}$ critical parameters $X_{(n-2) 1}$ to $X_{(n-2) n_{(n-2)}}$ influence the values for $X_{(n-1) 1}$ to $X_{(n-1) n_{(n-1)}}$; and so on until the start of the process chain (stage $1, n_{1}$ critical parameters $X_{11}$ to $X_{1 n_{1}}$, influenced by $n_{0}$ critical input parameters $X_{01}$ to $X_{0 n_{0}}$ ).

By Taylor expansion, the deviations $\Delta X_{k i},\left(i=1, \ldots, n_{k}\right)$, can be represented by a linear combination of the deviations $\Delta X_{(k-1) i}(i=$ $\left.1, \ldots, n_{(k-1)}\right)$, keeping only the first order terms of the Taylor series expansion:

$$
\begin{aligned}
\Delta X_{k i}=\frac{\partial X_{k i}}{\partial X_{(k-1) 1}} \Delta X_{(k-1) 1} & +\frac{\partial X_{k i}}{\partial X_{(k-1) 2}} \Delta X_{(k-1) 2}+\ldots \\
& +\frac{\partial X_{k i}}{\partial X_{(k-1) n_{(k-1)}}} \Delta X_{(k-1) n_{(k-1)}}
\end{aligned}
$$

and similarly, each deviation $\Delta X_{(k-1) i}\left(i=1, \ldots, n_{(k-1)}\right)$ can be expressed in terms of the deviations $\Delta X_{(k-2) i}\left(i=1, \ldots, n_{(k-2)}\right)$. Thus, calculating 
backwards through the entire process chain, the deviations $\Delta X_{k i},(i=$ $\left.1, \ldots, n_{k}\right)$, can be related to the deviations of the input parameters $X_{0 i}$ $\left(i=1, \ldots, n_{0}\right)$ at the entrance of the process chain.

Generalized, for each of the process stages, a matrix $\boldsymbol{\Gamma}_{\mathbf{q}}$, relating $\Delta \mathbf{X}_{\mathbf{q}}$ to $\Delta \mathbf{X}_{\mathbf{q}-\mathbf{1}}$, can be constructed:

$$
\boldsymbol{\Gamma}_{\mathbf{q}}=\left(\begin{array}{cccc}
\frac{\partial X_{q 1}}{\partial X_{(q-1) 1}} & \frac{\partial X_{q 1}}{\partial X_{(q-1) 2}} & \cdots & \frac{\partial X_{q 1}}{\partial X_{(q-1) n}(q-1)} \\
\frac{\partial X_{q 2}}{\partial X_{(q-1) 1}} & \frac{\partial X_{q 2}}{\partial X_{(q-1) 2}} & \cdots & \frac{\partial X_{q 2}}{\partial X_{(q-1) n}(q-1)} \\
\vdots & \vdots & \ddots & \vdots \\
\frac{\partial X_{q n_{q}}}{\partial X_{(q-1) 1}} & \frac{\partial X_{q n_{q}}}{\partial X_{(q-1) 2}} & \cdots & \frac{\partial X_{q n_{q}}}{\partial X_{(q-1) n}(q-1)}
\end{array}\right)
$$

Further, for any $X_{q i},\left(q=1, \ldots, k ; i=1, \ldots, n_{q}\right)$, the corresponding variance is:

$$
\sigma_{q i}^{2}=\left(\frac{\partial X_{q i}}{\partial X_{(q-1) 1}}\right)^{2} \sigma_{(q-1) 1}^{2}+\ldots+\left(\frac{\partial X_{q i}}{\partial X_{(q-1) n_{(q-1)}}}\right)^{2} \sigma_{(q-1) n_{(q-1)}}^{2}
$$

Or, in matrix-form: matrices $\boldsymbol{\Sigma}_{\mathbf{q}}$, relating $\sigma_{\mathbf{q}}^{\mathbf{2}}$ to $\sigma_{\mathbf{q}-\mathbf{1}}^{\mathbf{2}}$, with $\boldsymbol{\Sigma}_{\mathbf{q}}$ :

$$
\boldsymbol{\Sigma}_{\mathbf{q}}=\left(\begin{array}{cccc}
\left(\frac{\partial X_{q 1}}{\partial X_{(q-1) 1}}\right)^{2} & \left(\frac{\partial X_{q 1}}{\partial X_{(q-1) 2}}\right)^{2} & \cdots & \left(\frac{\partial X_{q 1}}{\partial X_{(q-1) n}(q-1)}\right)^{2} \\
\left(\frac{\partial X_{q 2}}{\partial X_{(q-1) 1}}\right)^{2} & \left(\frac{\partial X_{q 2}}{\partial X_{(q-1) 2}}\right)^{2} & \cdots & \left(\frac{\partial X_{q 2}}{\partial X_{(q-1) n}}\right)^{2} \\
\vdots & \vdots & \ddots & \vdots \\
\left(\frac{\partial X_{q n q}}{\partial X_{(q-1) 1}}\right)^{2} & \left(\frac{\partial X_{q n q}}{\partial X_{(q-1) 2}}\right)^{2} & \cdots & \left(\frac{\partial X_{q n_{q}}}{\partial X_{(q-1) n}(q-1)}\right)^{2}
\end{array}\right)^{2}
$$

For a $k$-stage process, the variance on the $X_{k i}$ can then be predicted:

$$
\sigma_{\mathrm{k}}^{2}=\mathbf{S} \sigma_{0}^{2} \quad \text { with } \quad \mathbf{S}=\boldsymbol{\Sigma}_{\mathrm{k}} \boldsymbol{\Sigma}_{(\mathrm{k}-1)} \ldots \boldsymbol{\Sigma}_{\mathbf{2}} \boldsymbol{\Sigma}_{\mathbf{1}}
$$

A cost function is subsequently derived, the variation propagation can thus be costed, and an inspection strategy that minimizes these costs is proposed. This approach is further illustrated with an example in Appendix 2.A. 
Villalobos et al. (1993) present a model for (automated) inspection strategies for production of printed circuit boards. The idea is to impose a dynamic inspection strategy based on information on the manufacturing and inspection process, and a global objective (e.g. minimal cost or minimal scrap). After each manufacturing stage and for each unit produced, a decision is taken on whether or not to remove the unit from production, and whether or not it should be inspected. In the Villalobos et al. (1993) model, the extent of inspection of the overall production process is limited by time: each possible inspection operation takes a fixed amount of time, and the fixed amount of total available inspection time is to be allocated among all inspection stations. This way, the problem becomes one of optimal control of a dynamic Markov process under time constraints. The Markov chain structure and transition matrix are subsequently derived.

In Barad and Braha (1996) and Emmons and Rabinowitz (2002) it is assumed that an inspection is made at each production stage, so there is no problem of allocating (a limited number of) inspection facilities to production stations. The former address the problem of finding the optimal (limits for the) input quantity in each stage, while the latter focus on the assignment and scheduling of inspection tasks.

The model of Barad and Braha (1996) (also set in the microelectronics industry) is essentially an optimal lot sizing problem in a MSPS with binomial yield and deterministic demand. After each production stage, a $100 \%$ reliable inspection is performed, so that all defective units are discarded. The solution to the problem consists of deciding on the number of products to process in the next stage, in order to try and meet the demand for non-defective finished units, at the lowest cost. There are three alternatives: processing all available non-defective units, processing less than available non-defective units by disposal of some (at a per unit cost), and processing more than available non-defective units by reworking some of the defective units or by purchasing the necessary semi-finished units (also at a per unit cost). A dynamic programming approach is suggested to define the optimal policy, both for single and multiple production runs.

Emmons and Rabinowitz (2002) address an inspection system for detecting malfunctioning processors in a MSPS: a processor (a stage in the MSPS) can either be up (designating proper function) or down (designating malfunction). When a stage is down, each unit processed at that stage 
acquires a defect, when a stage is up, no unit does. A finished product is conforming if and only if it has not acquired a single defect. Inspection is there to detect stages as down, leading to immediate restoration of the detected down stage to up. Perfect inspection is assumed, the impact of imperfect inspection is accounted for in Rabinowitz and Yahalom (2001).

The inspection system comprises several subsystems of single inspection facilities (IFs) responsible for inspecting a subset of production stages. In this setting three decisions are to be made: total inspection capacity (the number of IFs required), assignment of the stages to the IFs and inspection schedules in each subsystem. These three decisions are hierarchically structured, and thus solved through a hierarchical process. First, the inspection capacity is determined by solving a relaxed version of the base problem. The partition of the stages among the IFs is then determined by considering the inspection capacity from step 1 as the capacity of a multi-knapsack (bin packing) problem. Finally the inspection schedule for each subsystem is derived.

The model by Bai and Yun (1996) allows inspection effort allocation in a serial multistage production system (MSPS) for a product consisting of identical components. In this model, only a limited number of (automatic) inspection machines are available, and the rate of production is constrained by the rate of inspection. The inspection level is defined as the proportion of components inspected. An inspection cost model is proposed and a method is constructed to determine optimal location of inspection machines and optimal inspection level. An exact search algorithm considering all possible allocations is proposed for problems in which the number of stages $h$ and the number of inspection machines $m$ is relatively small. For larger problems a heuristic algorithm using backward dynamic programming is suggested.

\subsection{Concluding comment}

The literature review on MSPS inspection optimization reveals a void when it comes to determining solution methods for general MSPS-es with true joint optimization. This thesis aims at filling that void by presenting and validating a metaheuristic solution method in Chapters 4 and 5 . 


\section{A. A simple example of Chen's approach}

Consider a simple single-stage three-part stack-up problem, see Figure 2.1. The quality characteristic for each part $\left(X_{0 i}\right)$, and for the assembly $\left(X_{11}\right)$, is the length.

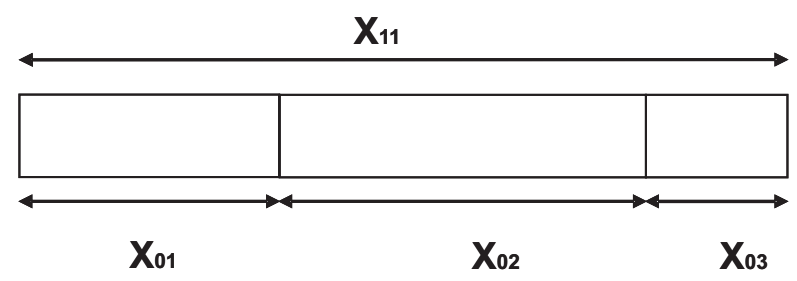

Figure 2.1: A three part stack-up assembly

The length of the assembly is the sum of the three part lengths,

$$
X_{11}=X_{01}+X_{02}+X_{03}
$$

assuming each part's length $X_{0 i}$ follows a normal distribution with mean $\mu_{0 i}$ and standard deviation $\sigma_{0 i}$, and that the parts' lengths are independent, it is straightforward to write that

$$
\sigma_{11}=\sqrt{\sigma_{01}^{2}+\sigma_{02}^{2}+\sigma_{03}^{2}}
$$

For the analysis of this simple inspection problem it will be assumed that part 1 is inspected and the others are not. With following inspection limits for part 1 , (with $t_{01}$ a scalar, the inspection parameter),

$$
\begin{aligned}
L L_{01} & =\mu_{01}-t_{01} \sigma_{01} \\
U L_{01} & =\mu_{01}+t_{01} \sigma_{01}
\end{aligned}
$$

and different costs

$$
\begin{aligned}
C_{f} & =\text { failure cost (when assembly length target is not achieved) } \\
C_{i} & =\text { part } 1 \text { inspection cost } \\
C_{s} & =\text { scrap cost if } X_{01} \text { is outside }\left[L L_{01}, U L_{01}\right]
\end{aligned}
$$

a decision tree (with repetitive rejection branch) can be constructed, see Figure 2.2. 


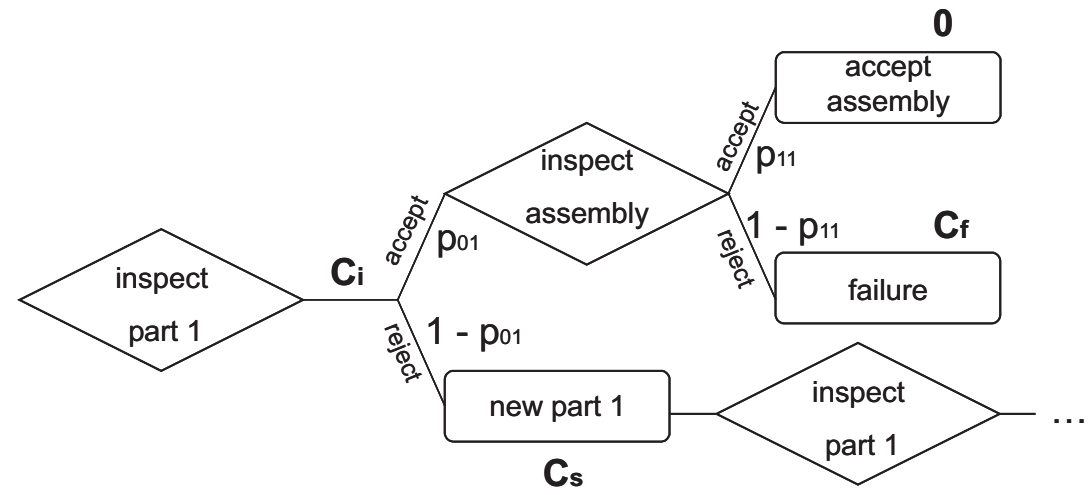

Figure 2.2: Decision tree

The total expected cost $C_{T}$ can now be calculated by summing the cost of each branch, multiplied with the branch probability. Accounting for the repetition of the rejection branch, this yields

$$
C_{T}=\frac{1}{p_{01}} C_{i}+\left(1-p_{11}\right) C_{f}+\frac{1-p_{01}}{p_{01}} C_{s}
$$

The different probabilities can be calculated as follows

$$
\begin{aligned}
& p_{01}=\int_{L L_{01}}^{U L_{11}} p d f\left(X_{01}\right) \cdot \mathrm{d} X_{01} \\
& p_{11}=\int_{-\infty}^{\infty} p_{X_{11} \mid X_{01}}\left(X_{01}\right) \cdot p d f\left(X_{01}\right) \cdot \mathrm{d} X_{01}
\end{aligned}
$$

where $p_{X_{11} \mid X_{01}}\left(X_{01}\right)$ represents the conditional (Bayesian) probability of accepting the assembly $\left(X_{11}\right)$ after having inspected and accepted part 1 $\left(X_{01}\right)$.

The probabilities and costs can subsequently be expressed as function of the inspection parameter $t_{01}$, the inspection limits can thus be optimized to minimize the total expected cost: find $t_{01}$ to minimize

$$
C_{T}\left(t_{01}\right)=\frac{1}{p_{01}\left(t_{01}\right)} C_{i}\left(t_{01}\right)+\left(1-p_{11}\left(t_{01}\right)\right) C_{f}+\frac{1-p_{01}\left(t_{01}\right)}{p_{01}\left(t_{01}\right)} C_{s}\left(t_{01}\right)
$$

$.48 \cdots$ 
For this example, the plot of the total expected $\operatorname{cost} C_{T}$ in function of the inspection parameter $t_{01}$, would have the general form suggested in Figure 2.3.

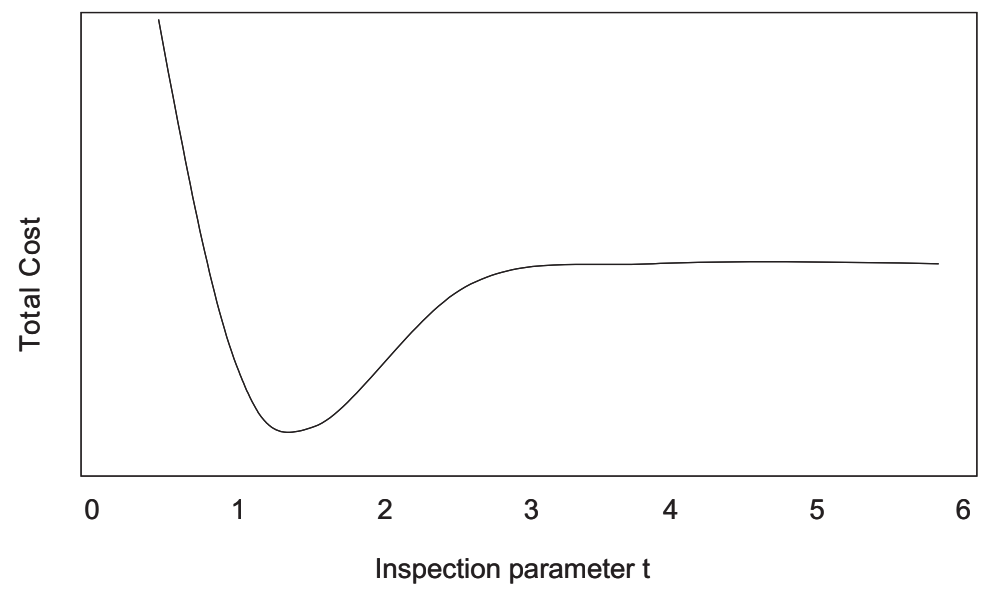

Figure 2.3: General evolution of total expected cost with inspection parameter $t_{01}$

The plot suggests inspection between $\mu_{01} \pm 1.2 \sigma_{01}$ is cost optimal. Tighter inspection causes the cost to increase significantly. The plot also shows the cost indifference for tolerances past $\mu_{01} \pm 3.3 \sigma_{01}$. This could be expected from the characteristics of the normal distribution: when inspecting the population of a normal distribution between $\mu_{01} \pm 3.3 \sigma_{01}$, less than $0.06 \%$ of the population lies outside the inspection interval. Therefore, inspection with such broad tolerances, in essence is the same as no inspection, hence the cost indifference. 



\section{Chapter 3}

\section{solving to the MSPS inspection optimization problem - an analytical approach}

\subsection{Chapter purpose and outline}

In this Chapter, analytical solutions to the MSPS inspection optimization problem are investigated. The Chapter is organized as follows: Section 3.1 introduces the MSPS modeling framework used in this thesis. In Section 3.2 analytical calculations for some examples cases are proposed, with an eye to gain an insight into the possibilities of tackling the MSPS inspection optimization problem analytically. Section 3.3 introduces the limitations of an analytical approach. In Appendix 3.B, two lemmata for integral calculus are proposed. Appendix 3.A displays the basic statistical constructs and notations frequently used in this Chapter.

\subsection{Model formulation}

\subsubsection{The serial multistage production system}

Consider a serial MSPS in which products travel sequentially from stage 1 to stage $n$ and inspection of products is performed by $k(k \leq n)$ inspection stations (see Figure 3.1). At each stage, a manufacturing operation is 


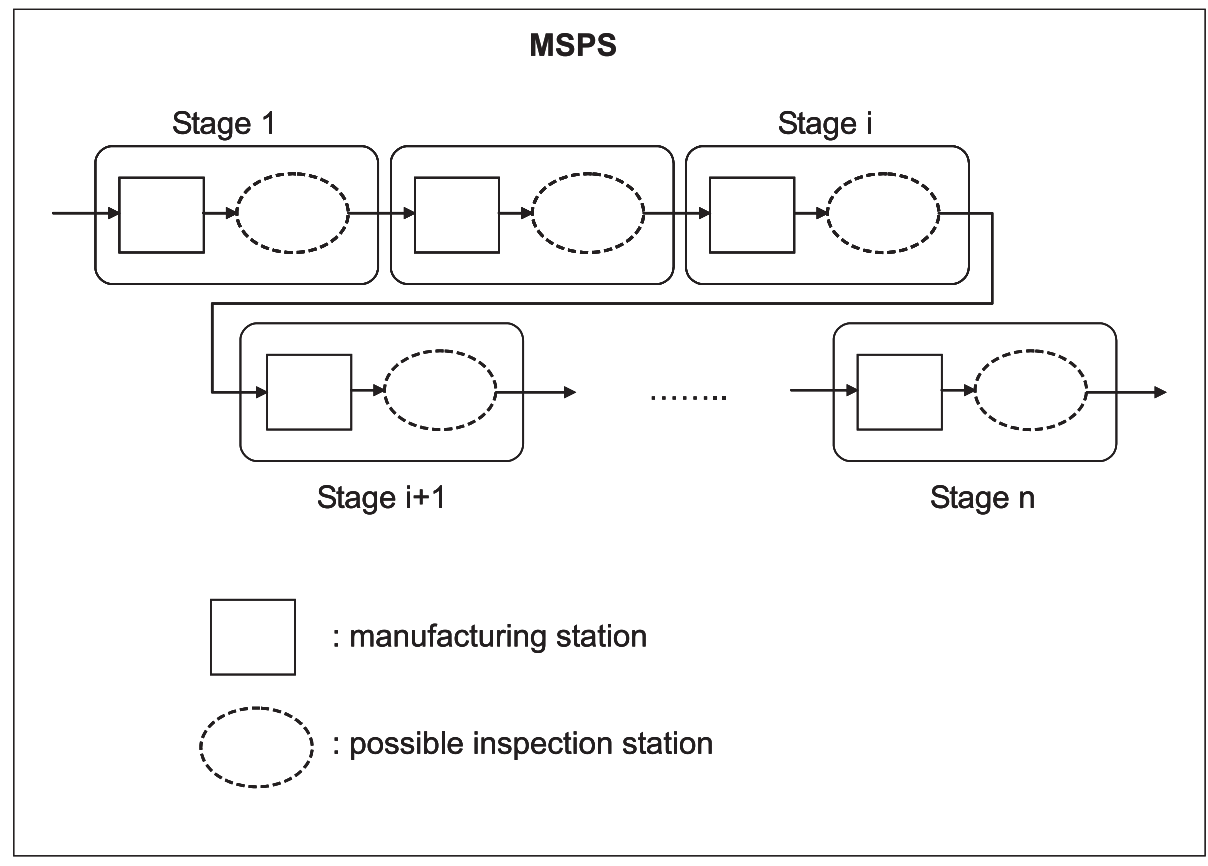

Figure 3.1: A serial n-stage MSPS

performed on the products, before moving on to an inspection station, or to the processing station of the next stage in case of no inspection.

After each of the processing stations, one of three inspection options can be chosen: no inspection (N), full inspection (F), or sampling inspection $(\mathrm{S})$. The first option, no inspection $(\mathrm{N})$, obviously does not necessitate any further inspection decision. If full inspection $(\mathrm{F})$ is chosen, inspection limits subsequently have to be determined. Finally, the sampling inspection option (S), requires a decision on the inspection limits, and the (single) sampling scheme parameters: the sample size and acceptance number.

In any MSPS, three types of parameters can be distinguished: process parameters, inspection parameters and cost parameters. When using the model to optimize the overall inspection strategy, only the inspection parameters are considered endogenous (as they can be changed in the inspection strategy optimization process), while the cost and process pa- 
rameters are exogenous because they cannot be changed for inspection strategy optimization purposes.

Prior to further model development the following notations are adopted.

$\begin{array}{ll}K & =\text { batchsize } \\ n & =\text { number of process stages } \\ I_{i} & =\text { inspection option for stage } i, \text { i.e. } I_{i} \in\{F, N, S\} \\ p_{i}^{\prime} & =\text { fault occurrence after stage } i \\ L I L_{i} & =\text { lower inspection limit in stage } i \text { (variable) } \\ U I L_{i} & =\text { upper inspection limit in stage } i \text { (variable) } \\ L S_{n} & =\text { lower specification limit after stage } n \text { (fixed) } \\ U S_{n} & =\text { upper specification limit after stage } n \text { (fixed) } \\ s_{i} & =\text { sample size for stage } i \\ t_{i} & =\text { acceptance number for stage } i \\ l_{i} & =\text { number of bad items in sample of stage } i \\ c_{T, i} & =\text { unit test cost in stage } i \\ c_{R, i} & =\text { unit rework cost in stage } i \\ c_{P} & =\text { unit penalty cost (after stage } n) \\ T C_{i} & =\text { test cost in stage } i \\ R C_{i} & =\text { rework cost in stage } i \\ T T C & =\text { total test cost } \\ T R C & =\text { total rework cost } \\ T P C & =\text { total penalty cost } \\ T I C & =\text { total inspection cost }\end{array}$

Consider a constant production and inspection rate, perfect inspection and perfect rework. Three types of cost are defined: test costs $\left(c_{T}\right)$, rework costs $\left(c_{R}\right)$ and the penalty cost $\left(c_{P}\right)$. Test cost is the cost of a single test or analysis. Rework or replacement costs are incurred if a defective product is discovered through testing, and reworked or replaced by a non-defective product. The penalty cost is incurred when a defective product is shipped to the customer. In the MSPS, product is defective whenever the value of its quality characteristic in stage $i$ lies outside its inspection limits, i.e. outside the interval $\left[L I L_{i}, U I L_{i}\right]$. MSPS output (after the last stage $n$ ) is defective if the value of the quality characteristic is not contained in the specification interval $\left[L S_{n}, U S_{n}\right]$.

The fault occurrence $p_{i}^{\prime}$ is the fraction of defective products in stage 
$i$. Because the inspection limits $\left(L I L_{i}, U I L_{i}\right)$ are independent variables of the inspection optimization problem under consideration, the fault occurrence $p_{i}^{\prime}$ will be a dependent variable. For a single production stage, its value can be calculated using standard statistics, if the distribution of the quality characteristic value is known, and the $L I L$ and $U I L$ for the stage are chosen. Also for the first stage of a MSPS, $p_{1}^{\prime}$ can be calculated this way. For the following stages $i(i=2, \ldots, n)$ however, the fault occurrence $p_{i}^{\prime}$ not only depends on the choice of inspection limits $\left(L I L_{i}, U I L_{i}\right)$, but also on the inspection strategy chosen in the previous stage(s).

Because it would be uneconomical to inspect a product if this were more expensive than reworking or replacing it, $c_{T, i}<c_{R, i}, \forall i$. Moreover, we assume that $c_{R, i}<c_{R, j}, \forall i<j$. This assumption avoids having to introduce separate intermediate penalty costs: the penalty cost of detecting a defect only in stage $j$, instead of earlier in stage $i$, is implicitly derived as $c_{R, j}-c_{R, i}$. Furthermore it is assumed that if a batch is rejected after acceptance sampling inspection $\mathrm{S}$, a full inspection $\mathrm{F}$ of the rejected batch is performed consecutively in the same stage.

\subsubsection{Determination of the TIC}

Determining the TIC is now straightforward:

$$
\begin{aligned}
& T I C=T T C+T R C+T P C \\
& \text { with }=\sum_{i=1}^{n} T C_{i} \\
& T T C=\sum_{i=1}^{n} R C_{i} \\
& T R C=c_{P} \cdot p_{n}^{\prime} . K \\
& T P C
\end{aligned}
$$


and with

$$
\begin{aligned}
& T C_{i}= \begin{cases}c_{T, i} \cdot K & \forall i:\left(I_{i}=F\right) \vee\left(\left(I_{i}=S\right) \wedge\left(l_{i}>t_{i}\right)\right) \\
c_{T, i} \cdot s_{i} & \forall i:\left(I_{i}=S\right) \wedge\left(l_{i} \leq t_{i}\right) \\
0 & \forall i: I_{i}=N\end{cases} \\
& R C_{i}= \begin{cases}c_{R, i} \cdot p_{i}^{\prime} \cdot K & \forall i:\left(I_{i}=F\right) \vee\left(\left(I_{i}=S\right) \wedge\left(l_{i}>t_{i}\right)\right) \\
c_{R, i} \cdot l_{i} & \forall i:\left(I_{i}=S\right) \wedge\left(l_{i} \leq t_{i}\right) \\
0 & \forall i:\left(I_{i}=N\right)\end{cases}
\end{aligned}
$$

Determining the optimal inspection strategy, i.e. the whole of inspection decisions that minimize the $T I C$, requires the determination of inspection options $I_{i}$ and the corresponding inspection limits $\left(L I L_{i}, U I L_{i}\right)$ and sampling parameters $\left(s_{i}, t_{i}\right)$, for all stages $i=1, \ldots, n$. Solving this optimization problem consists of finding the set of optimal values

$$
\left(I_{1}^{\natural}, \ldots, I_{n}^{\natural} ; L I L_{1}^{\natural}, \ldots, L I L_{n}^{\natural} ; U I L_{1}^{\natural}, \ldots, U I L_{n}^{\natural} ; s_{1}^{\natural}, \ldots, s_{n}^{\natural} ; t_{1}^{\natural}, \ldots, t_{n}^{\natural}\right)
$$

that minimize

$$
T I C\left(I_{1}, \ldots, I_{n} ; L I L_{1}, \ldots, L I L_{n} ; U I L_{1}, \ldots, U I L_{n} ; s_{1}, \ldots, s_{n} ; t_{1}, \ldots, t_{n}\right)
$$

Strictly, an exception should be made for cases when sampling inspection is chosen for the last stage, and the batch is subsequently accepted $\left(\left(I_{n}=S\right) \wedge l_{n} \leq t_{n}\right)$. All above equations hold, except for equation 3.4, which has to be corrected for the $l_{n}$ bad items found in the sample and thus becomes:

$$
T P C=c_{P} \cdot\left(p_{n}^{\prime} \cdot K-l_{n}\right)
$$

For practical purposes however, $l_{n} \leq t_{n}$ will normally be small enough for this correction to be negligible.

\subsection{Analytical calculations for a three-stage example}

A fictitious three stage serial MSPS is constructed, representing a stackup assembly operation, with the product dimension the quality characteristic under attention. For such a process, the following notations are adopted: the dimension of the component added in stage $i$ is denoted $\mathrm{X}_{i}$, the dimension of the assembly after stage $i$ is denoted $\mathrm{X}_{i}^{\star}$. A plain 
stack-up assembly mathematically comes down to performing an addition in each stage (the component added in each stage adds to the overall dimension), or symbolically

$$
\mathrm{X}_{3}^{\star}=\mathrm{X}_{1}+\mathrm{X}_{2}+\mathrm{X}_{3}
$$

In Table 3.2 the process and inspection characteristics are given, the cost parameters are grouped in Table 3.3. Normal distributions describe the dimensional characteristic of the components $\mathrm{X}_{i}$ added in each stage.

Table 3.2: Example 1: process and inspection characteristics

\begin{tabular}{|c|c|c|c|c|c|}
\hline stage & distribution & $\mu$ & $\sigma$ & LIL & UIL \\
\hline \hline 1 & normal & 10 & 0.4 & 9.3 & 10.7 \\
2 & normal & 10 & 0.2 & 19.2 & 20.8 \\
3 & normal & 10 & 0.3 & 29.1 & 30.9 \\
\hline
\end{tabular}

Table 3.3: Example 1: cost parameters

\begin{tabular}{|c|c|c|c|}
\hline stage & $c_{T, i}$ & $c_{R, i}$ & $c_{P}$ \\
\hline \hline 1 & 1 & 50 & - \\
2 & 1 & 100 & - \\
3 & 2 & 200 & 1000 \\
\hline
\end{tabular}

For this example, the TIC will be calculated analytically (if possible), for different inspection strategies. For clearer reference, only strategies with combinations of $\mathrm{F}$ and $\mathrm{N}$ inspection are considered, $\mathrm{S}$ inspection is omitted from this analysis. This can be done without loss of generality, since the cost effects of $\mathrm{S}$ inspection on the TIC can always be reduced to either the $\mathrm{N}$ case or the $\mathrm{F}$ case. This can be understood seeing the construction of the cost model: 


$$
\begin{aligned}
& \text { if } \quad\left(I_{i}=S\right) \wedge\left(l_{i}>t_{i}\right) \quad \text { then costs equal those of }\left(I_{i}=F\right) \\
& \text { if } \quad\left(I_{i}=S\right) \wedge\left(l_{i} \leq t_{i}\right) \quad \text { then costs exceed those of }\left(I_{i}=N\right)
\end{aligned}
$$

so that the costs of sampling inspection either (for "bad" batches) coincide with the costs of full inspection; or (for "good" batches) slightly exceed the costs of no inspection with the fixed sampling cost. This is also illustrated in Figure 3.2 from which it can be seen that sampling inspection will in fact never be cost optimal in a single sampling setting.

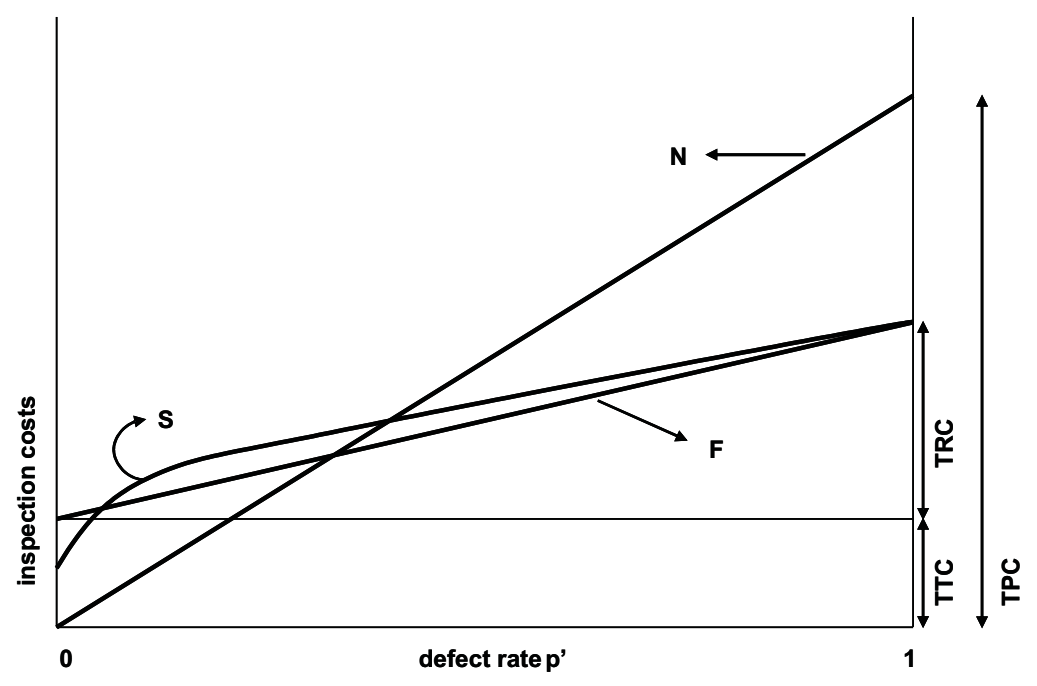

Figure 3.2: Inspection costs versus defect rate for different inspection options

Sampling inspection however remains a valuable inspection alternative instead of full inspection in cases where full inspection is impossible (testing is destructive or time-consuming), and likewise instead of no inspection in cases where no inspection is not an option (regulatory requirements for minimum sampling or sampling for reasons of process monitoring). 


\subsubsection{The general case}

From expressions 3.1 through 3.6, it can be seen that once the $p_{i}^{\prime}$ are known, TIC can be calculated immediately. By definition, $p_{i}^{\prime}$ (the fraction non-conforming in stage $i$ ) can be expressed as follows:

$$
p_{i}^{\prime}=\mathrm{P}\left[\mathrm{X}_{i}^{\star} \notin\left[L I L_{i}, U I L_{i}\right]\right]=1-\mathrm{P}\left[L I L_{i} \leq \mathrm{X}_{i}^{\star} \leq U I L_{i}\right]
$$

Generally, there are two options to calculate these $p_{i}^{\prime}$. The first is to explicitly calculate the distribution functions of the $\mathrm{X}_{i}^{\star}$, once these are available, the $p_{i}^{\prime}$ can be calculated through:

$$
p_{i}^{\prime}=1-\int_{L I L_{i}}^{U I L_{i}} f_{\mathrm{X}_{i}^{\star}}\left(x_{i}\right) \mathrm{d} x_{i}
$$

The second option is to use multiple integration. It avoids the explicit calculation of the distribution functions for the $\mathrm{X}_{i}^{\star}$, but necessitates the explicit mathematical description of the integration domain $\Omega$ to solve the multiple integral (example for stage 3 ):

$$
p_{3}^{\prime}=1-\iiint_{\Omega} f_{\mathrm{X}_{1}, \mathrm{X}_{2}, \mathrm{X}_{3}}\left(x_{1}, x_{2}, x_{3}\right) \mathrm{d} x_{1} \mathrm{~d} x_{2} \mathrm{~d} x_{3}
$$

In the previous expression, $f_{\mathrm{X}_{1}, \mathrm{X}_{2}, \mathrm{X}_{3}}\left(x_{1}, x_{2}, x_{3}\right)$ denotes the simultaneous distribution function, defined as:

$$
\begin{array}{r}
f_{\mathrm{X}_{1}, \mathrm{X}_{2}, \mathrm{X}_{3}}\left(x_{1}, x_{2}, x_{3}\right) \mathrm{d} x_{1} \mathrm{~d} x_{2} \mathrm{~d} x_{3}=\mathrm{P}\left[\left(x_{1} \leq \mathrm{X}_{1} \leq x_{1}+\mathrm{d} x_{1}\right)\right. \\
\cap\left(x_{2} \leq \mathrm{X}_{2} \leq x_{2}+\mathrm{d} x_{2}\right) \cap\left(x_{3} \leq \mathrm{X}_{3} \leq x_{3}+\mathrm{d} x_{3}\right)
\end{array}
$$

When the $\mathrm{X}_{i}$ are independent, the simultaneous distribution function reduces to the product of the individual distribution functions:

$$
f_{\mathrm{X}_{1}, \mathrm{X}_{2}, \mathrm{X}_{3}}\left(x_{1}, x_{2}, x_{3}\right)=f_{\mathrm{X}_{1}}\left(x_{1}\right) \cdot f_{\mathrm{X}_{2}}\left(x_{2}\right) \cdot f_{\mathrm{X}_{3}}\left(x_{3}\right)
$$

\subsubsection{The case of no inspection (NNN)}

When no inspection is performed in any of the stages, calculation of $p_{i}^{\prime}$ is straightforward. Assuming symmetrical inspection limits, and introduc$.58 \cdots$ 
ing $\mu_{i}^{\star}, \sigma_{i}^{\star}, \delta_{i}$ and $\kappa_{i}$ as

$$
\begin{aligned}
\mu_{i}^{\star} & =\text { expected value after stage } i \\
\sigma_{i}^{\star} & =\text { standard deviation after stage } i \\
\delta_{i} & =U I L_{i}-\mu_{i}^{\star}=\mu_{i}^{\star}-L I L_{i} \\
\kappa_{i} & =\frac{\delta_{i}}{\sigma_{i}^{\star}}
\end{aligned}
$$

$p_{i}^{\prime}$ can be expressed as follows:

$$
\begin{aligned}
p_{i}^{\prime} & =1-\mathrm{P}\left[L I L_{i} \leq \mathrm{X}_{i}^{\star} \leq U I L_{i}\right] \\
& =1-\left(2 \Phi\left(\kappa_{i}\right)-1\right) \\
& =2\left(1-\Phi\left(\kappa_{i}\right)\right)
\end{aligned}
$$

For example 1, using properties 3.40a and 3.40b, this becomes

$$
\begin{aligned}
& \mu_{1}^{\star}=\mu_{1}=10 \\
& \mu_{2}^{\star}=\mu_{1}+\mu_{2}=20 \\
& \mu_{3}^{\star}=\mu_{2}^{\star}+\mu_{3}=\mu_{1}+\mu_{2}+\mu_{3}=30 \\
& \sigma_{1}^{\star}=\sigma_{1}=0.4 \\
& \sigma_{2}^{\star}=\sqrt{\sigma_{1}^{2}+\sigma_{2}^{2}}=\sqrt{0.2} \approx 0.447 \\
& \sigma_{3}^{\star}=\sqrt{\sigma_{1}^{2}+\sigma_{2}^{2}+\sigma_{3}^{2}}=\sqrt{0.29} \approx 0.539 \\
& \delta_{1}=0.7 \\
& \delta_{2}=0.8 \\
& \delta_{3}=0.9 \\
& \kappa_{1}=1.75 \\
& \kappa_{2} \approx 1.789 \\
& \kappa_{3} \approx 1.671 \\
& p_{1}^{\prime} \approx 0.0801 \\
& p_{2}^{\prime}=0.0736 \\
& p_{3}^{\prime} \approx 0.0947
\end{aligned}
$$

meaning there are approximately $8.01 \%, 7.36 \%$ and $9.47 \%$ defectives after stages 1, 2 and 3 respectively in case of no inspection. For a batchsize $K$ of 1000 , and with the cost parameters of Table 3.3, the expected TIC for example 1 in case of no inspection (denoted $T I C_{N N N}$ ) is 94700 (= 
$\left.c_{P} . p_{3}^{\prime} \cdot K\right)$.

\subsubsection{The cases of full inspection in one of the three stages}

\section{The case NNF}

From the NNN case, the fault occurrence $p_{3}^{\prime}$ in stage 3 -when no inspection has taken place in stages 1 and 2- is known. In a batch of 1000 items, 94.7 bad items are expected in this case. This results in an expected inspection cost in stage 3 consisting of $T C_{3}=K c_{T, 3}=2000$ and $R C_{3}=$ $p_{3}^{\prime} \cdot K \cdot c_{R, 3}=94.7 * 200=18940$, or a total expected $T I C_{N N F}$ of 20940 .

\section{The case FNN}

Analytical calculation With the inspection assumptions: symmetrical inspection limits, perfect inspection and perfect rework, performing inspection in the first stage mathematically means truncating the normal distribution of stage 1 from above and below, with the upper and lower inspection limits respectively. The superscript ${ }^{\sharp}$ will be used to indicate this inspection consequence. With all other notations as introduced earlier in this Chapter, we find

$$
\begin{aligned}
\mathrm{E}\left[\mathrm{X}_{1}^{\sharp}\right] & =\mu_{1}=\mu_{1}^{\star}=10 \\
\operatorname{Var}\left[\mathrm{X}_{1}^{\sharp}\right] & =\left(1-\frac{2 \delta_{1} \phi\left(\delta_{1}\right)}{2 \Phi\left(\delta_{1}\right)-1}\right) \sigma_{1}^{2}=\left(\sigma_{1}^{\star}\right)^{2} \approx 0.0245 \\
\mathrm{E}\left[\mathrm{X}_{3}^{\star}\right] & =\mu_{1}+\mu_{2}+\mu_{3}=\mu_{3}^{\star}=30 \\
\operatorname{Var}\left[\mathrm{X}_{3}^{\star}\right] & =\left(1-\frac{2 \delta_{1} \phi\left(\delta_{1}\right)}{2 \Phi\left(\delta_{1}\right)-1}\right) \sigma_{1}^{2}+\sigma_{2}^{2}+\sigma_{3}^{2}=\left(\sigma_{3}^{\star}\right)^{2} \approx 0.1545
\end{aligned}
$$

From the NNN case, the fault occurrence of the first stage is known; 80.1 bad items are expected in a batch of 1000 items. With perfect inspection and rework, this means the expected inspection cost after full inspection in stage 1 , is the sum of $T C_{1}=K \cdot c_{T, 1}=1000$ and $R C_{1}=p_{1}^{\prime} \cdot K \cdot c_{R, 1}=$ $80.1 * 50=4005$. To this subtotal the expected total penalty cost must be added, $c_{P} . p_{3}^{\prime} . K$. To calculate or estimate the $p_{3}^{\prime}$ and thus the expected $T I C_{F N N}$, the two options described in Section 3.2.1 are available. 
Introducing the substitution

$$
\left\{\begin{array} { l } 
{ Y _ { 1 } = X _ { 1 } ^ { \sharp } + X _ { 2 } + X _ { 3 } } \\
{ Y _ { 2 } = X _ { 2 } } \\
{ Y _ { 3 } = X _ { 3 } }
\end{array} \Leftrightarrow \left\{\begin{array}{l}
X_{1}^{\sharp}=Y_{1}-Y_{2}-Y_{3} \\
X_{2}=Y_{2} \\
X_{3}=Y_{3}
\end{array}\right.\right.
$$

and given the independence of $\mathrm{X}_{1}^{\sharp}, \mathrm{X}_{2}$ and $\mathrm{X}_{3}$,

$$
\begin{gathered}
f_{\mathrm{Y}_{1}, \mathrm{Y}_{2}, \mathrm{Y}_{3}}\left(y_{1}, y_{2}, y_{3}\right)= \\
f_{\mathrm{X}_{1}^{\sharp}}\left(y_{1}-y_{2}-y_{3}\right) \cdot \mathbb{1}_{\left[L I L_{1}, U I L_{1}\right]}\left(y_{1}-y_{2}-y_{3}\right) \cdot f_{\mathrm{X}_{2}}\left(y_{2}\right) \cdot f_{\mathrm{X}_{3}}\left(y_{3}\right) \cdot|J|
\end{gathered}
$$

with $|J|$ :

$$
|J|=\left|\begin{array}{lll}
\frac{\partial \mathrm{X}_{1}^{\sharp}}{\partial \mathrm{Y}_{1}} & \frac{\partial \mathrm{X}_{1}^{\sharp}}{\partial \mathrm{Y}_{2}} & \frac{\partial \mathrm{X}_{1}^{\sharp}}{\partial \mathrm{Y}_{3}} \\
\frac{\partial \mathrm{X}_{2}}{\partial \mathrm{Y}_{1}} & \frac{\partial \mathrm{X}_{2}}{\partial \mathrm{Y}_{2}} & \frac{\partial \mathrm{X}_{2}}{\partial \mathrm{Y}_{3}} \\
\frac{\partial \mathrm{X}_{3}}{\partial \mathrm{Y}_{1}} & \frac{\partial \mathrm{X}_{3}}{\partial \mathrm{Y}_{2}} & \frac{\partial \mathrm{X}_{3}}{\partial \mathrm{Y}_{3}}
\end{array}\right|=\left|\begin{array}{ccc}
1 & -1 & -1 \\
0 & 1 & 0 \\
0 & 0 & 1
\end{array}\right|=1
$$

The marginal distribution for $\mathrm{Y}_{1}$ thus becomes

$$
\begin{aligned}
& f_{\mathrm{Y}_{1}}\left(y_{1}\right)=\int_{-\infty}^{\infty} \int_{-\infty}^{\infty}\left(f_{\mathrm{X}_{1}^{\sharp}}\left(y_{1}-y_{2}-y_{3}\right) .\right. \\
& \left.\mathbb{1}_{\left[L I L_{1}, U I L_{1}\right]}\left(y_{1}-y_{2}-y_{3}\right) \cdot f_{\mathrm{X}_{2}}\left(y_{2}\right) \cdot f_{\mathrm{X}_{3}}\left(y_{3}\right)\right) \mathrm{d} y_{2} \mathrm{~d} y_{3}
\end{aligned}
$$

In this case, $\mathrm{Y}_{1}=\mathrm{X}_{3}^{\star}$, so that

$$
\begin{aligned}
& p_{3}^{\prime}=1-\int_{L I L_{3}}^{U I L_{3}} f_{\mathrm{X}_{3}^{\star}}\left(x_{3}\right) \mathrm{d} x_{3} \\
&=1-\int_{L I L_{3}}^{U I L_{3}} f_{\mathrm{Y}_{1}}\left(y_{1}\right) \mathrm{d} y_{1} \\
&=1-\int_{L I L_{3}}^{U I L_{3}}\left[\int_{-\infty}^{\infty} \int_{-\infty}^{\infty} f_{\mathrm{X}_{1}^{\sharp}}\left(y_{1}-y_{2}-y_{3}\right) \cdot \mathbb{1}_{\left[L I L_{1}, U I L_{1}\right]}\left(y_{1}-y_{2}-y_{3}\right)\right. \\
&\left.f_{\mathrm{X}_{2}}\left(y_{2}\right) \cdot f_{\mathrm{X}_{3}}\left(y_{3}\right) \mathrm{d} y_{2} \mathrm{~d} y_{3}\right] \mathrm{d} y_{1}
\end{aligned}
$$


with

$$
f_{\mathrm{X}_{1}^{\sharp}}(\cdot)=\frac{\phi\left(\frac{(\cdot)-\mu_{1}}{\sigma_{1}}\right)}{\sigma_{1}\left(2 \Phi\left(\kappa_{1}\right)-1\right)}
$$

and with $f_{\mathrm{X}_{2}}(\cdot)$ and $f_{\mathrm{X}_{3}}(\cdot)$ the normal distribution. The appearance of the $\mathbb{1}$ function in the integrand has among other things the effect of limiting the domain for integration. This eventually causes the appearance of the integration variables in the integration limits. Therefore it will no longer be possible to analytically solve the triple integral (for a more elaborate discussion, see Appendix 3.B). For these types of integrals, we are immediately driven back on numerical integration, or estimation (see below).

Numerical calculation Numerical integration of expression $3.22 \mathrm{c}$ for example 1, using the MatLab software package, renders a value of 0.0633 for $p_{3}^{\prime}$ and thus an expected $T I C_{F N N}$ of $1000+4005+0.0633 * 1000$ $* 1000=68305$.

To this end, a convolution function was developed, based on the predefined MatLab conv function $(w=\operatorname{conv}(u, v)$ convolves vectors $u$ and $v)$. Algebraically, convolution is the same operation as multiplying the polynomials whose coefficients are the elements of $u$ and $v$.

Let $\mathrm{m}=\operatorname{length}(u)$ and $\mathrm{n}=\operatorname{length}(v)$. Then $w$ is the vector of length $\mathrm{m}+\mathrm{n}-1$ whose $k^{\text {th }}$ element is

$$
w(k)=\sum_{j} u(j) v(k+1-j)
$$

The sum is over all the values of $j$ which lead to legal subscripts for $u(j)$ and $v(k+1-j)$, specifically $j=\max (1, k+1-n): \min (k, m)$. When $.62 \ldots$ 
$\mathrm{m}=\mathrm{n}$, this gives

$$
\begin{aligned}
w(1) & =u(1) v(1) \\
w(2) & =u(1) v(2)+u(2) v(1) \\
w(3) & =u(1) v(3)+u(2) v(2)+u(3) v(1) \\
\cdots & \\
w(n) & =u(1) v(n)+u(2) v(n-1)+\ldots+u(n) v(1) \\
\cdots & \\
w(2 n-1) & =u(n) v(n)
\end{aligned}
$$

The convolution theorem says, roughly, that convolving two sequences is the same as multiplying their Fourier transforms. In order to make this precise, it is necessary to pad the two vectors with zeros and ignore roundoff error. Thus, if $X=\operatorname{fft}([x \operatorname{zeros}(1, \operatorname{length}(y)-1)])$ and $Y=$ $\mathrm{fft}([y \operatorname{zeros}(1, \operatorname{length}(x)-1)])$ then $\operatorname{conv}(x, y)=$ inverse $\operatorname{fft}(X * Y)$

Estimation If we were to assume that the normal distribution could still be used as approximation for the $\mathrm{X}_{3}^{\star}, p_{3}^{\prime}$ can be approximated by expression $3.17 \mathrm{c}$. For example 1 this becomes $\widehat{p}_{3}^{\prime} \approx 0.0220$ so that $\widehat{T I C}_{F N N} \approx$ 27005 .

Another estimate, or rather an upper bound, can be found through the use of the Camp-Meidel inequality discussed before (see expression 3.39). We find:

$$
p_{3}^{\prime}=\mathrm{P}\left[\left|\mathrm{X}_{3}^{\star}-\mu_{3}^{\star}\right|>\delta_{3}\right]<\frac{4 \sigma_{3}^{\star 2}}{9 \delta_{3}^{2}}
$$

or for the example: $p_{3}^{\prime}<0.0848$ and the expected $T I C_{F N N}<89805$. Comparison of these estimates with the numerical results found with MatLab, immediately shows that the first estimation, based on the assumption of a normal distribution for the $\mathrm{X}_{3}^{\star}$, is a gross underestimate and thus not at all useful; while the estimation based on the Camp-Meidel inequality brings a rough overestimate or rather a not very tight upper bound. 


\section{The case NFN}

Calculation According to the same line of reasoning as in the FNN case, the following substitution can be introduced:

$$
\left\{\begin{array} { l } 
{ \mathrm { Y } _ { 1 } = ( \mathrm { X } _ { 2 } ^ { \star } ) ^ { \sharp } + \mathrm { X } _ { 3 } = ( \mathrm { X } _ { 1 } + \mathrm { X } _ { 2 } ) ^ { \sharp } + \mathrm { X } _ { 3 } } \\
{ \mathrm { Y } _ { 2 } = \mathrm { X } _ { 3 } }
\end{array} \Leftrightarrow \left\{\begin{array}{l}
\left(\mathrm{X}_{2}^{\star}\right)^{\sharp}=\mathrm{Y}_{1}-\mathrm{Y}_{2} \\
\mathrm{X}_{3}=\mathrm{Y}_{2}
\end{array}\right.\right.
$$

This leads to:

$$
f_{\mathrm{Y}_{1}, \mathrm{Y}_{2}}\left(y_{1}, y_{2}\right)=f_{\left(\mathrm{X}_{2}^{\star}\right)^{\sharp}}\left(y_{1}-y_{2}\right) \cdot \mathbb{1}_{\left[L I L_{2}, U I L_{2}\right]}\left(y_{1}-y_{2}\right) \cdot f_{\mathrm{X}_{3}}\left(y_{2}\right) \cdot|J|
$$
with $|J|$ :

$$
|J|=\left|\begin{array}{cc}
1 & -1 \\
0 & 1
\end{array}\right|=1
$$

The marginal distribution for $\mathrm{Y}_{1}$ is now

$$
f_{\mathrm{Y}_{1}}\left(y_{1}\right)=\int_{-\infty}^{\infty} f_{\left(\mathrm{X}_{2}^{\star}\right)^{\sharp}}\left(y_{1}-y_{2}\right) \cdot \mathbb{1}_{\left[L I L_{2}, U I L_{2}\right]}\left(y_{1}-y_{2}\right) \cdot f_{\mathrm{X}_{3}}\left(y_{2}\right) \mathrm{d} y_{2}
$$

what leads to

$$
\begin{aligned}
& p_{3}^{\prime}=1-\int_{L I L_{3}}^{U I L_{3}} f_{\mathrm{X}_{3}^{\star}}\left(x_{3}\right) \mathrm{d} x_{3} \\
&=1-\int_{L I L_{3}}^{U I L_{3}} f_{\mathrm{Y}_{1}}\left(y_{1}\right) \mathrm{d} y_{1} \\
&=1-\int_{L I L_{3}}^{U I L_{3}}\left[\int_{-\infty}^{\infty} f_{\left(\mathrm{X}_{2}^{\star}\right)^{\sharp}}\left(y_{1}-y_{2}\right) \cdot \mathbb{1}_{\left[L I L_{2}, U I L_{2}\right]}\left(y_{1}-y_{2}\right) .\right. \\
&\left.f_{\mathrm{X}_{3}}\left(y_{2}\right) \mathrm{d} y_{2}\right] \mathrm{d} y_{1}
\end{aligned}
$$

where, analogous with the previous paragraph,

$$
f_{\left(\mathrm{X}_{2}^{\star}\right)^{\sharp}}(\cdot)=\frac{\phi\left(\frac{(\cdot)-\mu_{2}^{\star}}{\sigma_{2}^{\star}}\right)}{\sigma_{2}^{\star}\left(2 \Phi\left(\kappa_{2}\right)-1\right)}
$$

and $f_{\mathrm{X}_{3}}(\cdot)$ the normal distribution. 


\subsubsection{The cases of full inspection in more than one of the three stages (NFF, FNF, FFN, FFF)}

For these cases the mathematical formulation becomes even more cumbersome, since the second (or third) inspection implies a second (or third) truncation. This subsequent truncation has to be applied to an already truncated, complex compound function, and moreover the truncation also has the effect of limiting the domain for integration. This again causes the appearance of the integration variables in the integration limits. Therefore it will no longer be possible to analytically solve the triple integrals resulting from the cases with more than one inspection.

\subsection{Limitations of an analytical approach}

From the examples and calculations in the previous Section, it should be clear that the use of an analytical approach to tackle the MSPS inspection optimization problem at hand, is fairly limited. One is rapidly, even for trivial or ostensibly simple cases, driven back on numerical solution methods and estimation procedures, or limited to establishing bounds. As established, available estimates are poor. Also, numerical integration becomes cumbersome for two or more truncations (inspections). Therefore, the remaining option is to resort to (meta)heuristics. Following this course will be the subject of the next Chapter.

\section{A. General statistical notions}

\section{A.1. Common notations}

For any continuous distribution of a random variable $\mathrm{X}$ with probability density function (pdf): $f_{\mathrm{X}}(x), \forall x:-\infty<x<\infty$, the characteristics $\mathrm{E}[\mathrm{X}]$ (expected value of $\mathrm{X}$ ) and $\operatorname{Var}[\mathrm{X}]$ (variance of $\mathrm{X}$ ) are defined as:

$$
\mathrm{E}[\mathrm{X}]=\int_{-\infty}^{\infty} x f_{\mathrm{X}}(x) \mathrm{d} x
$$




$$
\operatorname{Var}[\mathrm{X}]=\mathrm{E}\left[(\mathrm{X}-\mathrm{E}[\mathrm{X}])^{2}\right]=\int_{-\infty}^{\infty}(x-\mathrm{E}[\mathrm{X}])^{2} f_{\mathrm{X}}(x) \mathrm{d} x
$$

Common notations for these distribution parameters are

$$
\begin{aligned}
\mu & =\mathrm{E}[\mathrm{X}] \\
\sigma^{2} & =\operatorname{Var}[\mathrm{X}]
\end{aligned}
$$

The positive root of the variance, i. e. $\sigma$, is called the standard deviation or dispersion. With these notations, the probability density function for the normal or Gaussian distribution is given by

$$
f_{\mathrm{X}}(x)=\frac{1}{\sqrt{2 \pi} \sigma} \exp \left(-\frac{1}{2}\left(\frac{x-\mu}{\sigma}\right)^{2}\right)
$$

Substituting $\mathrm{U}=\frac{\mathrm{X}-\mu}{\sigma}$ produces the standard normal distribution with pdf

$$
f_{\mathrm{U}}(u)=\phi(u)=\frac{1}{\sqrt{2 \pi}} \exp \left(-\frac{u^{2}}{2}\right)
$$

and

$$
\begin{aligned}
\mathrm{E}[\mathrm{U}] & =0 \\
\operatorname{Var}[\mathrm{U}] & =1
\end{aligned}
$$

With $\mathrm{P}[\mathrm{A}]$ denoting the probability of occurrence of event $\mathrm{A}$, the cumulative distribution functions (cdf) are defined as

$$
\begin{aligned}
& \mathrm{F}_{\mathrm{U}}(u)=\mathrm{P}[\mathrm{U} \leq u]=\Phi(u)=\int_{-\infty}^{u} f_{\mathrm{U}}(t) \mathrm{d} t \\
& \mathrm{~F}_{\mathrm{X}}(x)=\mathrm{P}[\mathrm{X} \leq x]=\Phi\left(\frac{x-\mu}{\sigma}\right)=\int_{-\infty}^{x} f_{\mathrm{X}}(t) \mathrm{d} t
\end{aligned}
$$

$.66 \ldots$ 
For the standard normal distribution the following symmetry properties hold:

$$
\begin{aligned}
\phi(-u) & =\phi(u) \\
\Phi(-u) & =1-\Phi(u)
\end{aligned}
$$

\section{A.2. Confidence intervals}

For normal distributions, the probability of $\mathrm{X}$ being within the interval $[\mu-k \sigma, \mu+k \sigma]$, is given by

$$
\mathrm{P}[|\mathrm{X}-\mu| \leq k \sigma]=\Phi(k)-\Phi(-k)=\Phi(k)-(1-\Phi(k))=2 \Phi(k)-1
$$

The probability that the variable $\mathrm{X}$ should deviate from its mean $\mu$ by more then $k$ times its standard deviation $\sigma$ is, of course, the complement of the previous:

$$
\mathrm{P}[|\mathrm{X}-\mu|>k \sigma]=1-(2 \Phi(k)-1)=2(1-\Phi(k))
$$

For any continuous distribution function with known mean $\mu$ and dispersion $\sigma$, it can be shown that this probability is bounded by

$$
\mathrm{P}[|\mathrm{X}-\mu|>k \sigma]<\frac{1}{k^{2}}
$$

This is known as Chebychev's inequality. The practical use of this upper bound remains rather limited as it is fairly broad. However, an extension of Chebychev's inequality exists that increases its usefulness without seriously restricting its application. This extension is valid for any continuous unimodal distribution function $f_{\mathrm{X}}(x)$ of $\mathrm{X}$, with known mean $\mu$ and dispersion $\sigma$ (Duncan, 1986, p. 104), and reads:

$$
\mathrm{P}[|\mathrm{X}-\mu|>k \sigma]<\frac{4}{9 k^{2}}
$$

This relation is known as the Camp-Meidel or Gauss-Winkler inequality and is attributed to Gauss (1821, Theoria Combinatoris Observationem Erroribus Minimis Obnoxiae, partim 1, §10). 


\section{A.3. Linear combination of random variables}

The sum $\mathrm{X}^{\star}$ of two normally distributed independent random variables $\mathrm{X}_{1}$ with mean $\mu_{1}$ and variance $\sigma_{1}^{2}$ and $\mathrm{X}_{2}$ with mean $\mu_{2}$ and variance $\sigma_{2}^{2}$ is a normally distributed random variable with mean $\mu^{\star}$ and variance $\left(\sigma^{\star}\right)^{2}$ equal to:

$$
\begin{aligned}
\mu^{\star} & =\mu_{1}+\mu_{2} \\
\left(\sigma^{\star}\right)^{2} & =\sigma_{1}^{2}+\sigma_{2}^{2}
\end{aligned}
$$

More general, the following holds for any linear combination of random variables $\mathrm{X}_{1}, \mathrm{X}_{2}, \ldots, \mathrm{X}_{n}$ :

$$
\mathrm{E}\left[a_{1} \mathrm{X}_{1}+a_{2} \mathrm{X}_{2}+\ldots+a_{n} \mathrm{X}_{n}\right]=a_{1} \mathrm{E}\left[\mathrm{X}_{1}\right]+a_{2} \mathrm{E}\left[\mathrm{X}_{2}\right]+\ldots+a_{n} \mathrm{E}\left[\mathrm{X}_{n}\right]
$$

This property is often referred to as the additivity or linearity of the expectation operator $\mathrm{E}[\cdot]$. Moreover, if and only if the variables $\mathrm{X}_{1}, \mathrm{X}_{2}, \ldots, \mathrm{X}_{n}$ are all mutually independent, it can be shown that

$\operatorname{Var}\left[a_{1} \mathrm{X}_{1}+a_{2} \mathrm{X}_{2}+\ldots+a_{n} \mathrm{X}_{n}\right]=a_{1}^{2} \operatorname{Var}\left[\mathrm{X}_{1}\right]+a_{2}^{2} \operatorname{Var}\left[\mathrm{X}_{2}\right]+\ldots+a_{n}^{2} \operatorname{Var}\left[\mathrm{X}_{n}\right]$

\section{A.4. Truncated normal distributions}

A random variable $\mathrm{X}$ has a doubly truncated normal distribution if its pdf is (Johnson and Kotz, 1970, p. 81-83)

$$
f_{\mathrm{X}}(x)=\frac{\frac{1}{\sqrt{2 \pi} \sigma} \exp \left(-\frac{1}{2}\left(\frac{x-\mu}{\sigma}\right)^{2}\right)}{\frac{1}{\sqrt{2 \pi} \sigma} \int_{A}^{B} \exp \left(-\frac{1}{2}\left(\frac{t-\mu}{\sigma}\right)^{2}\right) \mathrm{d} t} \quad A \leq \mathrm{X} \leq B
$$

The lower and upper truncation points are $A, B$ respectively; the degrees of truncation are $\Phi\left(\frac{A-\mu}{\sigma}\right)$ from below and $\left(1-\Phi\left(\frac{B-\mu}{\sigma}\right)\right)$ from above. If either $A$ is replaced with $-\infty$ or $B$ is replaced with $\infty$ the distribution is singly truncated from above or below, respectively.

In fact, such a doubly truncated function is a function where $1^{\circ}$ the values below $A$ and above $B$ are omitted, and $2^{\circ}$ the remainder is re-scaled so that the total probability density remains 1 . 
With the notations introduced in expressions 3.33 and 3.35, expression 3.43 can be rewritten as

$$
f_{\mathrm{X}}(x)=\frac{\phi\left(\frac{x-\mu}{\sigma}\right)}{\sigma\left(\Phi\left(\frac{B-\mu}{\sigma}\right)-\Phi\left(\frac{A-\mu}{\sigma}\right)\right)} \quad A \leq \mathrm{X} \leq B
$$

The function is only defined in the interval $[A, B]$. Introducing the $\mathbb{1}$ function ${ }^{1}$ in the notation emphasizes this:

$$
f_{\mathrm{X}}(x)=\frac{\phi\left(\frac{x-\mu}{\sigma}\right)}{\sigma\left(\Phi\left(\frac{B-\mu}{\sigma}\right)-\Phi\left(\frac{A-\mu}{\sigma}\right)\right)} \cdot \mathbb{1}_{[A, B]}(x)
$$

It can be shown that the expected value and variance of such a function are given by

$$
\begin{aligned}
& \mathrm{E}[\mathrm{X}]= \mu+\frac{\phi\left(\frac{A-\mu}{\sigma}\right)-\phi\left(\frac{B-\mu}{\sigma}\right)}{\Phi\left(\frac{B-\mu}{\sigma}\right)-\Phi\left(\frac{A-\mu}{\sigma}\right)} \\
& \operatorname{Var}[\mathrm{X}]= {\left[1+\frac{\left(\frac{A-\mu}{\sigma}\right) \phi\left(\frac{A-\mu}{\sigma}\right)-\left(\frac{B-\mu}{\sigma}\right) \phi\left(\frac{B-\mu}{\sigma}\right)}{\Phi\left(\frac{B-\mu}{\sigma}\right)-\Phi\left(\frac{A-\mu}{\sigma}\right)}\right.} \\
&\left.-\left(\frac{\phi\left(\frac{A-\mu}{\sigma}\right)-\phi\left(\frac{B-\mu}{\sigma}\right)}{\Phi\left(\frac{B-\mu}{\sigma}\right)-\Phi\left(\frac{A-\mu}{\sigma}\right)}\right)^{2}\right] \sigma^{2}
\end{aligned}
$$

In the case of symmetrical double truncation, $\mu-A=B-\mu=\delta$, expression 3.45 becomes

$$
f_{\mathrm{X}}(x)=\frac{\phi\left(\frac{x-\mu}{\sigma}\right)}{\sigma\left(2 \Phi\left(\frac{\delta}{\sigma}\right)-1\right)} \cdot \mathbb{1}_{[\mu-\delta, \mu+\delta]}(x)
$$

with expected value and variance given by

$$
\begin{aligned}
\mathrm{E}[\mathrm{X}] & =\mu \\
\operatorname{Var}[\mathrm{X}] & =\left(1-\frac{2 \delta \phi(\delta)}{2 \Phi(\delta)-1}\right) \sigma^{2}
\end{aligned}
$$

\footnotetext{
${ }^{1}$ the $\mathbb{1}$ function has a value of 1 inside its definition interval, and is zero otherwise
} 


\section{B. Some integral calculus}

To solve the integral

$$
\int_{L I L_{3}}^{U I L_{3}}\left[\int_{-\infty}^{\infty} \int_{-\infty}^{\infty} f_{\mathrm{X}_{1}^{\sharp}}\left(y_{1}-y_{2}-y_{3}\right) \cdot f_{\mathrm{X}_{2}}\left(y_{2}\right) \cdot f_{\mathrm{X}_{3}}\left(y_{3}\right) \mathrm{d} y_{2} \mathrm{~d} y_{3}\right] \mathrm{d} y_{1}
$$

the following lemmata are introduced:

\section{lemma 1}

$$
\int_{-\infty}^{\infty} e^{-\frac{1}{2}\left(\alpha y^{2}-2 \beta y\right)} \mathrm{d} y=\frac{\sqrt{2 \pi}}{\sqrt{\alpha}} \cdot e^{\frac{\beta^{2}}{2 \alpha}}
$$

proof of lemma 1

$$
\begin{aligned}
\int_{-\infty}^{\infty} e^{-\frac{1}{2}\left(\alpha y^{2}-2 \beta y\right)} \mathrm{d} y \\
=\int_{-\infty}^{\infty} e^{-\frac{1}{2} y \sqrt{\alpha}-\frac{\beta}{\sqrt{\alpha}}^{2}} \cdot e^{\frac{\beta^{2}}{2 \alpha}} \mathrm{d} y \\
=\frac{e^{\frac{\beta^{2}}{2 \alpha}}}{\sqrt{\alpha}} \cdot \int_{-\infty}^{\infty} e^{-\frac{1}{2} y \sqrt{\alpha}-\frac{\beta}{\sqrt{\alpha}}^{2}} \mathrm{~d}\left(y \sqrt{\alpha}-\frac{\beta}{\sqrt{\alpha}}\right) \\
\stackrel{!}{=} \frac{\sqrt{2 \pi}}{\sqrt{\alpha}} \cdot e^{\frac{\beta^{2}}{2 \alpha}}
\end{aligned}
$$

lemma 2

$$
\begin{aligned}
& \int_{L I L}^{U I L} e^{-\frac{1}{2}\left(\alpha y^{2}-2 \beta y\right)} \mathrm{d} y= \\
& \quad \frac{1}{\sqrt{\alpha}} \cdot e^{\frac{\beta^{2}}{2 \alpha}} \cdot\left[\Phi\left(U I L \cdot \sqrt{\alpha}-\frac{\beta}{\sqrt{\alpha}}\right)-\Phi\left(L I L \cdot \sqrt{\alpha}-\frac{\beta}{\sqrt{\alpha}}\right)\right]
\end{aligned}
$$

$.70 \cdots$ 


\section{proof of lemma 2}

$$
\begin{aligned}
& \int_{L I L}^{U I L} e^{-\frac{1}{2}\left(\alpha y^{2}-2 \beta y\right)} \mathrm{d} y \\
& \quad=\int_{L I L}^{U I L} e^{-\frac{1}{2} y \sqrt{\alpha}-\frac{\beta}{\sqrt{\alpha}}^{2}} \cdot e^{\frac{\beta^{2}}{2 \alpha}} \mathrm{d} y \\
& =e^{\frac{\beta^{2}}{2 \alpha}} \cdot \int_{L I L}^{U I L} e^{-\frac{1}{2} \cdot y \sqrt{\alpha}-\frac{\beta}{\sqrt{\alpha}}^{2}} \mathrm{~d} y \\
& \quad=\frac{e^{\frac{\beta^{2}}{2 \alpha}}}{\sqrt{\alpha}} \cdot \int_{\left(L I L \cdot \sqrt{\alpha}-\frac{\beta}{\sqrt{\alpha}}\right)}^{\left(U I L \cdot \sqrt{\alpha}-\frac{\beta}{\sqrt{\alpha}}\right)} e^{-\frac{1}{2} \cdot y \sqrt{\alpha}-\frac{\beta}{\sqrt{\alpha}}}{ }^{2} \mathrm{~d}\left(y \sqrt{\alpha}-\frac{\beta}{\sqrt{\alpha}}\right) \\
& \stackrel{!}{=} \frac{1}{\sqrt{\alpha}} \cdot e^{\frac{\beta^{2}}{2 \alpha}} \cdot\left[\Phi\left(U I L \cdot \sqrt{\alpha}-\frac{\beta}{\sqrt{\alpha}}\right)-\Phi\left(L I L \cdot \sqrt{\alpha}-\frac{\beta}{\sqrt{\alpha}}\right)\right]
\end{aligned}
$$

With the integrand of expression 3.49,

$$
\begin{aligned}
& f_{\mathrm{X}_{1}^{\sharp}}\left(y_{1}-y_{2}-y_{3}\right) \cdot f_{\mathrm{X}_{2}}\left(y_{2}\right) \cdot f_{\mathrm{X}_{3}}\left(y_{3}\right) \\
& =C \cdot \frac{1}{(2 \pi)^{3} \sigma_{1} \sigma_{2} \sigma_{3}} \cdot e^{-\frac{1}{2} \cdot{\frac{y_{1}-y_{2}-y_{3}-\mu_{1}}{\sigma_{1}}}^{2}+\frac{y_{2}-\mu_{2}}{\sigma_{2}}{ }^{2}+{\frac{y_{3}-\mu_{3}}{\sigma_{3}}}^{2}}
\end{aligned}
$$

integral 3.49 can now, with application of lemmata 1 and 2 on repeated occasions, be solved to:

$$
\frac{C}{\sqrt{2 \pi}} \cdot\left[\Phi\left(\frac{U I L_{3}-\left(\mu_{1}+\mu_{2}+\mu_{3}\right)}{\sqrt{\sigma_{1}^{2}+\sigma_{2}^{2}+\sigma_{3}^{2}}}\right)-\Phi\left(\frac{L I L_{3}-\left(\mu_{1}+\mu_{2}+\mu_{3}\right)}{\sqrt{\sigma_{1}^{2}+\sigma_{2}^{2}+\sigma_{3}^{2}}}\right)\right]
$$

where

$$
C=\frac{1}{\left(2 \Phi\left(\kappa_{1}\right)-1\right)}
$$


Solving the triple integral in expression $3.22 \mathrm{c}$, including the $\mathbb{1}$-function, i. e. ,

$$
\begin{gathered}
\int_{L I L_{3}}^{U I L_{3}}\left[\int_{-\infty}^{\infty} \int_{-\infty}^{\infty} f_{\mathrm{X}_{1}^{\sharp}}\left(y_{1}-y_{2}-y_{3}\right) \cdot \mathbb{1}_{\left[L I L_{1}, U I L_{1}\right]}\left(y_{1}-y_{2}-y_{3}\right) .\right. \\
\left.f_{\mathrm{X}_{2}}\left(y_{2}\right) \cdot f_{\mathrm{X}_{3}}\left(y_{3}\right) \mathrm{d} y_{2} \mathrm{~d} y_{3}\right] \mathrm{d} y_{1}
\end{gathered}
$$

starting with the integration over $y_{3}$ (obviously equivalent to starting with the integration over $y_{2}$ ), requires substitution of the integration limits, because $\left(y_{1}-y_{2}-y_{3}\right)$ is only defined in the interval $\left[L I L_{1}, U I L_{1}\right]$. The new integration domain for $y_{3}$ thus becomes

$$
\left[y_{1}-y_{2}-U I L_{1}, y_{1}-y_{2}-L I L_{1}\right]
$$

With lemma 2, the following can be derived for integration over $y_{3}$ :

$$
\begin{array}{r}
\int_{L I L_{3}}^{U I L_{3}}\left[\int_{-\infty}^{\infty} C^{\prime} \cdot f_{\mathrm{X}_{2}}\left(y_{2}\right) \cdot(\Phi\right. \\
\Phi\left[\left(y_{1}-y_{2}-L I L_{1}\right) \sqrt{\alpha}-\frac{\beta}{\sqrt{\alpha}}\right]- \\
\left.\left.\left.\Phi\left[y_{1}-y_{2}-U I L_{1}\right) \sqrt{\alpha}-\frac{\beta}{\sqrt{\alpha}}\right]\right) \mathrm{d} y_{2}\right] \mathrm{d} y_{1}
\end{array}
$$

The next integration, over $y_{2}$, now runs into analytical road blocks because of the appearance of $y_{2}$ in the $\Phi$-functions of the integrand. 


\section{Part II}

development and validation of a new solution method for the MSPS inspection optimization problem 



\section{Chapter 4}

\section{Solutions to the MSPS inspection optimization problem - a metaheuristic approach: an evolutionary algorithm and simulation}

\subsection{Chapter purpose and outline}

This Chapter starts with a general introduction to (4.1), preliminaries for (4.2), and an overview of (4.3) mathematical optimization.

Mathematical optimization can be defined as the formal title given to the branch of computational science that seeks to answer the question "What is best?" for problems in which the quality of any answer can be expressed as a numerical value (Computational Science Education Project, 1996). Mathematical optimization requires a mathematical formulation of the problem (model), and a mathematical or computational solution method (algorithm).

The specific computational solution method for solving the MSPS inspection optimization that is proposed in this dissertation, namely a metaheuristic consisting of an evolutionary algorithm combined with simulation, is presented next (Sections 4.4 and 4.5). This part of the Chapter is an adaptation and extension of: Van Volsem et al. (2006), "An 
Evolutionary Algorithm and Discrete Event Simulation for Optimizing Inspection Strategies for Multistage Processes", forthcoming in EJOR. Simulation is used to model the MSPS subject to inspection and to calculate the resulting inspection costs, an evolutionary algorithm is proposed to optimize the inspection strategies. The solution approach is outlined in Section 4.4, with the particulars of the simulation (4.4.1) and both versions of the evolutionary algorithm $(4.4 .2,4.4 .3)$. In Section 4.5 both algorithms are computed with an example, indicating the potential of this metaheuristic for optimizing quality inspection.

Further, in Section 4.6 the influence (sensitivity) of the (exogenous) cost parameters on the outcome of the MSPS inspection optimization problem is illustrated. This Section is an adaptation of the papers by Van Volsem (2002) and Van Volsem and Van Landeghem (2003).

Notes on statistical analysis of simulation output are summarized in Appendix 4.B. Finally, in Appendix 4.A, other commonly used metaheuristics are briefly described, and it is discussed why preference was given to an EA to tackle the MSPS inspection optimization problem.

\subsection{Introduction}

The goal of an optimization problem is to find the combination of parameters (the decision variables), which optimize (maximize or minimize ${ }^{1}$ ) a certain quantity (the objective function), possibly subject to some restrictions, for example on the allowed parameter ranges (the constraints). If a single objective function is to be optimized, then the problem is of single criterion optimization nature. The mathematical formulation of such an optimization problem may thus be stated as:

$$
\begin{array}{rll}
\operatorname{minimize} & f\left(x_{1}, x_{2}, \ldots, x_{n}\right) & \\
\text { subject to } & c_{i}\left(x_{1}, x_{2}, \ldots, x_{n}\right) \geq 0 & \text { for } i=1,2, \ldots, K \\
\text { and to } & c_{i}^{\prime}\left(x_{1}, x_{2}, \ldots, x_{n}\right)=0 & \text { for } i^{\prime}=1,2, \ldots, M
\end{array}
$$

In this formulation, the $x_{i}$ are the $n$ decision variables, $f$ is the objective function, the $c_{i}$ are the $K$ inequality constraints and the $c_{i}^{\prime}$ are the $M$

\footnotetext{
${ }^{1}$ any maximum of a function $f$ is a minimum of the function $-f$. Any optimization problem can therefore always be formulated as a minimization problem.
} 
equality constraints.

These optimization problems can be classified according to the nature of the objective function, the decision variables and the constraints. Such classifications help in recognizing and identifying the problem, in order to be able to recognize and identify an appropriate solution technique. A possible taxonomy is proposed in Table 4.1 .

Table 4.1: Taxonomy of optimization problems (CSEP, 1996)

\begin{tabular}{|c|c|c|}
\hline Characteristic & Property & Classification \\
\hline \multirow{2}{*}{$\begin{array}{l}\text { Number of } \\
\text { decision variables }\end{array}$} & one & Univariate \\
\hline & more & Multivariate \\
\hline \multirow{2}{*}{$\begin{array}{l}\text { Number of } \\
\text { objective functions }\end{array}$} & one & Single criterion \\
\hline & more & Multicriteria \\
\hline \multirow{3}{*}{$\begin{array}{l}\text { Type of } \\
\text { decision variables }\end{array}$} & real numbers & Continuous \\
\hline & real numbers and integers & Mixed integer \\
\hline & integers in permutations & Combinatorial \\
\hline \multirow{3}{*}{$\begin{array}{l}\text { Problem functions of } \\
\text { the decision variables }\end{array}$} & linear functions & Linear \\
\hline & quadratic functions & Quadratic \\
\hline & nonlinear functions & Nonlinear \\
\hline \multirow[t]{2}{*}{ Problem formulation } & subject to constraints & Constrained \\
\hline & not subject to constraints & Unconstrained \\
\hline
\end{tabular}

\subsection{Mathematical preliminaries on optimization}

\subsubsection{Types of minima}

In solving a problem of type 4.1, different types of "optimal" solutions or "minima" can be distinguished. With the introduction of the vector $\mathbf{x}=\left(x_{1}, x_{2}, \ldots, x_{n}\right)^{T}$, the global minimum $\mathbf{x}^{*}$ of $f(\mathbf{x})$ is defined by:

$$
f\left(\mathbf{x}^{*}\right) \leq f(\mathbf{y}), \forall \mathbf{y} \in S(\mathbf{x}): \mathbf{y} \neq \mathbf{x}^{*}
$$


where $S(\mathbf{x})$ is the set of possible values of the decision variables $\mathbf{x}$. A solution $\mathbf{x}^{*}$ is a local minimum of $f(\mathbf{x})$ if

$$
f\left(\mathbf{x}^{*}\right) \leq f(\mathbf{y}), \forall \mathbf{y} \in \mathcal{N}\left(\mathbf{x}^{*}, \eta\right): \mathbf{y} \neq \mathbf{x}^{*}
$$

where $\mathcal{N}\left(\mathbf{x}^{*}, \eta\right)$ is the set of possible solutions in the "neighborhood" of $\mathbf{x}^{*}$, i.e. within a distance $\eta$ of $\mathbf{x}^{*}$. This type of local minimum is further specified as a weak local minimum, if the solution $\mathrm{x}^{*}$ satisfies the strict inequality

$$
f\left(\mathbf{x}^{*}\right)<f(\mathbf{y}), \forall \mathbf{y} \in \mathcal{N}\left(\mathbf{x}^{*}, \eta\right): \mathbf{y} \neq \mathbf{x}^{*}
$$

it is called a strong local minimum.

If, in addition, $f(\mathbf{x})$ is a smooth function with continuous first order derivatives for all $\mathbf{x} \in S(\mathbf{x})$, then stationary points of $f(\mathbf{x})$ satisfy the equation

$$
\nabla f\left(\mathbf{x}^{*}\right)=0
$$

With $\nabla f$ denoting the gradient of the function $f$. It can be seen that the different minima $\mathbf{x}^{*}$ of $f(\mathbf{x})$ are all stationary points of $f(\mathbf{x})$, at least for unconstrained functions. For constrained optimization problems, the global minimum can be an extremum and not a stationary point. The different types of minima are displayed in Figure 4.5.
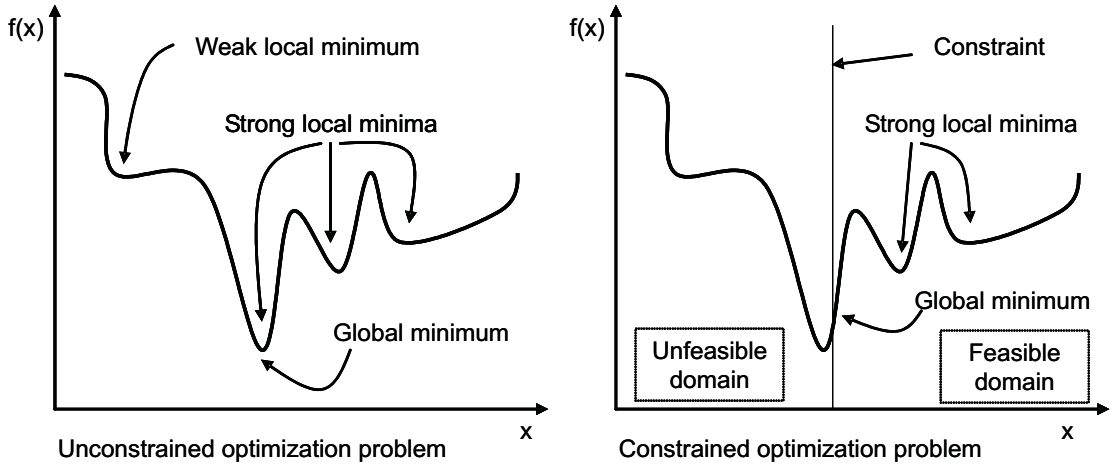

Figure 4.1: Types of minima 


\subsubsection{Optimality conditions}

\section{Unconstrained problems}

The necessary condition for $\mathbf{x}^{*}$ to be a local minimum of the objective function $f(\mathbf{x})$ is 4.5 , or more explicitly:

$$
\nabla f\left(\mathbf{x}^{*}\right)=\left[\frac{\partial f\left(\mathbf{x}^{*}\right)}{\partial x_{1}{ }^{*}}, \frac{\partial f\left(\mathbf{x}^{*}\right)}{\partial x_{2}{ }^{*}}, \ldots, \frac{\partial f\left(\mathbf{x}^{*}\right)}{\partial x_{n}{ }^{*}}\right]^{T}=0
$$

In other words, if the gradient of the objective function at $\mathbf{x}^{*}$ equals zero then the solution may be a local minimum or maximum. In this stationary point we may, though, also have a saddle point. The necessary condition 4.6 is thus not a sufficient condition. In order to establish the point as a local minimum the following Hessian matrix has to be determined:

$$
\mathbf{H}(\mathbf{x})=\left[\begin{array}{llll}
\frac{\partial f^{2}(\mathbf{x})}{\partial x_{1} x_{1}} & \frac{\partial f^{2}(\mathbf{x})}{\partial x_{1} x_{2}} & \cdots & \frac{\partial f^{2}(\mathbf{x})}{\partial x_{1} x_{n}} \\
\frac{\partial f^{2}(\mathbf{x})}{\partial x_{2} x_{1}} & \frac{\partial f^{2}(\mathbf{x})}{\partial x_{2} x_{2}} & \cdots & \frac{\partial f^{2}(\mathbf{x})}{\partial x_{2} x_{n}} \\
\vdots & \vdots & \ddots & \vdots \\
\frac{\partial f^{2}(\mathbf{x})}{\partial x_{n} x_{1}} & \frac{\partial f^{2}(\mathbf{x})}{\partial x_{n} x_{2}} & \cdots & \frac{\partial f^{2}(\mathbf{x})}{\partial x_{n} x_{n}}
\end{array}\right]
$$

Necessary and sufficient conditions for $\mathbf{x}^{*}$ to be a local minimum are:

$$
\left\{\begin{array}{l}
\nabla f\left(\mathbf{x}^{*}\right)=0 \\
\mathbf{H}\left(\mathbf{x}^{*}\right) \text { is positive definite }
\end{array}\right.
$$

If $\mathbf{H}\left(\mathbf{x}^{*}\right)$ is negative definite, $\mathbf{x}^{*}$ is a local maximum. If $\mathbf{H}\left(\mathbf{x}^{*}\right)$ is neither positive nor negative definite, $\mathrm{x}^{*}$ is a saddle point.

\section{Constrained problems}

For a constrained problem we may create the Lagrangian function of the form:

$$
L(\mathbf{x}, \lambda, \mu)=f(\mathbf{x})-\sum_{k=1}^{K} \lambda_{k} c_{k}(\mathbf{x})-\sum_{m=1}^{M} \mu_{m} c_{m}^{\prime}(\mathbf{x})
$$

\footnotetext{
${ }^{2} \mathrm{~A}$ matrix $\mathbf{H}$ is positive definite if $\forall \mathbf{x} \neq 0: \mathbf{x}^{T} \mathbf{H x}>0$.
} 
with the $\lambda_{k}$ and the $\mu_{m}$ the Lagrange multipliers. The necessary conditions for a local minimum in a constrained problem are the Kuhn-Tucker conditions:

$$
\left\{\begin{array}{l}
\nabla f\left(\mathbf{x}^{*}\right)-\sum_{k=1}^{K} \lambda_{k} \cdot \nabla c_{k}\left(\mathbf{x}^{*}\right)-\sum_{m=1}^{M} \mu_{m} \cdot \nabla c_{m}^{\prime}\left(\mathbf{x}^{*}\right)=0 \\
c_{k}\left(\mathbf{x}^{*}\right) \geq 0 \quad \text { for } k=1,2, \ldots, K \\
c_{m}^{\prime}\left(\mathbf{x}^{*}\right)=0 \quad \text { for } m=1,2, \ldots, M \\
\lambda_{k} \cdot c_{k}\left(\mathbf{x}^{*}\right)=0 \quad \text { for } k=1,2, \ldots, K \\
\lambda_{k} \geq 0 \quad \text { for } k=1,2, \ldots, K
\end{array}\right.
$$

\subsection{Optimization methods: a brief overview}

Single criterion optimization methods for continuous multivariate problems can be classified depending on the manner the minimum is searched for (distinguishing between deterministic or iterative search versus random or exploratory search), or depending on the class of problems (unconstrained versus constrained problems) to be solved. In the scope of this work, the classification based on the nature of the search is the most interesting one to follow.

Generally, in an (unconstrained) optimization problem, we seek a local minimizer of a real-valued function, $f(\mathbf{x})$. In other words, we seek $\mathbf{x}^{*}$, such that $f\left(\mathbf{x}^{*}\right) \leq f(\mathbf{x}), \forall \mathbf{x}$ close to $\mathbf{x}^{*}$ (see Section 4.2.2). Global optimization algorithms try to find an $\mathbf{x}^{*}$ that minimizes $f(\mathbf{x})$ over all possible vectors $\mathbf{x}$. This is a much harder problem to solve. We do not discuss it here because, at present, no efficient algorithm is known for performing this task. For many applications however, local minima are good enough, particularly when the user can draw on experience and/or problem specific knowledge to provide a good starting point for the algorithm.

\subsubsection{Solution methods based on systematic search techniques}

Most basic deterministic algorithms for finding (local) minima of multivariate continuous functions are of the iterative type. The techniques 
proposed are generally valid for unconstrained problems (constrained optimization algorithms are often extensions of unconstrained algorithms).

The iterative minimization methods can again be divided into two groups: nonderivative or direct search methods, requiring only the objective function values; gradient search methods, requiring gradient information; and second-derivative or Newton search methods, based on approximating the objective function locally by a quadratic model (Osyczka (2002, p. 16), Computational Science Education Project (1996, p. 16, 28)). Iterative methods work on a step-by-step basis: i.e. the next possible solution is established based on previous results, indicating where the minimum is likely to lie.

As these conventional methods are $1^{\circ}$ very well developed and described in literature, and $2^{\circ}$ only of secondary importance in this work, the reader is referred to textbooks, e.g. Winston (1991); Acton (1990); Dennis Jr and Schnabel (1983); Gill et al. (1983), for comprehensive descriptions of the techniques mentioned.

\subsubsection{Solution methods based on random search techniques}

Many problems of practical interest ${ }^{3}$ unfortunately cannot be satisfactorily ${ }^{4}$ solved by any of the methods sketched in the previous Section. When these methods, which are all algorithms for systematic or deterministic search, fail, one must resort to stochastic or random search techniques, also known as heuristics. These heuristics will mostly not deliver the optimal solution, but "guarantee" to find a "close to optimal" solution "relatively quickly".

A possible classification of basic heuristic solution techniques could start by dividing this large group of random search techniques into two major groups:

Construction heuristics which build feasible solutions from scratch, based on information about the desired solution.

Improvement heuristics which start from a feasible solution, and thereupon attempt to improve that solution.

\footnotetext{
${ }^{3}$ The problems addressed will mostly belong to the so called class of $\mathcal{N} \mathcal{P}$-complete problems, see Appendix C

${ }^{4}$ i.e. allowing calculation of the optimal solution in a reasonable amount of time
} 
There exists a trade-off between solution quality (its "closeness" to the true optimum) and calculation time, see Figure 4.2. A balance between the speed of basic heuristics and the accuracy of exact algorithms can be found in a class of solution procedures known as metaheuristics (Sörensen, 2003).

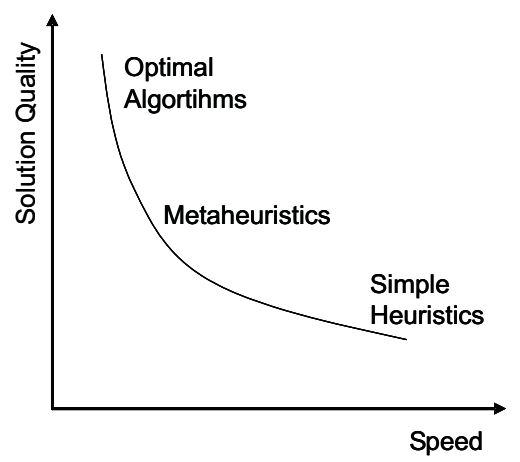

Figure 4.2: Solution quality versus calculation time (after Sörensen (2003))

Due to the variety of techniques and concepts comprised by metaheuristics, there is still no commonly agreed definition for metaheuristics. The definition used in the Metaheuristics Network ${ }^{5}$ is the following:

A metaheuristic is a set of concepts that can be used to define heuristic methods that can be applied to a wide set of different problems.

In other words, a metaheuristic can be seen as a general algorithmic framework which can be applied to different optimization problems with relatively few modifications to make them adapted to a specific problem.

In Appendix 4.A an attempt is made at providing a concise introduction to the broad field of metaheuristics.

\footnotetext{
${ }^{5}$ http://www.metaheuristics.org
} 


\subsection{A metaheuristic solution approach}

\subsubsection{Monte Carlo simulation to calculate TIC}

Law and Kelton (1982) define Monte Carlo simulation as a scheme employing random numbers, that is, $U(0,1)$ random variables, which is used for solving certain stochastic or deterministic problems where the passage of time plays no substantial role.

Generally, simulation is used to study processes that are too complex to permit analytical model formulation and/or evaluation. The complexity can be due to the size of the problem, the interactions between its subproblems, the inherent randomness of the problem, or a combination of these factors.

It is clear that the TIC as calculated in Section 3.1.2 refers to a single production batch.

Of course, the inspection planner should not rely on just a single problem instance (i.e. one batch) to decide which inspection strategy is the best. Different inspection strategy solutions should be evaluated over a number of problem instances to take into account the inherent stochastic properties of the production process. In the Evolutionary Algorithm presented below, each candidate solution will be evaluated based on the average TIC from a pre-determined number of simulated production batches.

$$
T I C=T T C+T R C+T P C
$$

with $^{6}$

$$
\begin{aligned}
T T C & =\sum_{i=1}^{n} T C_{i} \\
T R C & =\sum_{i=1}^{n} R C_{i} \\
T P C & =c_{P} \cdot p_{n}^{\prime} \cdot K
\end{aligned}
$$

\footnotetext{
${ }^{6}$ see Section 3.1
} 
and with

$$
\begin{aligned}
& T C_{i}= \begin{cases}c_{T, i} \cdot K & \forall i:\left(I_{i}=F\right) \vee\left(\left(I_{i}=S\right) \wedge\left(l_{i}>t_{i}\right)\right) \\
c_{T, i} \cdot s_{i} & \forall i:\left(I_{i}=S\right) \wedge\left(l_{i} \leq t_{i}\right) \\
0 & \forall i: I_{i}=N\end{cases} \\
& R C_{i}= \begin{cases}c_{R, i} \cdot p_{i}^{\prime} \cdot K & \forall i:\left(I_{i}=F\right) \vee\left(\left(I_{i}=S\right) \wedge\left(l_{i}>t_{i}\right)\right) \\
c_{R, i} \cdot l_{i} & \forall i:\left(I_{i}=S\right) \wedge\left(l_{i} \leq t_{i}\right) \\
0 & \forall i:\left(I_{i}=N\right)\end{cases}
\end{aligned}
$$

\subsubsection{An Evolutionary Algorithm to determine the optimal in- spection strategy - first version (EA/1)}

\section{Introduction}

To illustrate the use of metaheuristics for determining the optimal inspection strategy, an Evolutionary Algorithm (EA) is presented. As indicated in Section 4.0, Appendix 4.A briefly describes other commonly used metaheuristics, and it is discussed why preference was given to an EA to tackle the problem at hand.

Evolutionary (or Genetic) Algorithms are adaptive heuristic search methods based on population genetics. The basic concepts were developed by Holland (1975) and were forged into a problem solving methodology for complex optimization problems by De Jong (1975) and Goldberg (1989). The name evolutionary originates from the analogy of the heuristic with Darwin's theory on natural selection. In selective breeding, offspring are sought which have certain desirable characteristics, determined at the genetic level by combination of the parents' chromosomes. In a similar way, in seeking better solutions, EA's combine pieces of existing solutions. Thereto, in an EA, a solution to a problem is first encoded as a chromosome, and new generations of offspring are generated through an iteration process until some convergence criteria are met. The best chromosome generated is then decoded, providing the corresponding solution.

There are four main parts in the EA paradigm, namely the problem representation and initiation, the objective function evaluation (fitness calculation), the parent selection, and the actual evolutionary reproduction of candidate solutions. 


\section{Problem representation and initiation}

Every proposed solution is represented by a vector of the independent variables (inspection decision variables), coded as a chromosome constituted by as many genes as the number of independent variables. Determining the optimal inspection strategy, i.e. the whole of inspection decisions that minimize the $T I C$, requires the determination of inspection options $I_{i}$ and the corresponding inspection limits $\left(L I L_{i}, U I L_{i}\right)$ and sampling parameters $\left(s_{i}, t_{i}\right)$, for all stages $i=1, \ldots, n$. In other words, solving the optimization problem consists of finding the set of optimal values

$$
\left(I_{1}^{\natural}, \ldots, I_{n}^{\natural} ; L I L_{1}^{\natural}, \ldots, L I L_{n}^{\natural} ; U I L_{1}^{\natural}, \ldots, U I L_{n}^{\natural} ; s_{1}^{\natural}, \ldots, s_{n}^{\natural} ; t_{1}^{\natural}, \ldots, t_{n}^{\natural}\right)
$$

that minimize

$$
\operatorname{TIC}\left(I_{1}, \ldots, I_{n} ; L I L_{1}, \ldots, L I L_{n} ; U I L_{1}, \ldots, U I L_{n} ; s_{1}, \ldots, s_{n} ; t_{1}, \ldots, t_{n}\right)
$$

This first version of the EA (EA/1) does, however, not yet include the variable setting of sampling parameters $\left(s_{i}, t_{i}\right)$. These parameters are set fixed $\left(s_{i}=50, t_{i}=1 \forall i\right)$, and the EA/1 returns the set

$$
\left(I_{1}^{\natural}, \ldots, I_{n}^{\natural} ; L I L_{1}^{\natural}, \ldots, L I L_{n}^{\natural} ; U I L_{1}^{\natural}, \ldots, U I L_{n}^{\natural} ; 50,50, \ldots, 50 ; 1,1, \ldots, 1\right)
$$

that minimize

$$
T I C\left(I_{1}, \ldots, I_{n} ; L I L_{1}, \ldots, L I L_{n} ; U I L_{1}, \ldots, U I L_{n} ; 50,50, \ldots, 50 ; 1,1, \ldots, 1\right)
$$

Every candidate solution to the EA/ 1 thus is a set as in expression 4.11 , which can be denoted as an array of $n$ characters $I_{i}$, each character associated with the two inspection limits $L I L_{i}$ and $U I L_{i}$ for the corresponding stage. For example the vector

$$
\left[\begin{array}{llll}
F_{9.1}^{10.9} & N_{18.2}^{21.8} & S_{27.7}^{32.3} & F_{37.3}^{42.7}
\end{array}\right]
$$

denotes a 4-stage MSPS with full inspection in the first and last stage, no inspection ${ }^{7}$ in the second stage, and sampling inspection in the third

\footnotetext{
${ }^{7}$ Note that we keep inspection limits for each stage, even for stages with no inspection, to ensure maximum flexibility in constructing offspring (see further).
} 
stage. From the corresponding numbers, we read that inspection is performed between the limits 9.1 and 10.9 for the first stage, and so on for the other stages.

The basic idea is to start with a population of $M$ possible solutions to the problem. In EA/1, we use a population size $M$ of 50 . From this pool of initial solutions, some are selected (parents) to construct new solutions (children). The generation of the initial population is performed as follows: a first initial solution is read in, consisting of all N's, and initial inspection limits. We assume symmetrical inspection limits, i.e. the expected value in each stage $i$ is the arithmetic average of $\left(L I L_{i}, U I L_{i}\right)$. The construction algorithm for the initial population consists in randomizing the characters, and randomizing the limits by allowing (symmetrical) variation from the original limits by a certain user defined percentage (5\% is applied in the calculated case example of Section 4.5.1).

\section{Objective function evaluation (fitness calculation)}

For every candidate solution its fitness as a possible parent has to be evaluated, where fitness refers to measure of profit or goodness to be maximized while exploring the solution space. A naive choice is simply to use the value of the objective function for each candidate solution, but this is rarely a good idea, as it often leads to premature convergence to a poor local optimum (Reeves, 1993, pg. 168). This problem can be mitigated using some scaling procedure. Different procedures are proposed and investigated in literature. We use a scaling procedure which ensures that the fitness values are all in $[0,1]$, and their sum is 1 . This property allows us to set the probability of selecting a solution as a parent directly equal to its fitness value, so no additional conversion from fitness value to parent selection probability is required.

The fitness value $f$ for each solution $j$ in a population of $M$ solutions is calculated as follows (with $T I C>0$ ):

$$
f_{j}=\frac{1 / T I C_{j}}{\sum_{k=1}^{M}\left(1 / T I C_{k}\right)}
$$

This way, a smaller (better) TIC will result in a higher fitness value. This in fact corresponds to changing the minimization problem into a 
maximization problem ${ }^{8}$.

\section{Parent selection}

Parent selection for producing offspring is done as in Holland's original Genetic Algorithm, i.e. for each reproduction two parents are chosen: one parent is selected on a fitness basis, the other is chosen randomly. The idea behind this scheme is that in doing this, the parent chosen for its fitness ensures genetic quality, while the random parent ensures genetic diversity.

Obviously, a proper balance between genetic quality and diversity is required within the population in order to ensure efficient search. This is dealt with through careful selection of the population related factors at the outset of the EA: population size, selection of the initial population, fitness calculation, crossover and mutation operators.

\section{Reproduction}

The reproduction process makes use of the genes of the selected parents to produce offspring that will make up the next generation. The reproduction operators exchange segments of the parents to build one or two children. The most common way to perform this exchange is as follows: a single crossover point $\mathrm{X}$ is chosen randomly; the children are then constructed as the pre-X section from one parent followed by the post-X section of the other. After construction of the children, mutation can be used to randomly modify genes of a single individual to further explore the solution space and to preserve genetic diversity. The occurrence of mutation is usually associated with a low probability. The one or two children are added to the new generation. After filling the entire new population with children (new solutions), this generation of solutions can replace the previous one entirely or partially, a population size of $M$ being maintained throughout the course of the algorithm.

In EA/1, the new generation consists of $M-1$ children, the $M^{\text {th }}$ solution in the next generation population is the best solution from the

\footnotetext{
${ }^{8}$ As discussed in Section 4.1, maximization and minimization problems are readily interchangeable
} 
previous generation. Generating offspring is performed in two consecutive steps: first crossover (with the crossover operators described below) is applied, then the inspection limits are adapted. After these two steps, reproduction is completed and the children thus obtained can populate the new generation. This way, the simultaneous determination of inspection option and inspection limits can be achieved. The inspection limits' adaptation is implemented analogous to the randomization of the limits used in the construction algorithm: we allow the children's inspection limits to deviate from the parents' limits by a certain user defined percentage ( $5 \%$ is applied). The maximum number of generations is set to 500 , if no improvement is found after 50 generations, the EA is interrupted.

The standard crossover operator used in EA/1 randomly selects a crossover point, and constructs two new solutions by exchanging the tails (the whole of characters and limits) of both parents. An example for a six-stage MSPS and 2 as crossover point:

$$
\begin{aligned}
& \text { Parent 1: }\left[\begin{array}{llllll}
F_{9.1}^{10.9} & N_{18.2}^{21.8} & S_{27.7}^{32.3} & F_{37.3}^{42.7} & S_{46.5}^{53.5} & F_{56.0}^{64.0}
\end{array}\right] \\
& \text { Parent 2: }\left[\begin{array}{llllll}
N_{9.3}^{10.7} & F_{18.0}^{22.0} & F_{27.6}^{32.4} & S_{37.5}^{42.5} & N_{46.9}^{53.1} & S_{56.5}^{64.5}
\end{array}\right] \\
& \text { Child 1: }\left[\begin{array}{llllll}
F_{9.1}^{10.9} & N_{18.2}^{21.8} & F_{27.6}^{32.4} & S_{37.5}^{42.5} & N_{46.9}^{53.1} & S_{56.5}^{64.5}
\end{array}\right] \\
& \text { Child 2: }\left[\begin{array}{llllll}
N_{9.3}^{10.7} & F_{18.0}^{22.0} & S_{27.7}^{32.3} & F_{37.3}^{42.7} & S_{46.5}^{53.5} & F_{56.0}^{64.0}
\end{array}\right]
\end{aligned}
$$

Instead of mutation, inversion is used (see Reeves (1993, pg. 173)). It is applied through two reverse crossover operators, associated with a low probability (3\% is applied).

- reverse head crossover operator: This operator randomly chooses a crossover point (we will take 4 as example, and the same parents as above), and constructs two new solutions by exchanging the reversed heads (in reversing, only the characters, not the limits are reversed) of both parents.

Child 1: $\left[\begin{array}{llllll}S_{9.3}^{10.7} & F_{18.0}^{22.0} & F_{27.6}^{32.4} & N_{37.5}^{42.5} & S_{46.5}^{53.5} & F_{56.0}^{64.0}\end{array}\right]$
Child 2: $\left[\begin{array}{llllll}F_{9.1}^{10.9} & S_{18.2}^{21.8} & N_{27.7}^{32.3} & F_{37.3}^{42.7} & N_{46.9}^{53.1} & S_{56.5}^{64.5}\end{array}\right]$


- reverse tail crossover operator: This operator randomly chooses a crossover point (4 as example, same parents as above), and constructs two new solutions by exchanging the reversed tails (in reversing, only the characters, not the limits are reversed) of both parents.

\begin{tabular}{|c|c|c|c|c|}
\hline$F_{9.1}^{10.9}$ & $N_{18.2}^{21.8}$ & $S_{27.7}^{32.3}$ & $F_{37.3}^{42.7}$ & $S_{46.9}^{53.1}$ \\
\hline Child $2:\left[N_{9.3}^{10.7}\right.$ & $F_{18.0}^{22.0}$ & $F_{27.6}^{32.4}$ & $S_{37.5}^{42.5}$ & $F_{46.5}^{53.5}$ \\
\hline
\end{tabular}

\subsubsection{An Evolutionary Algorithm to determine the optimal in- spection strategy - second version (EA/2)}

In the second version of the Evolutionary Algorithm, EA/2, the variable setting of sampling parameters $\left(s_{i}, t_{i}\right)$ is included. It is clear that a completely random setting of the sampling parameters -although technically, in the algorithm, this would be perfectly possible- would lead to pointless sampling schemes, with no discriminatory power (see Section 1.6.1). Therefore, the variable setting of the sampling parameters is limited to a number of pre-determined combinations of $\left(s_{i}, t_{i}\right)$. In the algorithm, the combinations themselves, as well as the number of different combinations are user-defined. Any combination $\left(s_{i}, t_{i}\right)$, and as many different combinations as useful can be entered, to meet process-specific demands.

In EA $/ 2$, three combinations for $\left(s_{i}, t_{i}\right)$ are proposed, namely $(100,1)$, $(50,1)$ and $(25,0)$ - all for a constant batchsize $K=1000$. The corresponding OC curves are presented below.

It can be seen that the plan $(100,1)$ yields the highest discriminatory power, but also requires intensive (10\%) sampling. The discriminatory power of the $(50,1)$ plan is lower, on the other hand the sample size and thus the sampling costs are halved.

The $(25,0)$ plan then requires the least sampling, for still reasonable discriminatory power, especially in the region of low percent defective. A plan with a zero acceptance number is special, in the sense that its OC curve is convex throughout. Therefore, such plans are relatively hard on the producer, since the probability of acceptance starts to drop rapidly even for the smallest values of percent defective. Such a plan may be chosen when tests are destructive or costly and/or when the risk of letting defectives through is high (costly). 


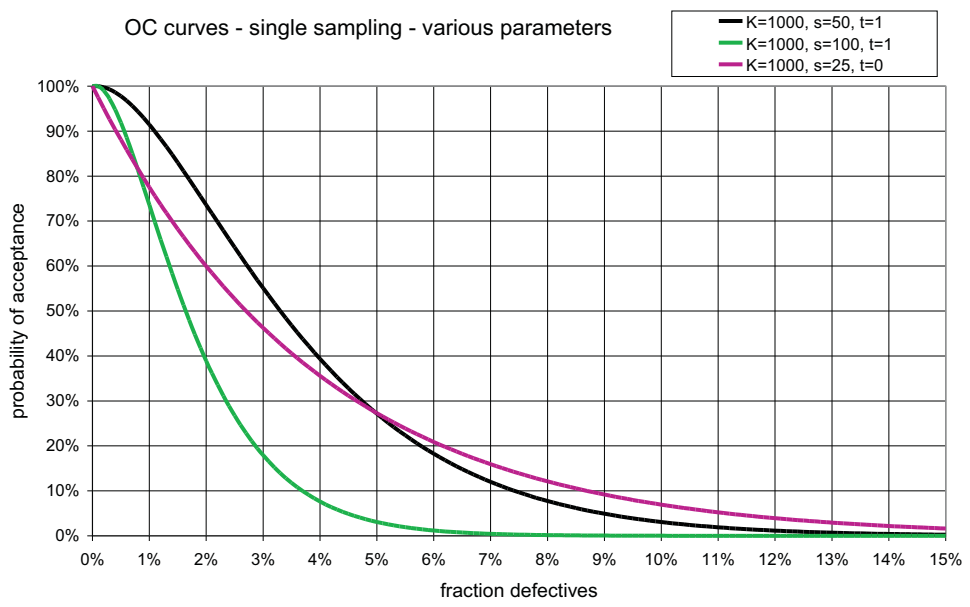

Figure 4.3: OC curves for single sampling schemes with various parameters

The solution vector's notation is extended as follows, to include the sampling paramaters:

$$
\left[\begin{array}{llll}
F_{9.1}^{10.9} & N_{18.2}^{21.8} & S_{27.7 ॥ 1}^{32.3 ॥ 100} & F_{37.3}^{42.7}
\end{array}\right]
$$

denoting a 4-stage MSPS, with sampling inspection in the third production stage, with sampling plan $(100,1)$.

\subsection{Computational testing}

As mentioned in the previous Section, careful selection of population related factors at the outset of the EA (such as population size, initial population, fitness calculation, crossover and mutation operators) is important to increase the probability of finding good solutions. The parameter settings were based on general recommendations found in textbooks on GA/EA's (Reeves (1993), Michaelewicz and Fogel (2000)), on insight in the problem specifics, as suggested in Silver (2004), and on several exploratory test runs.

The EA was tested -ceteris paribus- with population sizes 25, 50 and 100. This revealed no noticeable differences for the investigated problems. 
Therefore, a population size of 50 was selected to keep computation times acceptable while safeguarding solution diversity, as suggested by (Reeves (1993) and Michaelewicz and Fogel (2000)). As explained in the previous Section, inversion is used instead of mutation. The EA was tested with inversion parameters $6 \%, 12 \%$ and $20 \%$. This again yielded no significant differences, we opted for the smallest inversion percentage, i.e. $6 \%(3 \%$ reverse-head and 3\% reverse-tail). Solution evaluation is based on the average TIC from a number simulated production batches (simulation runs). The metaheuristic was tested with 25, 50 and 100 simulation runs. Convergence of the EA could be demonstrated with 50 and 100 runs, whereas 25 runs did not suffice. We therefore opted for 50 runs, to keep computation times acceptable. The number of simulation runs can also be derived dynamically, guaranteeing minimum confidence intervals for the simulation output of interest, see for example Law and Kelton (1982, pg. 302).

Furthermore, the randomization parameter for adaptation of the inspection limits was tested. It is intuitively clear that a smaller percentage will lead to longer computation times, while higher percentages might lack "precision". Values $2 \%, 5 \%$ and $10 \%$ were tested, $5 \%$ offered the best trade-off between computation time and precision: variation of only $2 \%$ led to more than doubling the average computation time, with no noticeable solution quality difference. With a variation parameter of $10 \%$, no gain in computation time was established.

\subsubsection{EA/1}

Since - to the best of the author's knowledge- no standard test cases exist in literature, a fictitious six stage serial MSPS was constructed, representing a stack-up assembly operation, the product dimension being the quality characteristic under attention. Mathematically speaking, this comes down to performing an addition in each stage (the component added in each stage adds to the overall dimension). In Table 4.2 the process characteristics are shown. We used a combination of normal and uniform distributions to describe the dimensional characteristic of the components added in each stage. For normal distributions the parameters 1 and 2 designate the distribution's mean and standard deviation, 
for uniform distributions the parameters designate the lower and upper boundary of the interval.

Table 4.2: Process characteristics

\begin{tabular}{|c|c|c|c|c|}
\hline stage & distribution & parm. 1 & parm. 2 & exp. value \\
\hline \hline 1 & normal & 10 & 0.3 & 10 \\
2 & normal & 10 & 0.5 & 20 \\
3 & uniform & 8.5 & 11.5 & 30 \\
4 & normal & 10 & 0.1 & 40 \\
5 & normal & 10 & 0.5 & 50 \\
6 & uniform & 9 & 11 & 60 \\
\hline
\end{tabular}

The parameters used in the cost model are shown in Table 4.3. The penalty $\operatorname{cost} c_{P}$ is set at 3000; to conform, the final products' dimension should be in the interval $\left[L S_{6}, U S_{6}\right]=[58,62]$. A batchsize $K=1000$ is assumed. As discussed in Section 3.1.1, these sets of parameters (process parameters and cost parameters) are exogenous to the inspection optimization problem. They do, however, influence the TIC and thus the outcome of the optimization process. For more details, see Appendix 4.6 included at the end of this Chapter.

Table 4.3: Cost parameters

\begin{tabular}{|c|c|c|}
\hline stage & Test Cost & Rework Cost \\
\hline \hline 1 & 1 & 50 \\
2 & 1 & 100 \\
3 & 2 & 200 \\
4 & 1 & 400 \\
5 & 1 & 800 \\
6 & 2 & 1600 \\
\hline
\end{tabular}

To test EA/ 1 for convergence, it was executed 25 times. This yielded minimal TIC's ranging from 123492 to 128763 , or a maximum $4 \%$ differ$.92 \ldots$ 
ence (average TIC $=125976$, with standard deviation $=1697^{9}$ ). The corresponding solution vectors are shown in Table 4.4, together with the number of generations and computing time necessary to find that solution (note that this number includes 50 generations of no improvement). $\mathrm{EA} / 1$ is coded in the $\mathrm{C}++$ programming language, a $\mathrm{PC}$ with a 2.53 $\mathrm{GHz}$ processor was used for program calculation. As the code is not optimized for speed, the indicated computation times are only of secondary importance.

Figure 4.4 demonstrates the apparent convergence. From the results Table 4.4 EA/1's convergence can be confirmed: it can be seen that all 25 solutions are of the same form $N N F X X F$, with $X \in\{S, N\}$ (the indifference between $S$ and $N$ in stages 4 and 5 is discussed below). Moreover, the inspection limits $L I L_{3}, U I L_{3}$ and $L I L_{6}, U I L_{6}$, corresponding with the stages where full inspection $\mathrm{F}$ is applied, are in the same range in each case.

In the first two stages, no inspection $\mathrm{N}$ is opted for. This means the cost avoidance of detecting defective products already in stages 1 or 2 does not outweigh the costs of performing full inspection in these stages. This can be explained considering the relatively low rework costs compared to the test costs in these stages.

In stages 3 and 6 , full inspection $\mathrm{F}$ is selected. For stage 6 this entails avoidance of penalty costs. Indeed, the inspection limits $L I L_{6}, U I L_{6}$ selected by EA/1, almost coincide with the specification limits $L S_{6}, U S_{6}$ (maximum difference $= \pm 0.051$ or less than $0.1 \%$ ). The choice for full inspection in stage 3 implies that the cost avoidance through detecting defective products outweighs the incurred test costs. The choice of inspection limits $L I L_{3}, U I L_{3}$ will balance both cost aspects.

The fact that there is no clear discrimination between $\mathrm{N}$ and $\mathrm{S}$ inspection in stages 4 and 5 , can be attributed to the full inspection $\mathrm{F}$ in stage 3 . Seeing this provides stage 4 with an input of $0 \%$ defectives, and considering the low added variance of the production operation in stage 4 , it can be argued that the fault occurrence in stage 5 will still be close to $0 \%$. This means that in stages 4 and 5 there will be very few defectives, reducing the need for (sampling) inspection. Performing sampling inspection $\mathrm{S}$ will thus not be advantageous compared to performing no

\footnotetext{
${ }^{9}$ for more insights on statistical output analysis see this Chapter's Appendix 4.B
} 
25 EA replications

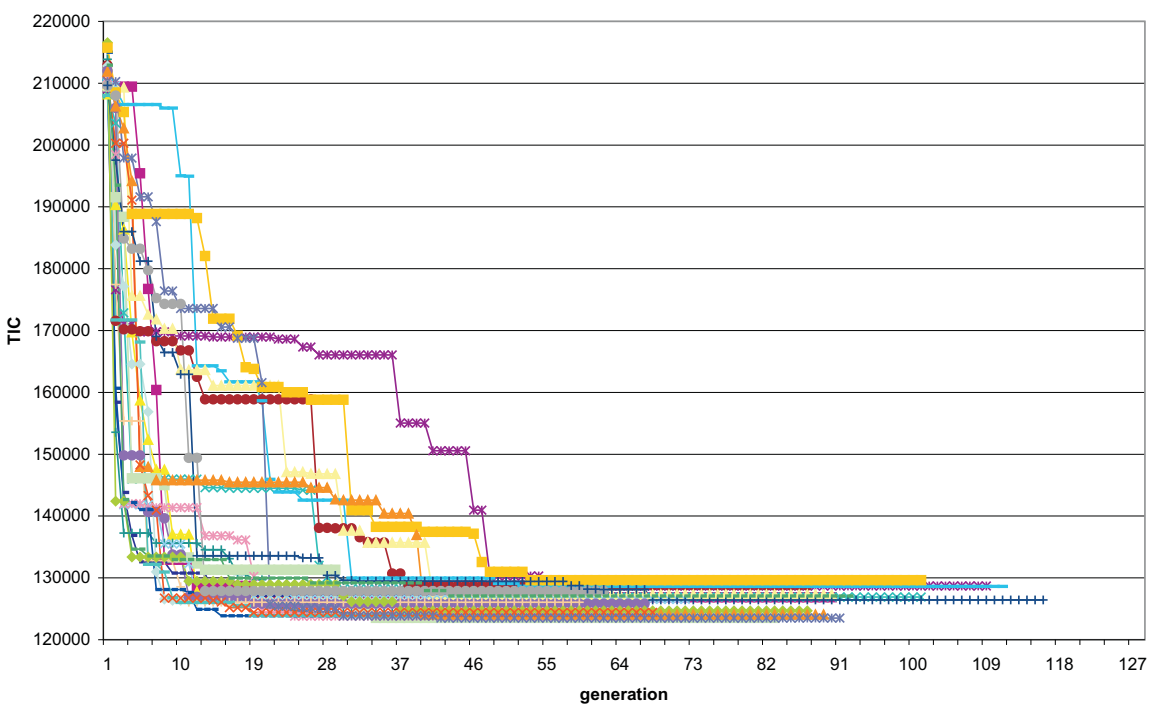

Figure 4.4: TIC as a function of generation number, for 25 replications of $E A / 1$ 
Section 4.5. Computational testing

Table 4.4: EA/1 Solutions

\begin{tabular}{|c|c|c|c|c|c|c|c|c|c|}
\hline \multicolumn{7}{|c|}{ solution vector } & TIC & gen. & time \\
\hline 1 & $N$ & $N$ & $F_{28.907}^{31.093}$ & $S_{38.745}^{41.255}$ & $N$ & $F_{58.015}^{61.985}$ & 126851 & 65 & 1h20' \\
\hline 2 & $N$ & $N$ & $F_{28.771}^{31.229}$ & $S_{38.157}^{41.843}$ & $S_{48.581}^{51.419}$ & $F_{58.018}^{61.982}$ & 126882 & 91 & $2 \mathrm{~h} 42^{\prime}$ \\
\hline 3 & $N$ & $N$ & $F_{28.771}^{31.229}$ & $N$ & $N$ & $F_{58.002}^{61.998}$ & 126894 & 102 & $2 \mathrm{~h} 56^{\prime}$ \\
\hline 4 & $N$ & $N$ & $F_{28.869}^{31.131}$ & $N$ & $S_{43.127}^{56.873}$ & $F_{57.968}^{62.032}$ & 128687 & 110 & $3 \mathrm{~h} 01$ ' \\
\hline 5 & $N$ & $N$ & $F_{28.875}^{31.125}$ & $N$ & $N$ & $F_{58.016}^{61.984}$ & 128763 & 88 & $2 \mathrm{~h} 20^{\prime}$ \\
\hline 6 & $N$ & $N$ & $F_{28.820}^{31.180}$ & $N$ & $S_{44.359}^{55.641}$ & $F_{57.993}^{62.007}$ & 124325 & 75 & $1 \mathrm{~h} 59^{\prime}$ \\
\hline 7 & $N$ & $N$ & $F_{28.798}^{31.202}$ & $N$ & $N$ & $F_{57.975}^{62.025}$ & 127170 & 63 & $1 \mathrm{~h} 27^{\prime}$ \\
\hline 8 & $N$ & $N$ & $F_{28.645}^{31.355}$ & $S_{38.448}^{41.552}$ & $N$ & $F_{57.991}^{62.009}$ & 128611 & 82 & $2 \mathrm{~h} 16^{\prime}$ \\
\hline 9 & $N$ & $N$ & $F_{28.840}^{31.160}$ & $N$ & $N$ & $F_{57.990}^{62.010}$ & 126352 & 58 & 1h18' \\
\hline 10 & $N$ & $N$ & $F_{28.843}^{31.157}$ & $N$ & $S_{47.230}^{52.770}$ & $F_{58.002}^{61.998}$ & 123549 & 83 & $2 \mathrm{~h} 11^{\prime}$ \\
\hline 11 & $N$ & $N$ & $F_{28.920}^{31.080}$ & $N$ & $N$ & $F_{58.012}^{61.988}$ & 127310 & 92 & $2 \mathrm{~h} 40^{\prime}$ \\
\hline 12 & $N$ & $N$ & $F_{28.910}^{31.090}$ & $N$ & $N$ & $F_{58.009}^{61.991}$ & 126522 & 83 & 2h36' \\
\hline 13 & $N$ & $N$ & $F_{28.810}^{31.190}$ & $N$ & $N$ & $F_{58.004}^{61.996}$ & 123820 & 73 & $1 \mathrm{~h} 51^{\prime}$ \\
\hline 14 & $N$ & $N$ & $F_{28.765}^{31.235}$ & $S_{37.277}^{42.723}$ & $S_{46.060}^{53.940}$ & $F_{57.989}^{62.011}$ & 125839 & 68 & 1h36' \\
\hline 15 & $N$ & $N$ & $F_{28.830}^{31.170}$ & $N$ & $S_{48.287}^{51.713}$ & $F_{58.015}^{61.985}$ & 126069 & 60 & $1 \mathrm{~h} 31^{\prime}$ \\
\hline 16 & $N$ & $N$ & $F_{28.763}^{31.237}$ & $S_{38.779}^{41.221}$ & $N$ & $F_{57.994}^{62.006}$ & 123883 & 64 & $1 \mathrm{~h} 31^{\prime}$ \\
\hline 17 & $N$ & $N$ & $F_{28.870}^{31.130}$ & $N$ & $N$ & $F_{58.000}^{62.000}$ & 123894 & 68 & 1h39' \\
\hline 18 & $N$ & $N$ & $F_{28.793}^{31.207}$ & $S_{38.032}^{41.968}$ & $N$ & $F_{57.988}^{62.012}$ & 124670 & 86 & $2 \mathrm{~h} 00^{\prime}$ \\
\hline 19 & $N$ & $N$ & $F_{28.904}^{31.096}$ & $N$ & $S_{40.620}^{59.380}$ & $F_{58.051}^{61.949}$ & 124093 & 89 & $2 \mathrm{~h} 23$ ' \\
\hline 20 & $N$ & $N$ & $F_{28.738}^{31.262}$ & $N$ & $S_{47.324}^{52.676}$ & $F_{57.993}^{62.007}$ & 124410 & 68 & $1 \mathrm{~h} 38^{\prime}$ \\
\hline 21 & $N$ & $N$ & $F_{28.792}^{31.208}$ & $N$ & $N$ & $F_{57.999}^{62.001}$ & 123492 & 91 & 2h06' \\
\hline 22 & $N$ & $N$ & $F_{29.020}^{30.980}$ & $N$ & $S_{46.566}^{53.434}$ & $F_{58.012}^{61.988}$ & 127899 & 62 & 1h27' \\
\hline 23 & $N$ & $N$ & $F_{28.740}^{31.260}$ & $N$ & $N$ & $F_{58.021}^{61.979}$ & 126442 & 117 & 3h12' \\
\hline 24 & $N$ & $N$ & $F_{28.821}^{31.179}$ & $S_{36.385}^{43.615}$ & $S_{46.677}^{53.323}$ & $F_{57.977}^{62.023}$ & 127066 & 92 & 2h33' \\
\hline 25 & $N$ & $N$ & $F_{28.918}^{31.082}$ & $N$ & $S_{46.460}^{53.540}$ & $F_{58.009}^{61.991}$ & 125902 & 60 & 1h33' \\
\hline
\end{tabular}


inspection N. On the other hand, it will not be disadvantageous either, given the relatively small sample size $\left(s_{i}=50, \forall i\right)$, the differential cost of performing sampling inspection in stages 4 or 5 compared to performing no inspection will not be substantial. This explains the apparent indifference in selecting $\mathrm{S}$ or $\mathrm{N}$ in stages 4 and 5 .

\subsection{2. $E A / 2$}

EA/2 was also executed 25 times, with the same process and cost parameters as used for EA/1. This yielded minimal TIC's ranging from 121890 to 132940 (average TIC $=125965$, with a standard deviation of 3260 ). The corresponding solution vectors are shown in Table 4.5, together with the number of generations necessary to find that solution (note that this number includes 50 generations of no improvement).

Comparison of these results with the results of $\mathrm{EA} / 1$ on different solution characteristics renders the following comments:

- General form of the solutions: in EA/1 the solutions were all of the form NNFXXF, while in EA/2 also solutions of the form NNSXXF were found. This is a direct result of the inclusion of variable sampling parameters in EA/2. Apparently, the fixed sampling plan $(50,1)$ included in EA/1 didn't suffice to opt for sampling inspection $\mathrm{S}$ as alternative to full inspection $\mathrm{F}$ in stage 3, while in EA/2 the more discriminative sampling plans $(25,0)$ and $(100,1)$ do.

- Average TIC: inclusion of variable sampling parameters (EA/2 versus EA/1) doesn't change the average TIC (125956 vs. 125975 or a negligible difference).

- Standard deviation on average TIC: inclusion of variable sampling parameters (EA/2 versus EA/1) causes an increased dispersion (std. dev. of 3260 versus 1697). 
Table 4.5: EA/2 Solutions

\begin{tabular}{|c|c|c|c|c|c|c|c|}
\hline \multicolumn{6}{|c|}{ solution vector } & TIC & gen. \\
\hline 1 & $N N$ & $F_{28.836}^{31.164}$ & $\begin{array}{l}S_{34.262}^{45.738} \| 100 \\
\end{array}$ & $N$ & $F_{57.996}^{62.004}$ & 121890 & 125 \\
\hline 2 & $N N$ & $F_{28.805}^{31.195}$ & $N$ & $N$ & $F_{58.010}^{61.990}$ & 126882 & 97 \\
\hline 3 & $N N$ & $S_{28.816 » 1}^{31.184 \text { ॥ } 100}$ & $N$ & $S_{46.976 » 1}^{53.024 » 100}$ & $F_{57.994}^{62.006}$ & 122252 & 80 \\
\hline 4 & $N N$ & $S_{28.832 ॥ 1}^{31.168 \text { ॥ } 100}$ & $N$ & $N$ & $F_{58.006}^{61.994}$ & 122806 & 165 \\
\hline 5 & $N N$ & $F_{28.842}^{31.158}$ & $N$ & $N$ & $F_{58.004}^{61.996}$ & 123020 & 67 \\
\hline 6 & $N N$ & $F_{28.817}^{31.183}$ & $S_{33.866 \text { ॥ } 14}^{46.134 » 50}$ & $S_{43.370 ॥ 1}^{56.630 ॥ 100}$ & $F_{58.003}^{61.997}$ & 123098 & 126 \\
\hline 7 & $N N$ & $F_{28.717}^{31.283}$ & $N$ & $N$ & $F_{58.011}^{61.989}$ & 123340 & 52 \\
\hline 8 & $N N$ & $F_{28.822}^{31.178}$ & $N$ & $N$ & $F_{57.986}^{62.014}$ & 123560 & 143 \\
\hline 9 & $N N$ & $F_{28.695}^{31.305}$ & $N$ & $N$ & $F_{57.999}^{62.001}$ & 123588 & 85 \\
\hline 10 & $N N$ & $S_{28.787 ॥ 0}^{31.213 ॥ 25}$ & $N$ & $N$ & $F_{57.990}^{62.010}$ & 123758 & 179 \\
\hline 11 & $N N$ & $F_{28.918}^{31.082}$ & $N$ & $N$ & $F_{57.999}^{62.001}$ & 124224 & 112 \\
\hline 12 & $N N$ & $S_{28.908 \text { ॥ } 1}^{31.092 ~} 100$ & $N$ & $N$ & $F_{58.0094}^{61.996}$ & 124900 & 148 \\
\hline 13 & $N N$ & $S_{28.889 \| 0}^{31.111 ॥ 25}$ & $N$ & $N$ & $F_{58.014}^{61.986}$ & 125010 & 122 \\
\hline 14 & $N N$ & $S_{28.766 ॥ 0}^{31.234 ॥ 25}$ & $S_{38.714 ॥ 1}^{41.286 \text { ॥ } 50}$ & $S_{43.480 ॥ 1}^{56.520 ॥ 50}$ & $F_{57.993}^{62.007}$ & 125401 & 75 \\
\hline 15 & $N N$ & $F_{28.950}^{31.050}$ & $N$ & $N$ & $F_{58.013}^{61.987}$ & 126324 & 174 \\
\hline 16 & $N N$ & $F_{28.763}^{31.237}$ & $S_{38.686 \text { ॥ } 1}^{41.314 \text { ॥ } 50}$ & $S_{39.480 ॥ 1}^{60.520 ॥ 50}$ & $F_{58.004}^{61.996}$ & 126388 & 67 \\
\hline 17 & $N N$ & $F_{28.822}^{31.178}$ & $N$ & $S_{46.757 ॥ 1}^{53.243 ॥ 100}$ & $F_{57.959}^{62.041}$ & 127168 & 123 \\
\hline 18 & $N N$ & $S_{28.882 ~}^{31.118}$ ॥ 100 & $N$ & $S_{48.032 ॥ 1}^{51.968 \text { ॥ } 100}$ & $F_{57.973}^{62.027}$ & 127882 & 80 \\
\hline 19 & $N N$ & $F_{28.882}^{31.118}$ & $S_{37.714 » 1}^{42.286 » 50}$ & $N$ & $F_{58.051}^{61.949}$ & 128522 & 75 \\
\hline 20 & $N N$ & $S_{28.975 ॥ 0}^{31.025 ॥ 25}$ & $N$ & $S_{47.310 ॥ 0}^{52.690 ॥ 25}$ & $F_{58.016}^{61.984}$ & 128879 & 92 \\
\hline 21 & $N N$ & $F_{28.750}^{31.250}$ & $N$ & $N$ & $F_{58.029}^{61.971}$ & 129880 & 110 \\
\hline 22 & $N N$ & $S_{28.888 ॥ 1}^{31.112 ॥ 100}$ & $N$ & $N$ & $F_{57.956}^{62.044}$ & 130172 & 88 \\
\hline 23 & $N N$ & $F_{28.818}^{31.182}$ & $N$ & $S_{45.485 ॥ 1}^{54.515 ॥ 50}$ & $F_{58.058}^{61.942}$ & 131038 & 123 \\
\hline 24 & $N N$ & $F_{28.837}^{31.163}$ & $N$ & $N$ & $F_{58.036}^{61.964}$ & 131058 & 59 \\
\hline 25 & $N N$ & $S_{28.925 ॥ 1}^{31.075 \text { ॥ } 100}$ & $N$ & $N$ & $F_{57.922}^{62.078}$ & 132940 & 146 \\
\hline
\end{tabular}




\subsection{Influence of the cost parameters on MSPS opti- mization}

\subsubsection{Simulation: process and assumptions}

To study the influence of the cost parameters, a fictitious three-stage chemical process is constructed. As a general picture of the cost influence is desired, the simulation study described below will explore the whole solution space (all inspection strategy possibilities). This differs from the EA approach where the heuristic paradigm implies a limited "guided walk" through the solution space. Therefore this particular study is limited to three stages with fixed single sampling plans, limiting the total number of inspection options to 27.

The process is modeled as follows, a single quality characteristic is considered;

1. The first process stage is a chemical reaction. The output in terms of the quality characteristic (the concentration of the produced chemical) is a normal distribution, with user-defined mean, standard deviation and a possible mean shift.

2. The second process stage is a purification (concentration). The output from the first stage is multiplied with a user-defined multiplication factor (representing the concentration factor of the quality characteristic under consideration), and noise (uniform distribution, user-defined interval) is added.

3. Finally, in the third and last process stage, blending is performed. This comes down to an addition: to the output from the second stage, a number drawn from a normal distribution (with userdefined parameters) is added.

After each of the three production stages, the user can choose the inspection options: perform no inspection, perform sampling inspection (single sampling scheme, user-defined sample size and acceptance number), or perform $100 \%$ inspection; inspection limits are also user-defined. This set of decisions constitutes the overall inspection strategy.

Concerning the quantification of costs, three types of cost are defined: the test/sampling cost (TC), the rework/replacement cost (RC) and the 
fault/failure cost (FC). The test cost is the cost of a single test or analysis. Rework or replacement cost is incurred when a defect is discovered through testing, and reworked (perfect rework is assumed) or replaced by a non-defective (immediate replacement is assumed). Fault or failure cost is incurred if a defect is passed on undetected to the next stage (or, for the last stage, to the customer).

This setup differs slightly from the cost options chosen in the EA models, where there is no explicit fault cost per stage. In the EA models, it is assumed that $c_{R, i}<c_{R, j}, \forall i<j$. This assumption avoids having to introduce separate intermediate fault costs: the penalty cost of detecting a defect only in stage $j$, instead of earlier in stage $i$, is implicitly derived as $c_{R, j}-c_{R, i}$. For the EA modeling and with respect to applications in practice, this assumption is very useful. But as in this case the focus is on the influence of the costs, it is more practical to make the fault costs explicit.

In case of rejection after acceptance sampling inspection, $100 \%$ inspection of the rejected batch is performed consecutively. This approach and these assumptions are consistent with similar simulation studies found in literature: this process model allowed replication of Tannock's results (Tannock, 1995, 1997). As this model addresses a multistage process, building on Tannock's single-stage approach, additional results were found.

\subsubsection{Simulation modeling: program}

The process simulation model was developed using Microsoft Excel and Visual Basic for Applications. The random numbers used were generated through a standard Linear Congruential algorithm ${ }^{10}$. For every scenario that was simulated, 100 replications were executed.

As explained in the previous Section, after each of the three process stages, one of three inspection options can be chosen: no inspection $(\mathrm{N})$, sampling inspection (S), and full inspection (F). This results in a total of $3^{3}=27$ possible overall inspection strategies. The code used to designate a specific inspection strategy is a three letter code, each letter referring to the inspection option after the corresponding process stage. For instance,

\footnotetext{
${ }^{10}$ see Appendix B
} 
the inspection strategy with the code NFS, has no inspection after the first process stage, full inspection after the second, and sampling inspection after the third process stage.

One replication consists of the generation of new sets of random numbers, and running the 27 possible inspection scenarios per set of random numbers. All relevant data for each scenario are written to disk for further analysis. The other inspection parameters (sampling size, acceptance number and inspection limits) are set at certain fixed values per experiment (see Tables 4.6 and 4.8).

\subsubsection{Influence of the cost parameters}

For a certain process parameter setting (see Table 4.6), set fixed during this series of experiments, different cost parameter settings were tested (see Table 4.7) for their influence on the optimal inspection strategy, i.e. that strategy that results in minimal total inspection costs (TIC).

Table 4.6: Process parameter settings for experiment series 1

\begin{tabular}{|c|c|c|}
\hline \multicolumn{3}{|c|}{ process stage } \\
\hline $\mathrm{N}$ & mean & standard deviation \\
\hline \hline 1 & 10 & 0.3 \\
\hline 2 & 15 & 0.45 \\
\hline 3 & 20 & 0.49 \\
\hline
\end{tabular}

\section{Experiment 1}

The primary research question here was to investigate the influence of the order of magnitude of the cost parameters in relation to each other:

What is the effect of the magnitude of and the relation between the Test Cost, the Rework Cost and the Fault Cost on the choice of optimal inspection strategy?

As a rule of thumb, the relation between the three different types of costs was set so that always $\mathrm{TC}<\mathrm{RC}<\mathrm{FC}$. This simple rule is based on 
common sense: if $\mathrm{TC}$ were larger than $\mathrm{RC}$, testing would be uneconomical. Similarly, if RC were larger than FC, rework would be uneconomical.

Second, to keep the number of experiments manageable, the costs were set so that

$$
F C=a R C=a^{2} T C
$$

with the multiplication factor $a$ successively adopting values between 2 and 100 .

This yields the grid of cost parameters shown in Table 4.7.

Table 4.7: Cost parameter settings for experiment series 1

\begin{tabular}{|r|l|l|l|}
\hline a & test cost & rework cost & fault cost \\
\hline \hline 2 & 10 & 20 & 40 \\
\hline 3 & 10 & 30 & 90 \\
\hline 5 & 10 & 50 & 250 \\
\hline 7 & 10 & 70 & 490 \\
\hline 8 & 10 & 80 & 640 \\
\hline 9 & 10 & 90 & 810 \\
\hline 10 & 10 & 100 & 1000 \\
\hline 12 & 10 & 120 & 1440 \\
\hline 15 & 10 & 150 & 2250 \\
\hline 20 & 10 & 200 & 4000 \\
\hline 50 & 10 & 500 & 25000 \\
\hline 100 & 10 & 1000 & 100000 \\
\hline
\end{tabular}

In this series of experiments, symmetrical inspection limits were set for all process stages (i.e. the expected value is the arithmetic average of the upper inspection limit (UIL) and the lower inspection limit (LIL)). The values of the limits were set so that the process capability index $C_{p k}$ for each of the process stages was in the interval [0.8, 0.9]. All inspection parameter settings are summarized in Table 4.8 .

Based on the parameter settings in Tables 4.6, 4.7 and 4.8, the results in Table 4.9 were obtained: for different values of the multiplication factor $a$, different optimal inspection strategies were found. 
Table 4.8: Inspection parameter settings for experiment series 1

\begin{tabular}{|l|c||l|c|}
\hline inspection parameter & value & inspection parameter & value \\
\hline \hline LIL stage 1 & 9.2 & UIL stage 1 & 10.8 \\
\hline LIL stage 2 & 13.8 & UIL stage 2 & 16.2 \\
\hline LIL stage 3 & 18.7 & UIL stage 3 & 21.3 \\
\hline sample size stage 1 & 50 & accept. nr stage 1 & 2 \\
\hline sample size stage 2 & 50 & accept. nr stage 2 & 2 \\
\hline sample size stage 3 & 50 & accept. nr stage 3 & 1 \\
\hline
\end{tabular}

For increasing values of $a$, a gradual shift from NNN over FNN and FFN to FFF is observed. For relatively low values of $a$, the no-inspection strategy is cost optimal, because of the relatively low penalty for faults. When $a$-and thus also the fault penalty- increases, the full-inspection strategy will gain the upper hand. The point of reversal to the fullinspection strategy will of course also depend on the $C_{p k}$ value. In this series of experiments, the $C_{p k}$ values were set at a relatively high value, meaning a relatively low occurrence of faults. It can be predicted that for lower values of $C_{p k}$, the NNN-FFF reversal will occur sooner.

As illustrated in Figure 4.5, the relation between $a$ and the total inspection cost for the FFF and NNN strategies is respectively linear (varies with $a$ ) and parabolic (varies with $a^{2}$ ). This can in fact be calculated analytically if the fault occurence $p$ for each of the process stages is known. In the FFF strategy, all faults are detected, incurring test cost $\mathrm{TC}$ for all items, rework/replacement cost $\mathrm{RC}$ for the defective ones, and no fault cost FC. As defined before in equation $7, \mathrm{RC}=a \mathrm{TC}$. TC was set 10 for all experiments, so $\mathrm{RC}=10 a$ and the total cost is proportional to $a$. The total inspection cost TIC for the FFF strategy can be predicted based on the fault probabilities $p_{1}, p_{2}$ and $p_{3}$ for the three process stages, and the batchsize $K$ :

$$
T I C=\sum_{i=1}^{3}\left(T C_{i}+R C_{i}+F C_{i}\right)
$$

with, for the FFF case, $\forall i$ 
Section 4.6. Influence of the cost parameters on MSPS optimization

Table 4.9: Optimal inspection strategies for experiment series 1

\begin{tabular}{|c|c|c|}
\hline multipl. factor $a$ & optimal insp. strategy & minimal TIC \\
\hline \hline 2 & NNN & 5903 \\
\hline 3 & NNN & 13514 \\
\hline 5 & NNN & 37390 \\
\hline 7 & NNN & 73142 \\
\hline 8 & FNN & 92114 \\
\hline 9 & FNN & 102865 \\
\hline 10 & FNN & 114145 \\
\hline 12 & FFN & 142247 \\
\hline 15 & FFF & 163259 \\
\hline 20 & FFF & 167678 \\
\hline 50 & FFF & 194195 \\
\hline 100 & FFF & 228390 \\
\hline
\end{tabular}

$$
\left\{\begin{array}{l}
T C_{i}=10 K \\
R C_{i}=10 K p_{i} a \\
F C_{i}=0
\end{array}\right.
$$

yielding:

$$
T I C_{F F F}=10 K\left(3+a\left(p_{1}+p_{2}+p_{3}\right)\right)
$$

In the NNN strategy, no inspection is performed, all faults are passed on undetected, incurring only fault costs FC. For NNN, $\forall i$ :

$$
\left\{\begin{array}{l}
T C_{i}=0 \\
R C_{i}=0 \\
F C_{i}=10 K p_{i}^{\prime} a^{2}
\end{array}\right.
$$

so that in this case:

$$
T I C_{N N N}=10 K a^{2}\left(p_{1}^{\prime}+p_{2}^{\prime}+p_{3}^{\prime}\right)
$$


Figure 4.5: TIC versus multiplication factor $a$ for NNN, FFF and cost optimal inspection strategies

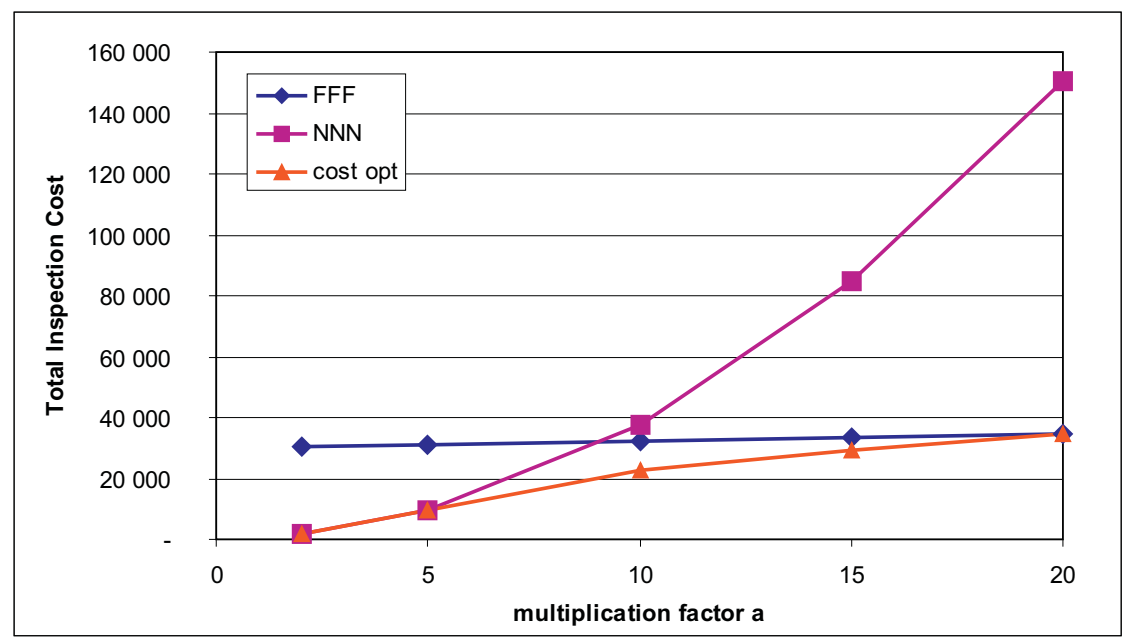

The reversal NNN to FFF thus occurs at that value of $a$ where the NNN-parabola and the FFF-straight line intersect, i.e. at the positive root of:

$$
\left(p_{1}^{\prime}+p_{2}^{\prime}+p_{3}^{\prime}\right) a^{2}-\left(p_{1}+p_{2}+p_{3}\right) a-3=0
$$

Note that of course $p_{1}^{\prime}=p_{1}$, because the fault occurrence for the first process stage equals the fault probability. For the second and third stage, however, the fault occurrence also depends on the inspection strategy chosen in the previous stages. Also note that the location of the intersection point is independent of the batch size $K$, but dependent on the number of process stages.

For this experiment, $K$ was set at 5000, and the a posteriori fault occurrences were $p_{1}^{\prime}+p_{2}^{\prime}+p_{3}^{\prime}=0.0298$ and $p_{1}+p_{2}+p_{3}=0.0176$. Equation 4.20 then becomes $0.0298 a^{2}-0.0176 a-3=0$, and intersection of FFF and NNN curves occurs at the value $a=10.33$. In Figure 4.5, the relation between the minimal total inspection costs and the multiplication factor $a$ is illustrated for this experiment. One can distinguish the parabolic start of the curve (NNN strategy for low values of $a$ ) and the linear ending of 
Section 4.6. Influence of the cost parameters on MSPS optimization

the curve (FFF strategy for high values of $a$ ).

\section{Experiment 2}

A second research question regarding the influence of the cost parameters on the inspection strategy was:

For fixed values of $T C$ and $F C$, what is the influence of $R C$ ?

For this experiment, the same process and inspection parameters were set (see Tables 4.6 and 4.8). Table 4.10 shows the cost parameters. TC and $\mathrm{FC}$ were set so that $\mathrm{RC}$ can vary over several orders of magnitude, while still conforming to $\mathrm{TC}<\mathrm{RC}<\mathrm{FC}$.

Table 4.10: Cost parameter settings for experiment series 2

\begin{tabular}{|l|l|l|}
\hline test cost & rework cost & fault cost \\
\hline \hline 10 & 100 & 100000 \\
\hline 10 & 1000 & 100000 \\
\hline 10 & 10000 & 100000 \\
\hline
\end{tabular}

In Table 4.11, the results of the experiment are summarized. In the first section of the tTable, the absolute value of the TIC -for each of the 27 inspection options and the three values for RC- is tabulated. In the second section, the relative value of the TIC, in relation to the base: $\mathrm{RC}=100$, is displayed. The most important finding is that the influence of the RC on the total inspection cost (TIC) seems to be fairly small, except for the FFF strategy.

From the results in the second section of Table 4.11, one can see the influence of the $\mathrm{RC}$ diminish with the number of process stages where full inspection is applied. In the FFF case, the $\mathrm{TIC}_{\mathrm{RC}=1000}$ is approximately 1.5 times the $\mathrm{TIC}_{\mathrm{RC}=100}$, and the $\mathrm{TIC}_{\mathrm{RC}=10000}$ is more than 6.5 times the $\mathrm{TIC}_{\mathrm{RC}=100}$. For the cases where 2 out of 3 stages have full inspection, these ratios drop significantly: $\mathrm{TIC}_{\mathrm{RC}=1000} / \mathrm{TIC}_{\mathrm{RC}=100}$ is about 1.02, while $\mathrm{TIC}_{\mathrm{RC}=10000} / \mathrm{TIC}_{\mathrm{RC}=100}$ is about 1.25 . For the cases where only one stage has full inspection, the ratio $\mathrm{TIC}_{\mathrm{RC}=1000} / \mathrm{TIC}_{\mathrm{RC}=100}$ is 
Table 4.11: Cost parameter settings for experiment series 2

\begin{tabular}{|c|l|l|l||c|c|}
\hline strategy & \multicolumn{3}{|c|}{ minimal TIC (abs.) } & \multicolumn{2}{c|}{ minimal TIC (rel.) } \\
\hline & $\mathrm{RC}=100$ & $\mathrm{RC}=1000$ & $\mathrm{RC}=10000$ & $\mathrm{RC}=1000$ & $\mathrm{RC}=10000$ \\
\hline \hline FFF & 158839 & 238390 & 1033900 & 1.5008 & 6.5091 \\
\hline FFS & 2487464 & 2545640 & 3127400 & 1.0234 & 1.2573 \\
\hline FFN & 2503442 & 2561420 & 3141200 & 1.0232 & 1.2548 \\
\hline FNF & 2674404 & 2741040 & 3407400 & 1.0249 & 1.2741 \\
\hline FSF & 2679904 & 2746540 & 3412900 & 1.0249 & 1.2735 \\
\hline NFF & 3982993 & 4054930 & 4774300 & 1.0181 & 1.1987 \\
\hline SFF & 3988493 & 4060430 & 4779800 & 1.0180 & 1.1984 \\
\hline FNS & 6116914 & 6152140 & 6504400 & 1.0058 & 1.0633 \\
\hline FSS & 6122414 & 6157640 & 6509900 & 1.0057 & 1.0633 \\
\hline FNN & 6149875 & 6184750 & 6533500 & 1.0057 & 1.0624 \\
\hline FSN & 6155375 & 6190250 & 6539000 & 1.0057 & 1.0623 \\
\hline NFS & 6499430 & 6548300 & 7037000 & 1.0075 & 1.0827 \\
\hline SFS & 6504930 & 6553800 & 7042500 & 1.0075 & 1.0826 \\
\hline NFN & 6517406 & 6566060 & 7052600 & 1.0075 & 1.0821 \\
\hline SFN & 6522906 & 6571560 & 7058100 & 1.0075 & 1.0820 \\
\hline NNF & 9336646 & 9387460 & 9895600 & 1.0054 & 1.0599 \\
\hline NSF & 9342146 & 9392960 & 9901100 & 1.0054 & 1.0598 \\
\hline SNF & 9342146 & 9392960 & 9901100 & 1.0054 & 1.0598 \\
\hline SSF & 9347646 & 9398460 & 9906600 & 1.0054 & 1.0598 \\
\hline NNS & 14654281 & 14656810 & 14682100 & 1.0002 & 1.0019 \\
\hline NSS & 14659781 & 14662310 & 14687600 & 1.0002 & 1.0019 \\
\hline SNS & 14659781 & 14662310 & 14687600 & 1.0002 & 1.0019 \\
\hline SSS & 14665281 & 14667810 & 14693100 & 1.0002 & 1.0019 \\
\hline NNN & 14927000 & 14927000 & 14927000 & 1 & 1 \\
\hline NSN & 14932500 & 14932500 & 14932500 & 1 & 1 \\
\hline SNN & 14932500 & 14932500 & 14932500 & 1 & 1 \\
\hline SSN & 14938000 & 14938000 & 14938000 & 1 & 1 \\
\hline
\end{tabular}


smaller than 1.01, and $\mathrm{TIC}_{\mathrm{RC}=10000} / \mathrm{TIC}_{\mathrm{RC}=100}$ is around 1.07. For the scenarios without a fully inspected stage, both ratios approximate 1 .

The overall influence of $\mathrm{RC}$ can thus be considered small: only for the FFF case, the RC really weighs on the TIC, but even then still less than proportional: for an increase in RC with a factor 100, TIC increases with a factor 6.5. This is mainly due to the relatively small percentage defectives.

Additionally, findings of the first experiment are confirmed here: in experiment 2 , because of the high fault penalty, the FFF strategy always is cost optimal.

\subsubsection{Conclusions}

The simulation method described is proven capable of providing an insight into the influence of the cost parameters on the alternative inspection strategies. For the selected frame of problems and parameters, the cost optimal inspection strategy in function of the cost parameter multiplication factor $a$, was determined. For both extreme inspection scenarios, full-inspection FFF and no-inspection NNN, the total inspection cost TIC increased linear resp. parabolic with $a$. At the low end of the spectrum of values for $a$, the NNN strategy proved cost optimal (the relatively low fault costs don't exceed the test costs). At the high end, FFF inspection is most economic (test costs are justified to avoid high fault penalties). In the zone where the shift from NNN to FFF occurs, other strategies prove optimal: the "mixed" strategies FNN and FFN.

For the selected frame of problems and parameters, the Rework Cost $\mathrm{RC}$ contributes little to the total inspection cost TIC, its influence on the choice of inspection strategy can thus be considered small.

\section{A. Metaheuristics: an overview}

Metaheuristics can, analogous to the optimization algorithms described in Section 4.3.1, also be classified according to the nature of the search. This yields a first rough division into three main classes namely neighborhoodbased, population-based and mixed forms known as hybrid metaheuristics. 


\section{A.1. Neighborhood-based metaheuristics}

Neighborhood-based metaheuristics, also known as local search metaheuristics, iteratively go from one solution to the next, using an operation called a move. These moves allow reaching any solution $\mathbf{y}$ in the neighborhood $\mathcal{N}(\mathbf{x}, \eta)$ of the solution $\mathbf{x}$ where the move initiated from (see Section 4.2). According to the type of metaheuristic, specific rules apply to these moves to ensure an efficient search of the solution space. Generally, the search will be conducted on two "levels", with on the first level a local search operator to find the local optimal solution (i.e. within the neighborhood), governed by the metaheuristic framework on the second level, allowing "escapes" from these local optima (the metaheuristic will thereto temporarily allow moves resulting in solutions of worse quality than the current solution). Moves are performed until a predefined stopping criterion is reached (preferably this is when a solution of sufficient quality is found, but it can also be that the maximum number of iterations is reached).

Popular metaheuristics in this class are e.g. simulated annealing (SA), tabu search (TS), and greedy randomized adaptive search procedure (GRASP)

\section{Simulated Annealing}

Simulated Annealing (SA) is commonly acknowledged to be the oldest among the metaheuristics and surely one of the first algorithms that includes an explicit strategy to escape from local minima. The origins of the algorithm are in statistical mechanics and it was first presented as a search algorithm in Kirkpatrick et al. (1983).

The SA heuristic mimics the annealing process of liquified metals as they cool into a minimum energy crystalline structure. During such a cooling process, the metal atoms can shift, and do so in order to reach a state of minimal energy at temperature zero (or at the end of the cooling process). Theoretically, the state of minimal energy is the defect-free, completely regular crystal. However, depending on the specific cooling circumstances, a state can be reached that conforms to a structure with defects, which is nevertheless stable in the sense that any disturbance from that structure will increase its energy level.

The mechanism that allows escape from these local minima is the 
annealing schedule that fixes the cooling temperatures and times. The fundamentals of a cooling schedule to create a defect-free crystal are as follows: initially the temperature is set to a value above melting point, allowing the atoms to move and thus restore defects. The atom movement however also creates new defects. When the number of defects restored no longer exceeds the number of defects created, the temperature is lowered, after which the rate of defect destruction again exceeds the rate of defect creation. After time, the two rates are equal again and the temperature is subsequently lowered again.

SA algorithms mimic this controlled cooling process by starting from an initial solution and by initializing the so-called temperature parameter $T$. Then the following is repeated until the stopping criterion is satisfied: A solution $\mathbf{y}$ from the neighborhood $\mathcal{N}(\mathbf{x}, \eta)$ of the solution $\mathbf{x}$ is randomly sampled and it is accepted as new current solution depending on $f(\mathbf{y})$, $f(\mathbf{x})$ and $T$. $\mathbf{y}$ replaces $\mathbf{x}$ if $f(\mathbf{y})<f(\mathbf{x})$ or, in case $f(\mathbf{y}) \geq f(\mathbf{x})$, with a probability which is a function of $T$ and $f(\mathbf{y})-f(\mathbf{x})$. The probability is generally computed following $e^{-\frac{f(\mathbf{y})-f(\mathbf{x})}{T}}$.

The temperature $T$ is decreased during the search process, thus at the beginning of the search the probability of accepting moves that lead to temporarily worse solutions is higher and it gradually decreases, ultimately leading to an iterative improvement algorithm.

SA is proven to always converge to the optimal solution, albeit only in infinite time. The most critical step in constructing SA heuristics is the setting of the cooling schedule. In practice, SA has been successfully applied to a wide variety of problems, with the speed (or rather, the lack thereof) of the heuristic as most important drawback.

This proven lack of speed in convergence was the main reason not to try using an SA based metaheuristic for the MSPS inspection optimization.

\section{Tabu Search}

In Tabu Search (TS), the strategy to allow temporarily worse solutions in order to escape from local optima, is governed by keeping track of previous solutions in a specific way, by means of the so-called tabu list.

TS was introduced as a search technique by Glover (1986) and Hansen 


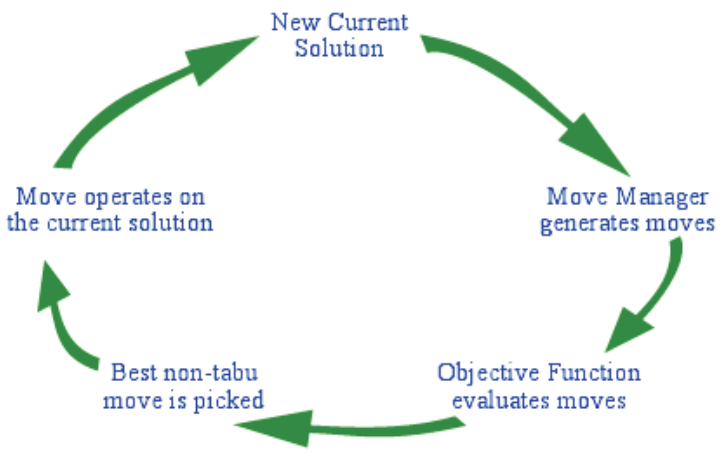

Figure 4.6: Schematic operating principle of Tabu Search Algorithms (from the Computational Infrastructure for Operations Research - open source. (http://www.coinor.org/))

(1986). Like all neighborhood-based heuristics, it uses a local search procedure to move from one solution to the next (within the neighborhood), but as the search progresses, the TS method allows modification of the neighborhood itself to escape from local optimality. The solutions admitted to this new neighborhood, are determined through the use of special memory structures (the tabu list for the short-term memory, to prevent the algorithm to return to recent, previous solutions; and long term memory structures, to ensure diversification (forcing the search into unexplored regions of the solution space) and intensification (forcing the search to return to interesting but insufficiently explored regions of the solution space).

Tabu search provides a range of strategic options, involving various levels of short term and long term memory. Thus, it can be -and iswidely applied.

The reason it was not applied for the MSPS inspection optimization problem at hand lies in the fact that for this problem, no a priori advisable "moves" could be devised. In that case, working with random moves is an alternative, but with random moves the relative benefit of tabu search with respect to other metaheuristics such as evolutionary algorithms is undone. 


\section{GRASP}

Unlike the previously discussed metaheuristics, which are all improvement heuristics, GRASP (Greedy Randomized Adaptive Search Procedure), is a construction heuristic. A solution is constructed from a list with solution attributes, ranked according to the "benefit" an attribute is expected to have on the solution. After a solution has been constructed (with attributes most likely to bring benefit preferably included), a local search operator will find a local optimum. The quality of this solution is evaluated, and this provides a basis for reordering the list of solution attributes, according to the updated relative benefits. This procedure is repeated until reaching of the stopping criterion.

The main reason for not using greedy heuristics in MSPS inspection optimization again is the lack of a priori knowledge on the effect local (in one stage) changes have on the global (over all stages) solutions.

For MSPS inspection optimization, population-based metaheuristics where therefore elected over neighborhood-based metaheuristics.

\section{A.2. Population-based metaheuristics}

In population-based metaheuristics, on every iteration, moves are conducted on a "population" of feasible solutions, rather than on a single solution as is the case in neighborhood-based metaheuristics. Populationbased metaheuristics attempt to improve the solutions in the population by allowing them to "combine". The specific strategy of this combination process depends on the type of metaheuristic, and combination is conducted until the predefined stopping criterion is reached.

Well-known metaheuristics of this type are genetic or evolutionary algorithms (GA/EA) and ant systems such as ant colony optimization (ACO).

\section{Ant Colony Optimization}

Ant Colony optimization is a population based search technique inspired by the complex social behaviors of ants. These behavior patterns can be "translated" to provide models for solving difficult combinatorial optimization problems. The attempt to develop algorithms inspired by one 
aspect of ant behavior, the ability to find shortest paths (see below, after Wikipedia, http://en.wikipedia.org/), has become the field of ant colony optimization (ACO). The essential trait in ACO is the combination of a priori information on promising solutions with a posteriori information on previously obtained good solutions.

Ants (initially) wander randomly, and upon finding food return to their colony while laying down pheromone trails. If other ants find such a path, they are likely not to keep travelling at random, but instead to follow the trail, returning and reinforcing it if they eventually find food.

Over time, however, the pheromone trail starts to evaporate, thus reducing its attractive strength. The more time it takes for an ant to travel down the path and back again, the more time the pheromones have to evaporate. A short path, by comparison, gets marched over faster, and thus the pheromone density remains high as it is laid on the path as fast as it can evaporate.

Thus, when one ant finds a good (i. e. short) path from the colony to a food source, other ants are more likely to follow that path, and positive feedback eventually leaves all the ants following a single path. The idea of the ant colony algorithm is to mimic this behavior with simulated ants walking around the graph representing the problem to solve.

Because there is nothing in the MSPS inspection optimization problem that easily translates into distances or paths, the ACO paradigm doesn't fit the nature of the problem very well. It was therefore not selected as basis solution technique.

\section{Genetic and Evolutionary Algorithms}

As amply discussed earlier in this Chapter, evolutionary algorithms are population based search methods that take their inspiration from natural selection and survival of the fittest in the biological world. Each iteration of the algorithm involves a competitive selection that aims to improve solution quality. The solutions with high fitness (indication of solution quality) are recombined with other solutions by swapping parts of the (encoded) solution with another. Solutions can also undergo mutation, by making a small change to a single element of the solution. Repeated application of recombination and mutation are used to generate new solutions that are biased towards promising regions of the solution space. 
Section 4.B. Notes on statistical analysis of simulation output

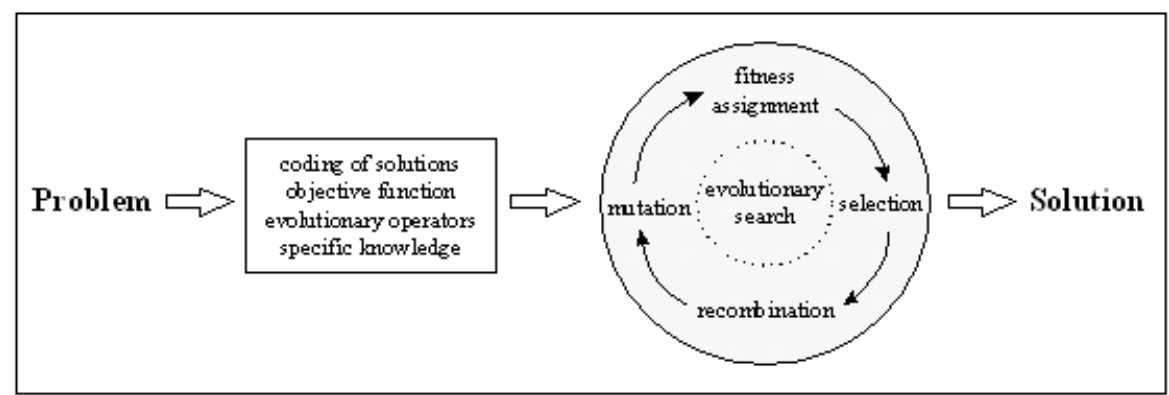

Figure 4.7: Schematic operating principle of Genetic and Evolutionary Algorithms (from the GEATbx: Genetic and Evolutionary Algorithm Toolbox for use with MATLAB. (http://www.geatbx.com))

Smart recombination should ensure a smart search path towards the right region in the solution space, while mutation should avoid the risk of getting stuck in local optima.

Within the family of population-based metaheuristics, the MSPS inspection optimization problem best fitted the paradigm of evolutionary algorithms, and coding the solution vectors as strings of chromosomes was straightforward. It therefore was almost a natural choice to elect an EA as a basis for the proposed solution technique.

\section{A.3. Hybrid metaheuristics}

This family of metaheuristics uses elements from both previous categories of metaheuristics. Aspects of neighborhood-based metaheuristics and population-based metaheuristics are combined to create new high-quality metaheuristics. An example is a genetic algorithm that uses tabu search to improve the individual solutions within each population.

\section{B. Notes on statistical analysis of simulation output}

Since in EA/1 and EA/2, simulation is used to calculate average TIC's for every solution the evolutionary strategy proposes, sound simulation output analysis is necessary before jumping to conclusions. For instance, when a solution is claimed to be "optimal", i.e. the solution's average TIC 
is the lowest the algorithm can find, is it then really demonstrably better than other solutions? In other words, does the optimal solution differ statistically significant from other solutions? The answer to these questions can be found with elements from Analysis of Variance (ANOVA). In the cases of EA/ 1 and EA/2, families of confidence intervals can be calculated to compare the average TIC of the optimal solution in pairs to the average TIC of the other solutions in the last (best) generation. When all of those paired mean differences are significantly different from 0 , then the optimal solution is significantly better than the other solutions.

For $k$ solutions in the last generation ( $k=$ population size), a family of $k-1$ confidence intervals on the paired mean differences can be calculated. Introducing the following notations:

$$
\begin{aligned}
\mu_{j} & =\mathrm{E}\left[T I C^{j}\right] \\
\overline{T I C^{j}} & =\frac{1}{n} \sum_{i=1}^{n} T I C_{n}^{j}
\end{aligned}
$$

where $n$ represents the number of simulation replications, and $j$ indicates the $j^{\text {th }}$ solution in the last generation $(j=1, \ldots, k)$, the desired family of confidence intervals can be represented as follows:

$$
\begin{aligned}
\mu_{o p t}-\mu_{2} & =\overline{T I C^{o p t}}-\overline{T I C^{2}} \pm \sqrt{(k-1) F_{0.05}^{k(n-1)}} \cdot s \cdot \sqrt{\frac{2}{n}} \\
\mu_{o p t}-\mu_{3} & =\overline{T I C^{o p t}}-\overline{T I C^{3}} \pm \sqrt{(k-1) F_{0.05}^{k(n-1)}} \cdot s \cdot \sqrt{\frac{2}{n}} \\
\mu_{o p t}-\mu_{4} & =\overline{T I C^{o p t}}-\overline{T I C^{4}} \pm \sqrt{(k-1) F_{0.05}^{k(n-1)}} \cdot s \cdot \sqrt{\frac{2}{n}} \\
& \vdots \\
\mu_{o p t}-\mu_{k} & =\overline{T I C^{o p t}}-\overline{T I C^{k}} \pm \sqrt{(k-1) F_{0.05}^{k(n-1)}} \cdot s \cdot \sqrt{\frac{2}{n}}
\end{aligned}
$$

Where

$$
\begin{aligned}
F_{0.05}^{k(n-1)=} & \text { critical value of } F \text { that leaves } 5 \% \text { in the upper }(4.25) \\
& \text { tail, for } k(n-1) \text { degrees of freedom } \\
s^{2}= & \frac{1}{k(n-1)} \sum_{j=1}^{k} \sum_{i=1}^{n}\left(T I C_{j}^{i}-\overline{T I C^{j}}\right)^{2}
\end{aligned}
$$


These intervals are simultaneously true with $95 \%$ confidence. When none of the intervals contains 0 , it can thus be inferred with $95 \%$ confidence that the optimal solution is significantly better than the other solutions.

When the computational examples described in this Chapter were calculated, statistical analysis was not yet included in the programming of EA/1 and EA/2, thus a full statistical analysis of these examples is not available. The computational examples in the next Chapter are all calculated with a more recent version of the algorithm, going by the name of EA/2stat. For those examples the statistical analysis is available and will be referred to where appropriate. 



\section{Chapter 5}

\section{a case study}

\subsection{Chapter purpose and outline}

In this Chapter, a case study is built to explore the characteristics, possibilities and limitations of the EA/2stat metaheuristic. In Section 5.1, the different cases are presented, and in Section 5.2 the results are discussed. Finally a note on solutions' statistical inferences is made in Section 5.3.

\subsection{6 cases}

Initially, a set of 26 fictitious 4 -stage processes was built.

The set consists of 10 additive processes (A through J), 10 multiplicative processes ( $\mathrm{K}$ through $\mathrm{T}$ ), and 6 mixed processes ( $\mathrm{U}$ through $\mathrm{Z}$ ). It was compiled in such a fashion that the expected value after each process step is the same: 10 after process step 1, 20 after process step 2, 30 after process step 3 and 40 after process step 4 . What is different is the manner in adding 10 in each step: by addition or multiplication; with different distributions, multiplication factors and added noise. Moreover, in cases A through $\mathrm{G}$, the penalty cost is varied. In cases $\mathrm{J}$ through $\mathrm{Z}$, the penalty cost is kept at 1000. The inspection and rework costs for each stage are kept constant for all cases (see Table 5.11).

All these assumptions allow that the same inspection strategy be used as initial solution for all cases, in order to rule out the influence of the initial solution. 
Table 5.1: Cases A through J, general setting

\begin{tabular}{|c|c|c|c|}
\hline cases ABCDEFGHIJ & distribution & mean & exp. value \\
\hline \hline step 1 & normal & $\mu=10$ & 10 \\
\hline step 2 & add normal & $\mu=10$ & 20 \\
\hline step 3 & add normal & $\mu=10$ & 30 \\
\hline step 4 & add normal & $\mu=10$ & 40 \\
\hline
\end{tabular}

Table 5.2: Cases $A / B / C / D / E$, specific setting

\begin{tabular}{|c|c|c|c|c|c|}
\hline case & $\mathrm{A}$ & $\mathrm{B}$ & $\mathrm{C}$ & $\mathrm{D}$ & $\mathrm{E}$ \\
\hline step 1 & $\sigma=0.1$ & $\sigma=0.1$ & $\sigma=0.1$ & $\sigma=0.2$ & $\sigma=0.2$ \\
\hline step 2 & $\sigma=0.1$ & $\sigma=0.1$ & $\sigma=0.1$ & $\sigma=0.2$ & $\sigma=0.2$ \\
\hline step 3 & $\sigma=0.1$ & $\sigma=0.1$ & $\sigma=0.1$ & $\sigma=0.2$ & $\sigma=0.2$ \\
\hline step 4 & $\sigma=0.1$ & $\sigma=0.1$ & $\sigma=0.1$ & $\sigma=0.2$ & $\sigma=0.2$ \\
\hline penalty cost & 1000 & 10000 & 100000 & 1000 & 10000 \\
\hline
\end{tabular}

Step 1's result always is a draw from a normal distribution, the mean equal to 10, and varying standard deviations. For the additive process cases A through J (see Tables 5.1, 5.2 and 5.3), steps 2 through 4 each consist of the addition of another draw from a normal distribution with mean $=10$, and varying standard deviation. For the multiplicative processes $\mathrm{K}$ through $\mathrm{O}$ (see Tables 5.4 and 5.5), steps 2 through 4 consist of multiplying the process value from the previous step with a fixed multiplication factor, and to add white noise consecutively. For the multiplicative processes $\mathrm{P}$ through $\mathrm{T}$ (see Tables 5.6 and 5.7), multiplication is performed with a factor drawn from a normal distribution. Finally, for the mixed processes U through Z (see Tables 5.8, 5.9 and 5.10), step 2 and 4 are multiplicative (multiplication with a factor drawn from a normal distribution), step 3 is additive (addition of a term drawn from a normal distribution with mean $=10$, and varying standard deviation). 
Table 5.3: Cases $F / G / H / I / J$, specific setting

\begin{tabular}{|c|c|c|c|c|c|}
\hline case & $\mathrm{F}$ & $\mathrm{G}$ & $\mathrm{H}$ & $\mathrm{I}$ & $\mathrm{J}$ \\
\hline step 1 & $\sigma=0.2$ & $\sigma=0.2$ & $\sigma=0.2$ & $\sigma=0.1$ & $\sigma=0.01$ \\
\hline step 2 & $\sigma=0.1$ & $\sigma=0.1$ & $\sigma=0.01$ & $\sigma=0.2$ & $\sigma=0.2$ \\
\hline step 3 & $\sigma=0.2$ & $\sigma=0.2$ & $\sigma=0.2$ & $\sigma=0.1$ & $\sigma=0.01$ \\
\hline step 4 & $\sigma=0.1$ & $\sigma=0.1$ & $\sigma=0.01$ & $\sigma=0.2$ & $\sigma=0.2$ \\
\hline penalty cost & 1000 & 10000 & 1000 & 1000 & 1000 \\
\hline
\end{tabular}

Table 5.4: Cases $K$ through $O$, general setting

\begin{tabular}{|c|c|c|c|}
\hline cases KLMNO & $\begin{array}{c}\text { distribution } \\
\text { or operation }\end{array}$ & $\begin{array}{c}\text { mean } \\
\text { or factor } / \text { noise }\end{array}$ & exp. value \\
\hline \hline step 1 & normal & $\mu=10$ & 10 \\
\hline step 2 & multiply & $\mathrm{x} 2+$ noise $\mathrm{N}(0, \sigma)$ & 20 \\
\hline step 3 & multiply & $\mathrm{x} 3 / 2+$ noise $\mathrm{N}(0, \sigma)$ & 30 \\
\hline step 4 & multiply & $\mathrm{x} 4 / 3+$ noise $\mathrm{N}(0, \sigma)$ & 40 \\
\hline
\end{tabular}

Table 5.5: Cases $K / L / M / N / O$, specific setting

\begin{tabular}{|c|c|c|c|c|c|}
\hline case & $\mathrm{K}$ & $\mathrm{L}$ & $\mathrm{M}$ & $\mathrm{N}$ & $\mathrm{O}$ \\
\hline step 1 & $\sigma=0.1$ & $\sigma=0.1$ & $\sigma=0.1$ & $\sigma=0.1$ & $\sigma=0.2$ \\
\hline step 2 & $\sigma=0.01$ & $\sigma=0.05$ & $\sigma=0.1$ & $\sigma=0.01$ & $\sigma=0.01$ \\
\hline step 3 & $\sigma=0.01$ & $\sigma=0.05$ & $\sigma=0.1$ & $\sigma=0.1$ & $\sigma=0.01$ \\
\hline step 4 & $\sigma=0.01$ & $\sigma=0.05$ & $\sigma=0.1$ & $\sigma=0.01$ & $\sigma=0.01$ \\
\hline penalty cost & 1000 & 1000 & 1000 & 1000 & 1000 \\
\hline
\end{tabular}

Table 5.6: Cases $P$ through $T$, general setting

\begin{tabular}{|c|c|c|c|}
\hline cases PQRST & $\begin{array}{c}\text { distribution } \\
\text { or operation }\end{array}$ & $\begin{array}{c}\text { mean } \\
\text { or factor }\end{array}$ & exp. value \\
\hline \hline step 1 & normal & $\mu=10$ & 10 \\
\hline step 2 & multiply with normal & $\mathrm{N}(2, \sigma)$ & 20 \\
\hline step 3 & multiply with normal & $\mathrm{N}(3 / 2, \sigma)$ & 30 \\
\hline step 4 & multiply with normal & $\mathrm{N}(4 / 3, \sigma)$ & 40 \\
\hline
\end{tabular}


Table 5.7: Cases $P / Q / R / S / T$, specific setting

\begin{tabular}{|c|c|c|c|c|c|}
\hline case & $\mathrm{P}$ & $\mathrm{Q}$ & $\mathrm{R}$ & $\mathrm{S}$ & $\mathrm{T}$ \\
\hline step 1 & $\sigma=0.1$ & $\sigma=0.1$ & $\sigma=0.1$ & $\sigma=0.1$ & $\sigma=0.2$ \\
\hline step 2 & $\sigma=0.01$ & $\sigma=0.05$ & $\sigma=0.1$ & $\sigma=0.01$ & $\sigma=0.01$ \\
\hline step 3 & $\sigma=0.01$ & $\sigma=0.05$ & $\sigma=0.1$ & $\sigma=0.1$ & $\sigma=0.01$ \\
\hline step 4 & $\sigma=0.01$ & $\sigma=0.05$ & $\sigma=0.1$ & $\sigma=0.01$ & $\sigma=0.01$ \\
\hline penalty cost & 1000 & 1000 & 1000 & 1000 & 1000 \\
\hline
\end{tabular}

Table 5.8: Cases U through Z, general setting

\begin{tabular}{|c|c|c|c|}
\hline cases PQRST & $\begin{array}{c}\text { distribution } \\
\text { or operation }\end{array}$ & $\begin{array}{c}\text { mean } \\
\text { or factor }\end{array}$ & exp. value \\
\hline \hline step 1 & normal & $\mu=10$ & 10 \\
\hline step 2 & multiply with normal & $\mathrm{N}(2, \sigma)$ & 20 \\
\hline step 3 & add normal & $\mu=10$ & 30 \\
\hline step 4 & multiply with normal & $\mathrm{N}(4 / 3, \sigma)$ & 40 \\
\hline
\end{tabular}

Table 5.9: Cases $U / V / W$, specific setting

\begin{tabular}{|c|c|c|c|}
\hline case & $\mathrm{U}$ & $\mathrm{V}$ & $\mathrm{W}$ \\
\hline step 1 & $\sigma=0.1$ & $\sigma=0.1$ & $\sigma=0.1$ \\
\hline step 2 & $\sigma=0.01$ & $\sigma=0.05$ & $\sigma=0.1$ \\
\hline step 3 & $\sigma=0.1$ & $\sigma=0.1$ & $\sigma=0.1$ \\
\hline step 4 & $\sigma=0.01$ & $\sigma=0.05$ & $\sigma=0.1$ \\
\hline penalty cost & 1000 & 1000 & 1000 \\
\hline
\end{tabular}

Table 5.10: Cases $X / Y / Z$, specific setting

\begin{tabular}{|c|c|c|c|}
\hline case & $\mathrm{X}$ & $\mathrm{Y}$ & $\mathrm{Z}$ \\
\hline step 1 & $\sigma=0.2$ & $\sigma=0.2$ & $\sigma=0.2$ \\
\hline step 2 & $\sigma=0.01$ & $\sigma=0.05$ & $\sigma=0.1$ \\
\hline step 3 & $\sigma=0.2$ & $\sigma=0.2$ & $\sigma=0.2$ \\
\hline step 4 & $\sigma=0.01$ & $\sigma=0.05$ & $\sigma=0.1$ \\
\hline penalty cost & 1000 & 1000 & 1000 \\
\hline
\end{tabular}


Table 5.11: Fixed parameters for all cases

\begin{tabular}{|c|c|c|}
\hline & test cost & rework cost \\
\hline step 1 & 1 & 100 \\
\hline step 2 & 1 & 200 \\
\hline step 3 & 1 & 300 \\
\hline step 4 & 1 & 400 \\
\hline \hline lower specification & 39.6 \\
\hline \multicolumn{2}{|c|}{ upper specification } & 40.4 \\
\hline
\end{tabular}

\subsection{Discussion}

\subsubsection{The additive cases (A through $J)$ : general observations}

A quick glance at the top section of Table 5.12 leads to the following general observations:

- If a form of inspection is selected after the final process stage, the selected inspection limits almost coincide with the specification limits (39.6, 40.4). This illustrates the capability of the EA/2stat algorithm (which has the ability to select its own inspection limits for each stage) to find cost optimal inspection strategies - at least for the final stage.

- Apparently for this group of processes, it is never worthwhile to perform inspection after the second process stage, regardless of process and cost parameters. Inspection after the third process stage is only justified in specific cases (very high relative penalty cost, case $\mathrm{E}$; relatively large process variation added specifically in stage 3, case $\mathrm{H}$ )

- Diverse inspection strategies are opted for after stage 1; in a lot of cases it does apparently pay off to counter variation, one way or another, already at such an early stage in the process. 
Table 5.12: Winners

\begin{tabular}{|c|c|c|c|c|c|}
\hline case & \multicolumn{4}{|c|}{ winner solution vector } & TIC \\
\hline $\mathrm{A}$ & $N$ & $N$ & $N$ & $N$ & 42320 \\
\hline $\mathrm{B}$ & $S_{9.940 ॥ 0}^{10.060 ॥ 25}$ & $N$ & $N$ & $F_{39.595}^{40.405}$ & 229623 \\
\hline $\mathrm{C}$ & $F_{9.988}^{10.012}$ & $N$ & $N$ & $F_{39.595}^{40.405}$ & 1601070 \\
\hline $\mathrm{D}$ & $S_{9.790 ॥ 1}^{10.210 ॥ 100}$ & $N$ & $N$ & $S_{39.592 » 1}^{40.402 ॥ 50}$ & 294652 \\
\hline $\mathrm{E}$ & $F_{9.929}^{10.071}$ & $N$ & $F_{28.566}^{31.434}$ & $F_{39.5957}^{40.403}$ & 2042840 \\
\hline $\mathrm{F}$ & $F_{9.834}^{10.166}$ & $N$ & $N$ & $S_{39.583 ॥ 0}^{40.417 \| 25}$ & 163121 \\
\hline $\mathrm{G}$ & $S_{9.966 ॥ 0}^{10.034 ॥ 25}$ & $N$ & $N$ & $F_{39.594}^{40.406}$ & 879159 \\
\hline $\mathrm{H}$ & $S_{9.835 ॥ 1}^{10.165 ॥ 100}$ & $N$ & $F_{29.575}^{30.425}$ & $N$ & 106446 \\
\hline $\mathrm{I}$ & $N$ & $N$ & $N$ & $F_{39.582}^{40.418}$ & 197724 \\
\hline $\mathrm{J}$ & $N$ & $N$ & $N$ & $F_{39.589}^{40.411}$ & 149304 \\
\hline $\mathrm{K}$ & $S_{9.911 ॥ 0}^{10.089 ॥ 50}$ & $N$ & $N$ & $N$ & 38718 \\
\hline $\mathrm{L}$ & $F_{9.954}^{10.046}$ & $N$ & $N$ & $N$ & 78168 \\
\hline $\mathrm{M}$ & $F_{9.972}^{10.018}$ & $N$ & $N$ & $S_{39.169 \text { ॥ } 0}^{40.831 ॥ 25}$ & 210125 \\
\hline $\mathrm{N}$ & $F_{9.953}^{10.047}$ & $N$ & $N$ & $N$ & 80716 \\
\hline $\mathrm{O}$ & $F_{9.912}^{10.088}$ & $N$ & $N$ & $N$ & 67394 \\
\hline $\mathrm{P}$ & $F_{9.938}^{10.062}$ & $N$ & $N$ & $S_{39.558 ॥ 1}^{40.442 \text { ॥ } 100}$ & 437244 \\
\hline Q & $N$ & $N$ & $N$ & $F_{39.594}^{40.406}$ & 823800 \\
\hline $\mathrm{R}$ & $N$ & $N$ & $N$ & $F_{39.602}^{40.398}$ & 887324 \\
\hline $\mathrm{S}$ & $N$ & $N$ & $N$ & $F_{39.559}^{40.441}$ & 843576 \\
\hline $\mathrm{T}$ & $S_{9.968 ॥ 1}^{10.032 » 50}$ & $N$ & $N$ & $S_{39.581 ॥ 1}^{40.419 » 50}$ & 454260 \\
\hline $\mathrm{U}$ & $N$ & $N$ & $N$ & $S_{39.530 ॥ 0}^{40.470 ॥ 25}$ & 320795 \\
\hline $\mathrm{V}$ & $N$ & $N$ & $N$ & $S_{39.595 ॥ 0}^{40.405 ॥ 25}$ & 777465 \\
\hline $\mathrm{W}$ & $N$ & $N$ & $N$ & $F_{39.594}^{40.406}$ & 860468 \\
\hline $\mathrm{X}$ & $S_{9.959 \text { ॥ } 0}^{10.041 ॥ 25}$ & $N$ & $N$ & $S_{39.565 ॥ 0}^{40.4035 ॥ 25}$ & 422702 \\
\hline $\mathrm{Y}$ & $N$ & $N$ & $N$ & $F_{39.549}^{40.451}$ & 786644 \\
\hline $\mathrm{Z}$ & $N$ & $N$ & $S_{26.513 ॥ 1}^{33.487 ॥ 100}$ & $S_{39.556 \text { ॥ } 100}^{40.444 » 100}$ & 864012 \\
\hline
\end{tabular}




\subsubsection{Case $A$, the additive base case}

The cost optimal inspection strategy for case A seems to be not to perform inspection whatsoever. Moreover, the statistical analysis (discussed in Appendix 4.B) shows that this NNNN solution does differ significantly from all other candidate solutions, and thus it can rightfully claim the title of "best" solution for case A.

\subsubsection{Comparison of case $A$ to cases $B$ and $C$}

Cases B and C differ only from case A in penalty cost (see Table 5.2). An immediate effect of these higher penalty costs on the optimal inspection strategy is that full inspection after the final process stage becomes worthwhile for cases B and C.

And apparently, inspection after the first process stage also pays off. For case B the cheapest $(25,0)$ sampling plan is chosen, while for case C, where the penalty cost is raised even higher, full inspection after the first stage is opted for.

\subsubsection{Comparison of case $A$ to cases $D$ and $E$}

Case D introduces larger process variation (the standard deviation is doubled from 0.1 to 0.2 in all process stages). The outcome on the inspection strategy is the introduction of sampling inspection after the first and last process stage, compared to the NNNN strategy of case A.

For case E, which has the same process variation as case D but a higher penalty cost, performing even more inspection is paying off: full inspection after three of the four process stages is cost optimal.

Comparing cases $\mathrm{A}$ and $\mathrm{D}$, and cases $\mathrm{B}$ and $\mathrm{E}$ in pairs (both pairs have equal penalty costs but different process variation) nicely shows the combined influence of the cost and process parameters on the inspection strategy.

\subsubsection{Comparison of cases $F, G, H, I$ and $J$}

Cases F, G and I have larger process variation than case A, but, unlike cases $\mathrm{D}$ and $\mathrm{E}$, not in all process stages. Case $\mathrm{H}$ and $\mathrm{J}$ have larger process 
variation in 2 stages, and reduced process variation in the other 2 process stages (see Table 5.3).

Cases F and G are the same but for the penalty cost. The effect of the raise in penalty cost is a justification of full inspection after the final process stage for case $\mathrm{G}$ compared to sampling inspection for case $\mathrm{F}$.

Final full inspection is selected in cases G, I and J. For case G the justification is the higher penalty cost, while for cases I and J large variation is added in the final stage, so it makes sense to have full inspection there. In case $\mathrm{H}$, large inspection is added in process stage 3, while the final process stage brings quasi no extra variation. This is reflected in the optimal strategy for case $\mathrm{H}$ where full inspection after stage 3 is selected and the final stage is left uninspected.

In cases $\mathrm{B}$ through $\mathrm{H}$, in each case some form of inspection after stage 1 is selected; in cases I and $\mathrm{J}$ not. For case I and $\mathrm{J}$, a form of inspection after stage 2, where large process variation is introduced, could be expected, but this is not confirmed in the results. Cost-wise it apparently suffices to sort it all out after the final process stage.

Specifically comparing case A to case $\mathrm{J}$ shows that the extra variation introduced in stages 2 and 4 of case I, compared to case A, justifies final inspection, but not inspection after stage 2 . Including case $\mathrm{J}$ in this comparison shows that the reduction in variation for stages 1 and 3 of case J, compared to case I, cannot compensate for the large variation that is added anyhow in stage 4 and thus cannot render the final inspection superfluous.

\subsubsection{The multiplicative cases ( $\mathrm{K}$ through $\mathrm{T}$ ): general observa- tions}

In cases $\mathrm{K}$ through $\mathrm{O}$, process multiplication is established by multiplying the values from the previous step with a constant multiplier, and adding noise afterwards. In cases $\mathrm{P}$ through $\mathrm{T}$, the multiplier is not a constant, but a number drawn from a normal distribution (with mean: the desired multiplication factor, and (small) standard deviation: acting as noise). See Tables 5.4, 5.5, 5.6 and 5.7.

General observations:

- Cases K through T: apparently for this entire group of processes, 
it is never worthwhile to perform inspection after the second and third process stages, regardless of process and cost parameters.

- Cases K through O: a form of inspection after the first stage is always selected. This first stage thus apparently already brings so much variation in the process (relative to the other stages) that inspection after this stage pays off.

- cases P through T: a form of final inspection is always selected. Again, the selected inspection limits almost coincide with the specification limits $(39.6,40.4)$.

\subsubsection{Comparison of cases $K, L, M, N$ and $O$}

In the base case $\mathrm{K}$, the least process variation is induced. This results in the cheapest and least stringent inspection strategy: sampling inspection only after the first process stage (where the largest variation is induced and the rework cost is the lowest). The additional (smaller) variation added in the latter stages cannot justify any inspection further down the process line.

In cases $\mathrm{L}$ and $\mathrm{M}$ the added variation in the latter stages is increased. This has as -on first thought unexpected- effect that the inspection after stage 1 is tightened to full inspection. But as full inspection after stage 1 implies a tighter distribution to start with for the consecutive process stages, this effect is explained together with the knowledge that the rework cost is the lowest after stage 1 .

For case $\mathrm{M}$ (the case with the largest process variation of the three cases $\mathrm{K}, \mathrm{L}$ and $\mathrm{M}$ ) an additional final sampling inspection is selected on top of full inspection after stage 1. This is the only final inspection for which the inspection limits do not approximate to the specification limits. Given the process variation pattern, the choice for a final inspection is not unexpected, but the selected inspection limits are. Lacking a logical explanation, this is attributed to a possible flaw in the algorithm: an occasional entrapment in a local, sub-optimal solution. For any metaheuristic, there will always be a trade off between computation time and solution quality. Tightening algorithm EA/2stat to prevent an occasional local entrapment is possible, and not even extremely difficult, but at cost of 
(seriously) lengthening computation time. And, as any solution provided by (meta)heuristic algorithms should be scrutinized by the end-user (who is, or at least should be, a process specialist) before implementation, this kind of flaw should be discovered in solution analysis.

In case $\mathrm{N}$ process variation in stages 2 and 4 is reduced compared to case $\mathrm{M}$, the effect is that final inspection is no longer justified (in case $\mathrm{N}$ the optimal strategy is quasi identical to the selected strategy for case L, and also the TIC is similar. The way of adding process variance in the latter stages (evenly for case K, unevenly for case N) thus seems to have no impact on the inspection strategy, as long as the total added variance does not exceed a certain threshold). For case O, which is similar to case $\mathrm{K}$ but for the first stage, a similar inspection strategy is suggested, with tightened full inspection after stage 1.

\subsubsection{Comparison of cases $P, Q, R, S$ and $T$}

In base case $\mathrm{P}$ an FNNS optimal inspection strategy is proposed. In case $\mathrm{T}$, which is similar except for stage 1, an SNNS strategy is selected. It is counter-intuitive that sampling inspection after stage 1 suffices in case $\mathrm{T}$ (where stage 1 has larger variation) whereas in case $\mathrm{P}$ full inspection after stage 1 is selected. However, when the solution output is scrutinized, it is found that the "second best" solution for case $\mathrm{P}$ is, in vector notation:

$$
\left[S_{9.945 ॥ 1}^{10.055 » 100} \quad N \quad N \quad S_{39.558 » 1}^{40.44 » 100}\right]
$$

with $T I C=438124$. Moreover, the statistical analysis shows that the "winner" is not significantly distinguishable from the "second best".

Cases Q, R and $\mathrm{S}$ all show a similar NNNF optimal strategy. The added process variation compared to case $\mathrm{P}$ thus has the effect of shifting the final inspection from $\mathrm{S}$ to $\mathrm{F}$, but simultaneously of rendering inspection after stage 1 superfluous. Within cases $\mathrm{Q}, \mathrm{R}$ and $\mathrm{S}$, the manner in adding variation has no effect on the optimal inspection strategy (cfr. cases $\mathrm{K}$ and $\mathrm{N}$ ). For case $\mathrm{S}$, an inspection after stage 3 instead of after stage 4 could be expected (as in case $\mathrm{H}$ ), but this is not confirmed. Apparently the added variation through multiplication in stage 4 justifies postponing inspection for case $\mathrm{S}$, even if this implies higher rework costs (400 after stage 4 versus 300 after stage 3 ). 


\subsubsection{Comparison of cases $U, V, W, X, Y, Z$}

For the "mixed" cases U through W only final inspection is selected. In cases $\mathrm{U}$ and $\mathrm{V}$ final sampling inspection suffices, while in case $\mathrm{W}$ (the most process variation) final full inspection is justified. In case X, the larger variation of process stage 1 justifies sampling inspection there, supplemented with a final sampling inspection. For case Y, inspection after the first stage is omitted but the final sampling inspection is replaced with a full inspection. For case $\mathrm{Z}$, the larger process variation of stage 3 apparently justifies sampling inspection there, after which a final sampling inspection suffices.

\subsection{Note on the statistical significance of the results}

Unless stated otherwise, all winner solutions were different from the other solutions (in the population of the final generation) in a statistically significant manner, as discussed in 4.B. Families of simultaneous confidence intervals as described by Equations 4.23 are calculated for all final populations, they can be visualized as in Figure 5.1.

In Figures like these, the winning solution is compared to the other solutions in the last generation the evolutionary algorithm has reached. The dots indicate the paired mean differences, while the streak indicates the confidence interval. When none of these confidence intervals contain 0 , it can be inferred that the winning solution significantly differs from the other solutions (for figure clarity, only the first (best) 25 of the 49 other solutions are taken). Figure 5.2 shows the results for case $\mathrm{P}$, where the winning solution does not differ significantly from the second best solution.

An example of EA/2stat output files is listed in Appendix A. 


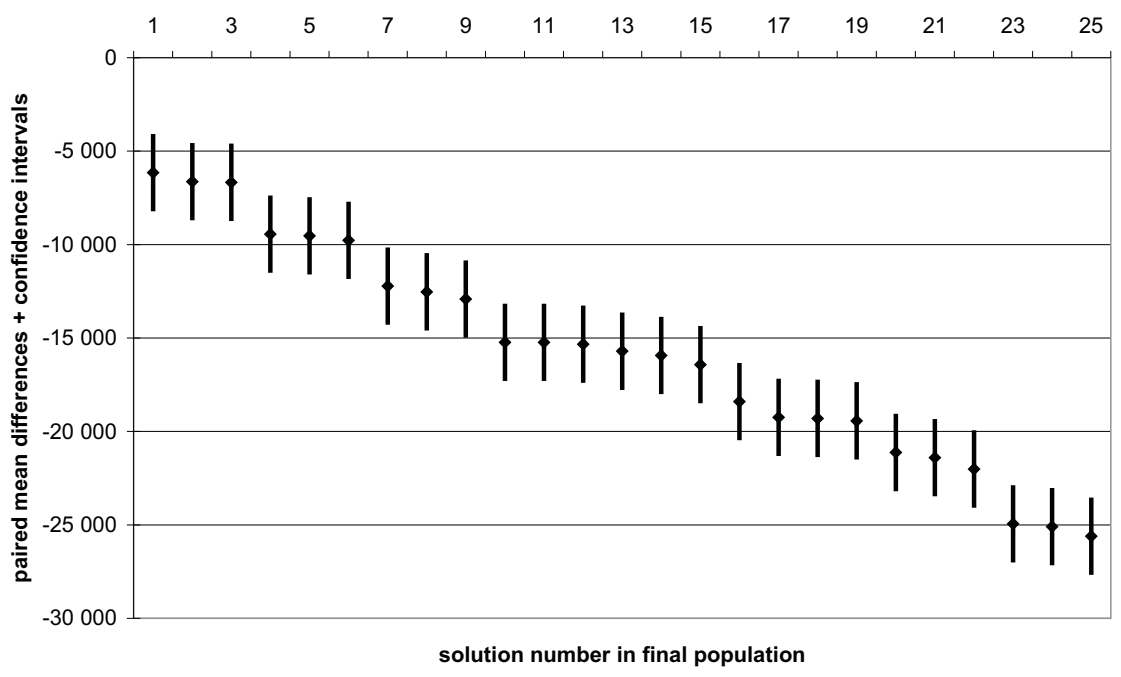

Figure 5.1: Paired mean differences between solutions, and their confidence intervals: case $B$

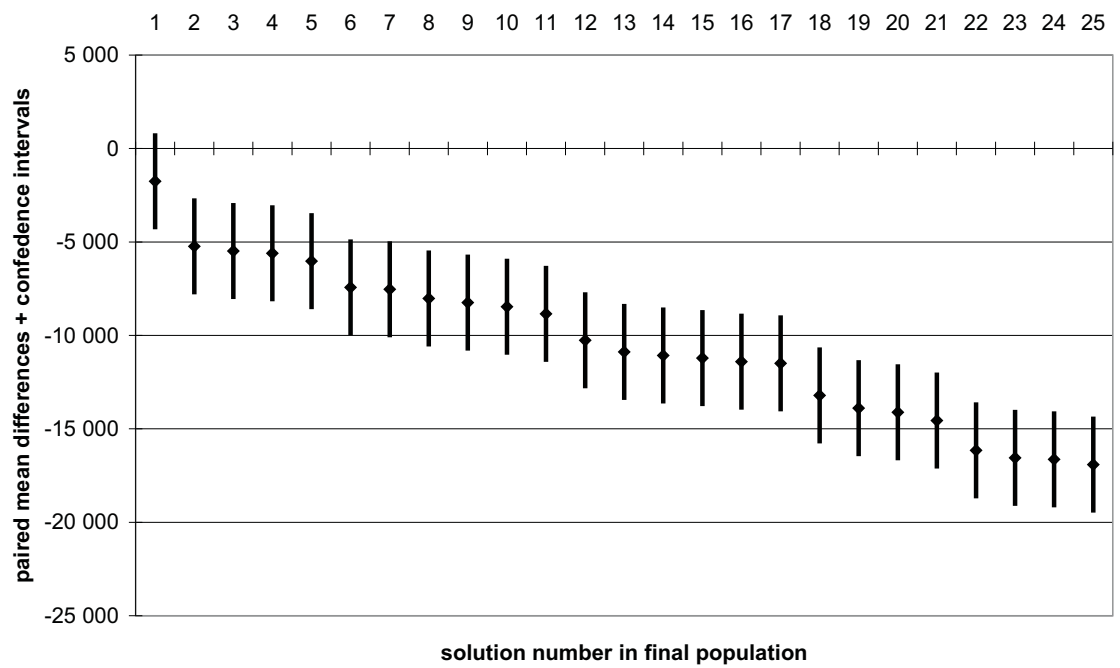

Figure 5.2: Paired mean differences between solutions, and their confidence intervals: case $P$ 


\section{Chapter 6}

\section{concluding comments and suggestions for further research}

\subsection{Concluding comments}

Efficient production quality control is a major issue to manufacturers. Most production processes consist of a sequence of production stages. Each stage (but the last) produces input for the next production stage. As the production processes at each stage are generally stochastic in nature, deviations from product specifications occur, which, without intervention, will accumulate in the course of the production process. Quality inspection only at the last stage could therefore result in a large number of faulty products and high rework and scrap costs.

An optimal inspection strategy for a so-called serial multistage production system (MSPS) has to decide on (i) the number and location of inspection stations, (ii) the size of the production fraction subject to inspection (sample size) and (iii) the rigor of the inspections (acceptance limits) at each inspection station that minimize total expected inspection costs.

To our best of knowledge, this dissertation contains the first method for jointly optimizing the number and location of inspection stations, their inspection type, inspection limits and inspection sampling parameters. In the proposed EA/2stat metaheuristic, simulation is used to model the multistage production system subject to inspection and to calculate the 
resulting inspection costs, an evolutionary algorithm is suggested to optimize the inspection strategies. Computational testing illustrates potential of the metaheuristic for optimizing quality inspection. The development of this method has already given rise to two international publications (Van Volsem et al. (2006), Van Volsem and Van Landeghem (2003)).

\subsection{Suggestions for further research}

As in every $\mathrm{PhD}$ project, more questions are raised in the process of the research than there are questions answered. Where this dissertation ends, a dozen others could take off. The most natural continuations are in the area of the algorithm; it can certainly be further improved and extended.

Currently, an extension incorporating asymmetrical inspection limits and imperfect inspection is being developed.

A further important extension could be to adapt the algorithm so that instead of just a single quality characteristic, multiple quality characteristics could simultaneously be dealt with.

Other extensions could accommodate features such as a dynamic determination of the number of simulation runs or the number of generations, in order to optimize computation time.

On a higher level, a new version could explicitly include minimum quality levels (i. e. specifications) for (some of) the intermediate process stages, instead of only dealing with final specifications. This would allow tackling even more complex process chains, or allow connecting a sequence of related processes. On the other hand, this would inadvertently also seriously complicate matters, as this implies a multi-criterium decision, and thus involves an entirely new domain of research.

Of course, the nature of the algorithm's search can also be further explored. It is likely that other (most likely hybrid-type) metaheuristics are also capable of efficiently tackling the MSPS inspection optimization problem, and this certainly deserves some attention. The algorithm in its current form could also benefit from adding some sort of local search after the global evolutionary search.

Another obvious continuation of this research is in its application: validation of the $\mathrm{EA} / 2$ stat algorithm through a real-life case study in a process environment could lead to a lot of new insights. In fact, the first 
steps towards performing real-life case studies are already laid out; two major companies (dairy industry and soft drink industry) have already shown interest and have agreed on trial studies.

Further research is also needed on developing test sets or designing problem instances for evaluating solution approaches for optimizing inspection strategies for multistage processes. In other areas of operations research, for instance in vehicle routing, different standard test sets are available against which potential new metaheuristics can be benchmarked or at least easily compared to other solution approaches. A comparable test environment concept for MSPS quality inspection optimization would certainly be nice to have. 



\section{Part III}

\section{appendices}





\section{Appendix A}

\section{EA2/stat output: an example}

\section{A.1. Results file: final generation}

Below two final generation files are listed. 50 solutions are summed up, in order of ascending TIC (for the second example, only the first (best) 25 solutions are displayed).

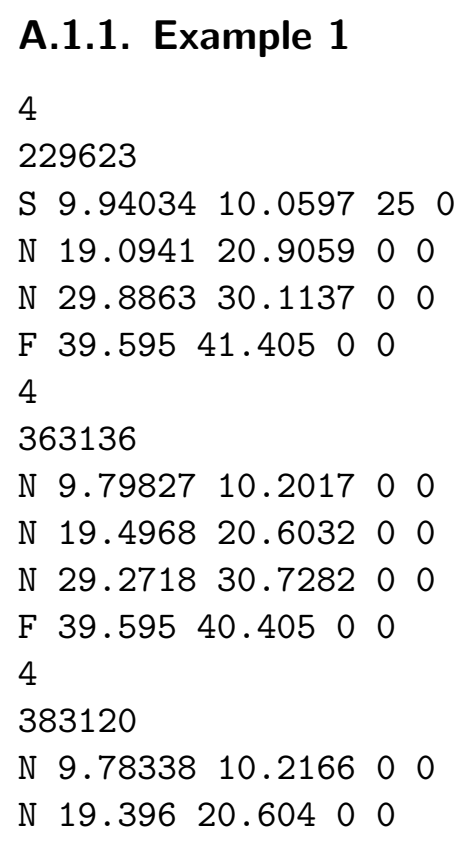




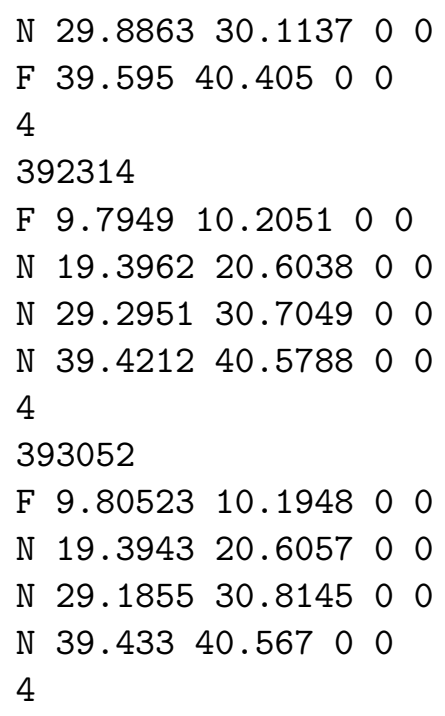




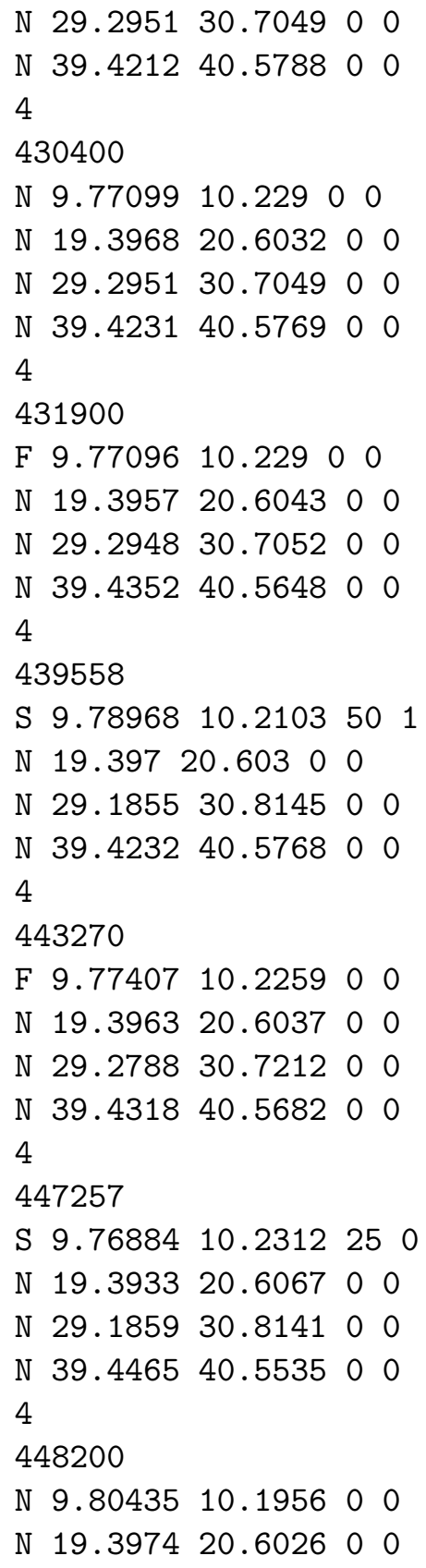




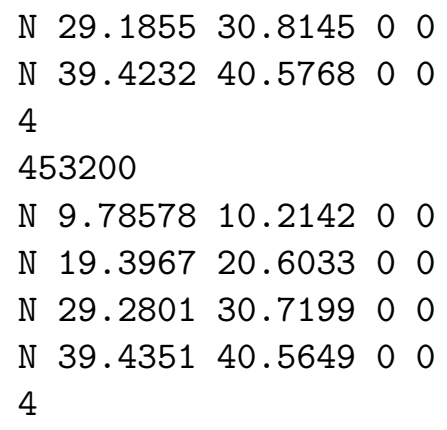




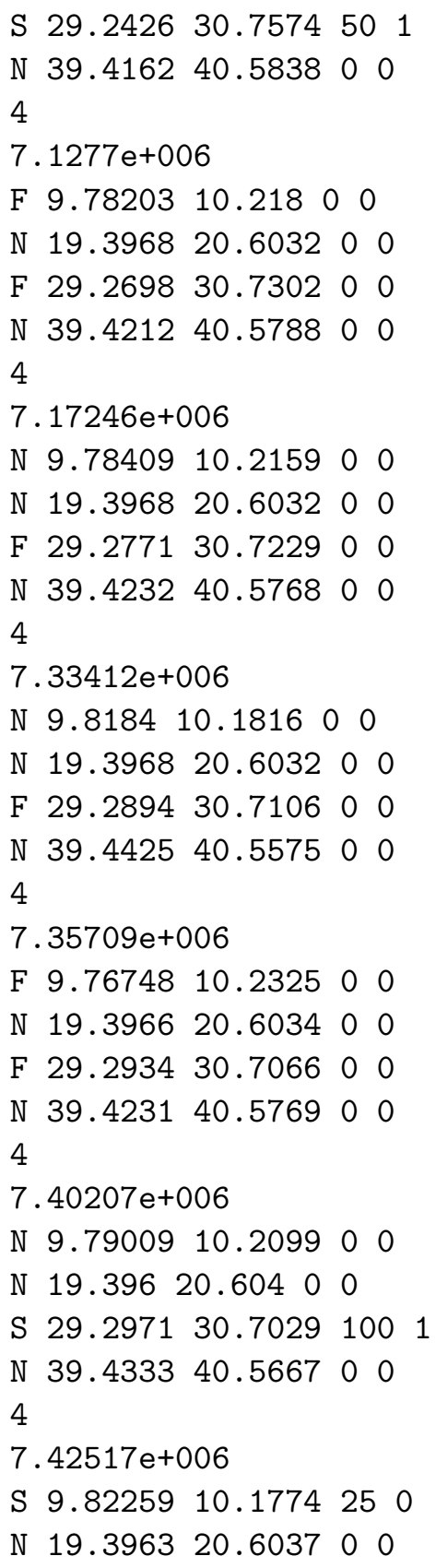




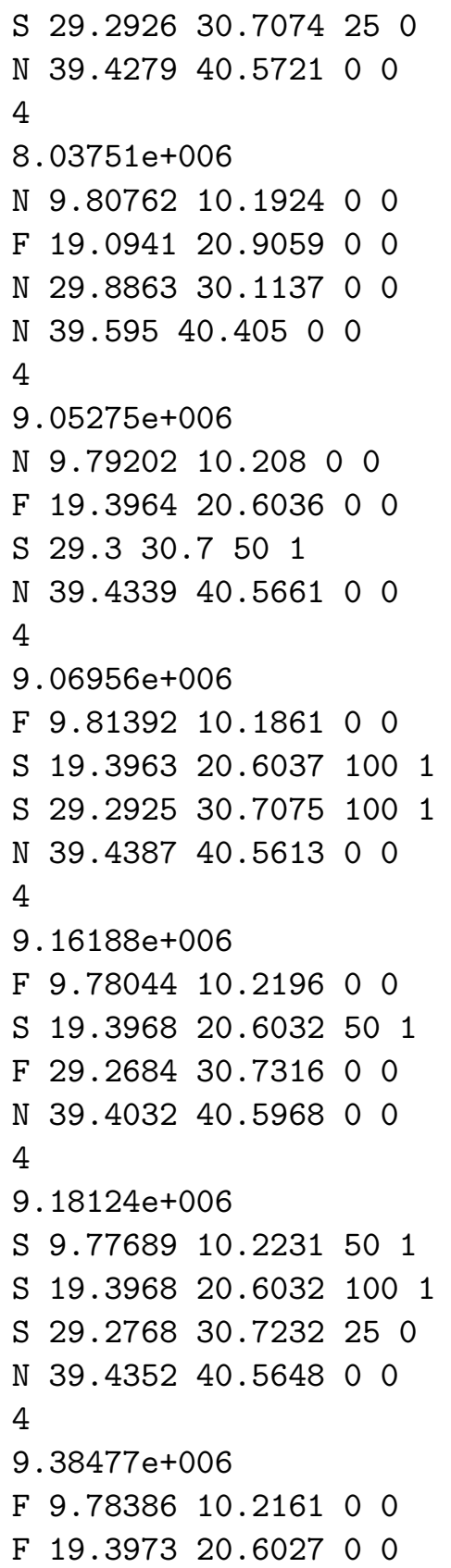




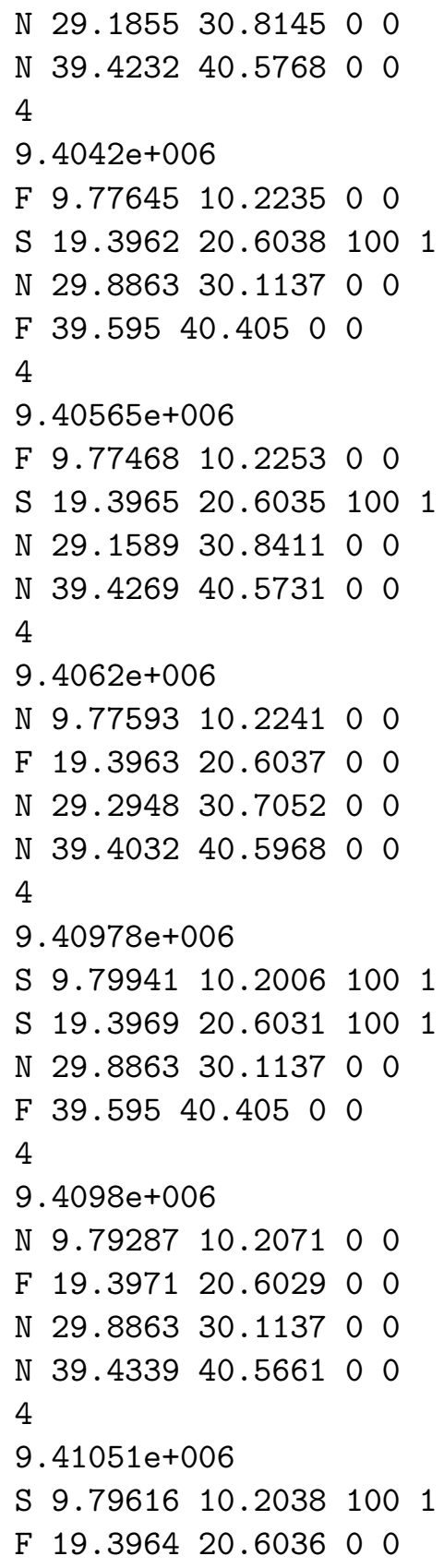




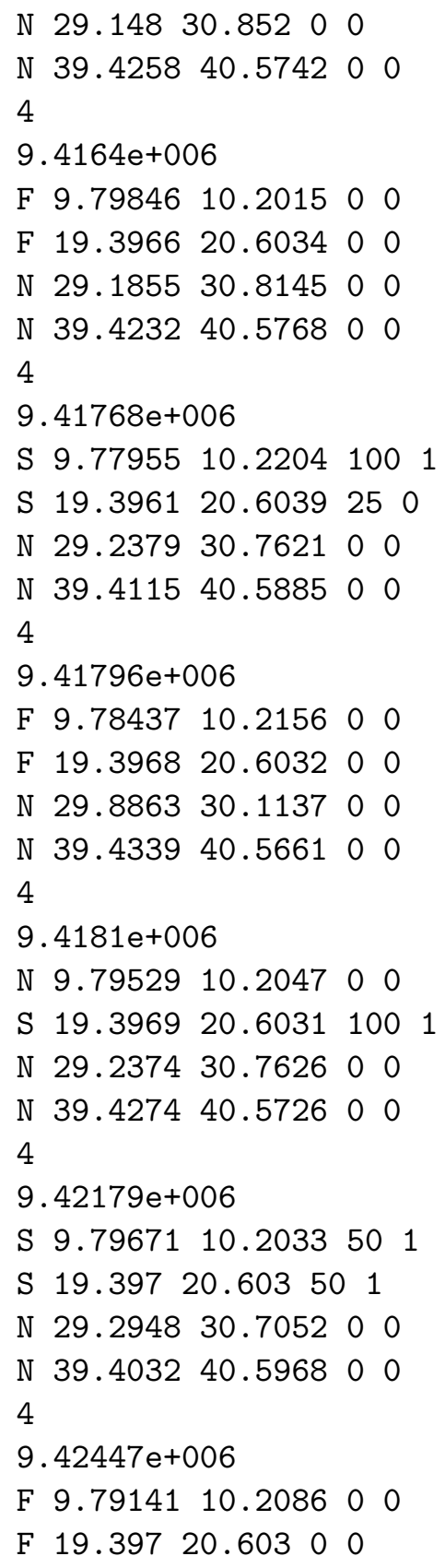




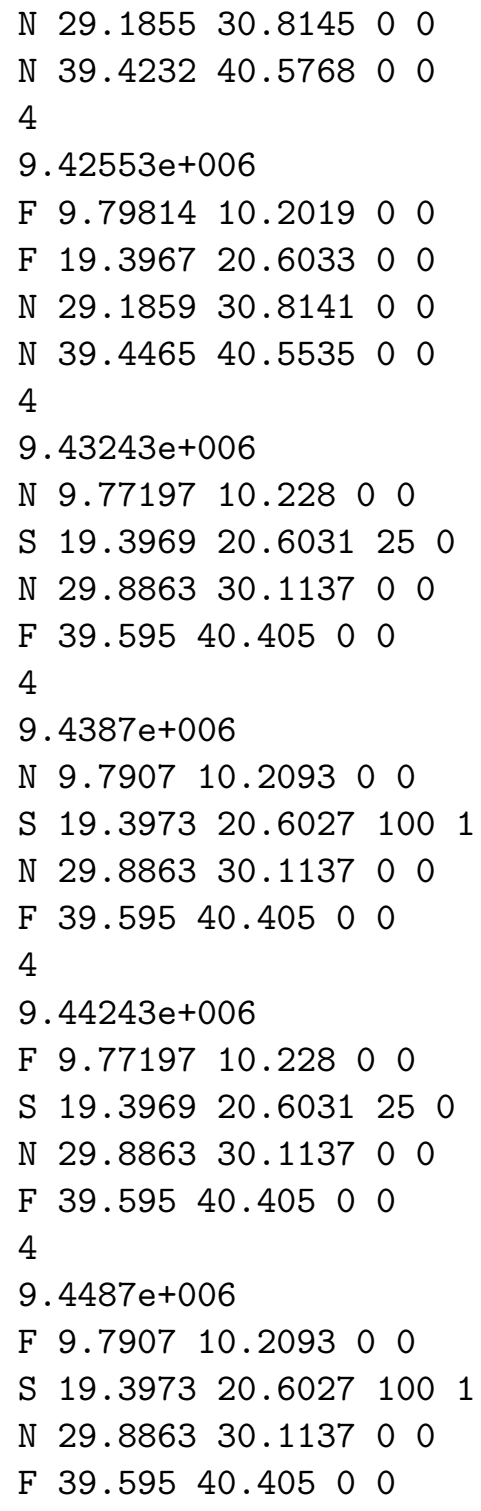




\section{A.1.2. Example 2}

4

163121

F 9.8336310 .166400

N $19.320620 .6794 \quad 0 \quad 0$

N $29.4913 \quad 30.508700$

S 39.583340 .4167250

4

180794

F 9.9301810 .069800

N 19.373720 .626300

N 29.49930 .50100

N $39.888640 .1114 \quad 0 \quad 0$

4

181216

F 9.9380110 .06200

N 19.379220 .620800

N 29.498930 .501100

N $39.801340 .1987 \quad 0 \quad 0$

4

181339

S 9.9365810 .06341001

N $19.377320 .6227 \quad 0 \quad 0$

N $29.4913 \quad 30.5087 \quad 0 \quad 0$

S 39.583340 .4167250

4

181958

S 9.9322410 .0678501

N 19.377920 .622100

N 29.498630 .501400

N 39.72940 .27100

4

182156

F 9.93810 .06200

N 19.381220 .618800

N $29.498630 .5014 \quad 00$

$.144 \ldots$ 


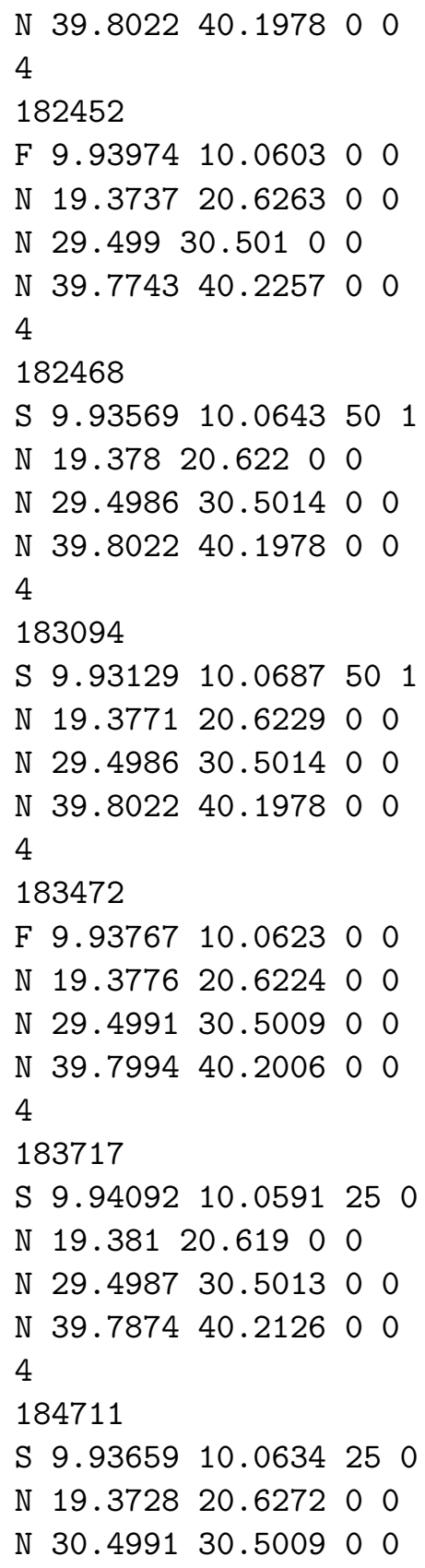




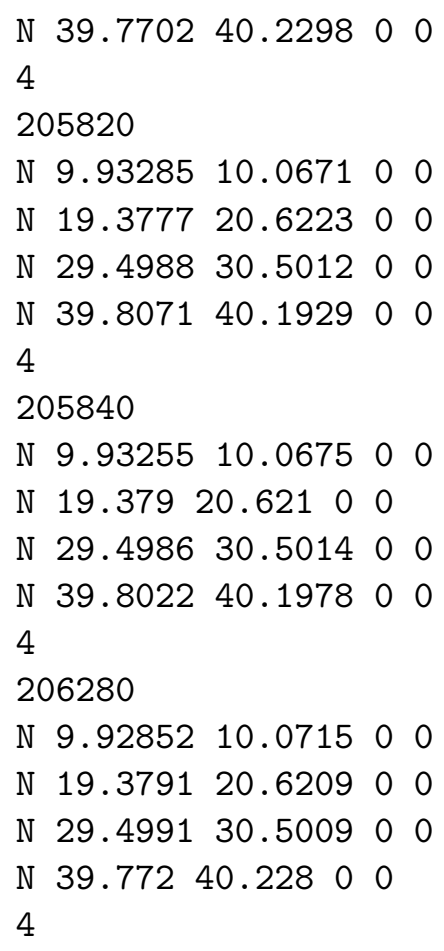

$.146 \ldots$ 


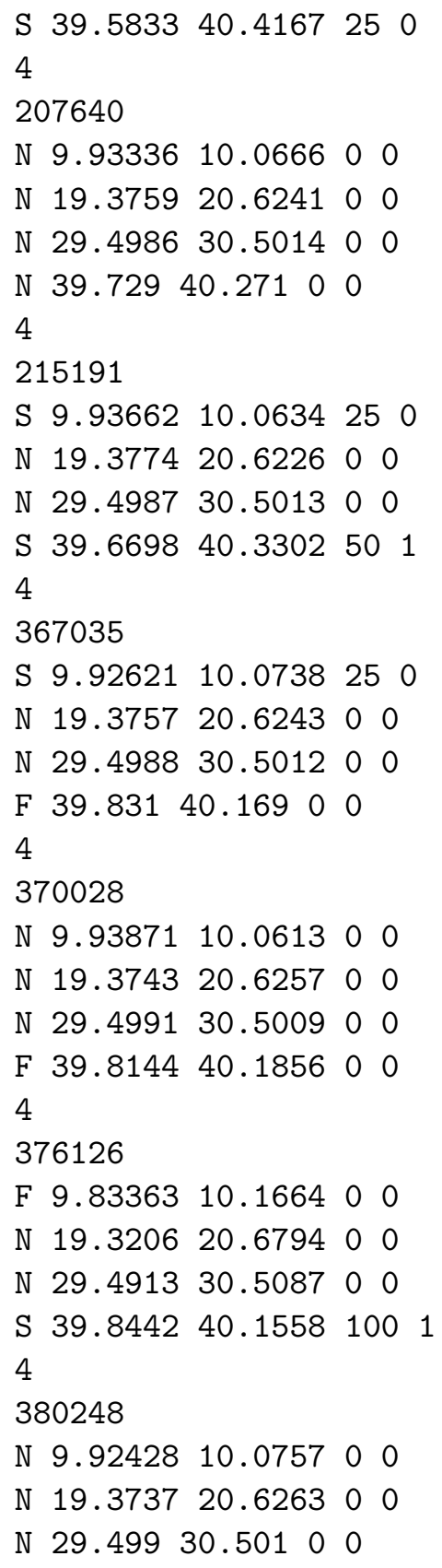




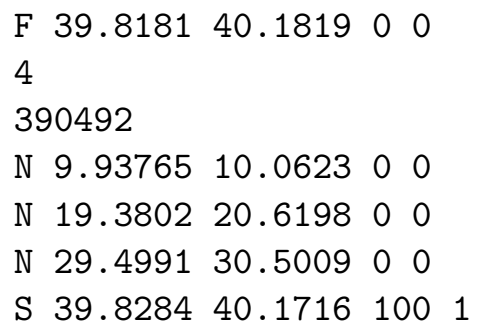

\section{A.2. Results file: statistical analysis}

Below the two corresponding statistical analysis results files are listed. There are 49 lines ( 24 for the second example): the winning solution is compared to all 49 other solutions in the final generation. The first figure is the paired mean difference, the second and third figures are the high and low bounds of the (simultaneous) confidence interval (see Section 4.B, Formulas 4.23).

\section{A.2.1. Example 1}

$\begin{array}{lcc}-133513 & -27914.4 & -239112 \\ -153497 & -47898.4 & -259096 \\ -162691 & -57092.4 & -268290 \\ -163429 & -57830.4 & -269028 \\ -164645 & -59046.4 & -270244 \\ -173205 & -67606.4 & -278804 \\ -186361 & -80762.4 & -291960 \\ -195985 & -90386.4 & -301584 \\ -200777 & -95178.4 & -306376 \\ -202277 & -96678.4 & -307876 \\ -209935 & -104336 & -315534 \\ -213647 & -108048 & -319246 \\ -217634 & -112035 & -323233 \\ -218577 & -112978 & -324176 \\ -223577 & -117978 & -329176 \\ -225069 & -119470 & -330668 \\ -226177 & -120578 & -331776\end{array}$

$\cdot 148 \cdots$ 
Section A.2. Results file: statistical analysis

$\begin{array}{lll}-231777 & -126178 & -337376 \\ -231977 & -126378 & -337576 \\ -6.59077 e+006 & -6.48517 e+006 & -6.69637 e+006 \\ -6.89808 e+006 & -6.79248 e+006 & -7.00368 e+006 \\ -6.94284 e+006 & -6.83724 e+006 & -7.04844 e+006 \\ -7.1045 e+006 & -6.9989 e+006 & -7.21009 e+006 \\ -7.12746 e+006 & -7.02186 e+006 & -7.23306 e+006 \\ -7.17245 e+006 & -7.06685 e+006 & -7.27805 e+006 \\ -7.19555 e+006 & -7.08995 e+006 & -7.30115 e+006 \\ -7.80789 e+006 & -7.70229 e+006 & -7.91349 e+006 \\ -8.82312 e+006 & -8.71752 e+006 & -8.92872 e+006 \\ -8.83994 e+006 & -8.73434 e+006 & -8.94553 e+006 \\ -8.93226 e+006 & -8.82666 e+006 & -9.03786 e+006 \\ -8.95161 e+006 & -8.84601 e+006 & -9.05721 e+006 \\ -9.15514 e+006 & -9.04954 e+006 & -9.26074 e+006 \\ -9.17458 e+006 & -9.06898 e+006 & -9.28018 e+006 \\ -9.17603 e+006 & -9.07043 e+006 & -9.28162 e+006 \\ -9.17658 e+006 & -9.07098 e+006 & -9.28218 e+006 \\ -9.18015 e+006 & -9.07455 e+006 & -9.28575 e+006 \\ -9.18018 e+006 & -9.07458 e+006 & -9.28578 e+006 \\ -9.18089 e+006 & -9.07529 e+006 & -9.28649 e+006 \\ -9.18678 e+006 & -9.08118 e+006 & -9.29237 e+006 \\ -9.18805 e+006 & -9.08246 e+006 & -9.29365 e+006 \\ -9.18834 e+006 & -9.08274 e+006 & -9.29393 e+006 \\ -9.18848 e+006 & -9.08288 e+006 & -9.29408 e+006 \\ -9.19217 e+006 & -9.08657 e+006 & -9.29776 e+006 \\ -9.19485 e+006 & -9.08925 e+006 & -9.30045 e+006 \\ -9.19591 e+006 & -9.09031 e+006 & -9.30151 e+006 \\ -9.2028 e+006 & -9.0972 e+006 & -9.3084 e+006 \\ -9.20908 e+006 & -9.10348 e+006 & -9.31468 e+006 \\ -9.2128 e+006 & -9.1072 e+006 & -9.3184 e+006 \\ -9.21908 e+006 & -9.11348 e+006 & -9.32468 e+006\end{array}$




\section{A.2.2. Example 2}

$\begin{array}{lll}-17673.0 & -437.7 & -34908.3 \\ -18095.0 & -859.7 & -35330.3 \\ -18218.0 & -982.7 & -35453.3 \\ -18837.0 & -1601.7 & -36072.3 \\ -19035.0 & -1799.7 & -36270.3 \\ -19331.0 & -2095.7 & -36566.3 \\ -19347.0 & -2111.7 & -36582.3 \\ -19973.0 & -2737.7 & -37208.3 \\ -20351.0 & -3115.7 & -37586.3 \\ -20596.0 & -3360.7 & -37831.3 \\ -21590.0 & -4354.7 & -38825.3 \\ -42699.0 & -25463.7 & -59934.3 \\ -42719.0 & -25483.7 & -59954.3 \\ -43159.0 & -25923.7 & -60394.3 \\ -43859.0 & -26623.7 & -61094.3 \\ -44179.0 & -26943.7 & -61414.3 \\ -44480.0 & -27244.7 & -61715.3 \\ -44519.0 & -27283.7 & -61754.3 \\ -52070.0 & -34834.7 & -69305.3 \\ -203914.0 & -186678.7 & -221149.3 \\ -206907.0 & -189671.7 & -224142.3 \\ -213005.0 & -195769.7 & -230240.3 \\ -217127.0 & -199891.7 & -234362.3 \\ -227371.0 & -210135.7 & -244606.3\end{array}$




\section{Appendix B}

\section{random number generation}

When performing Monte Carlo simulation, random numbers are used. Thus, the quality of the simulation will inevitably and inherently depend on the quality of the random numbers.

Methods of generating and dealing with random numbers are well established. As it is difficult, if not impossible, to get a computer to do something by chance, all classical random number generators are based upon specific mathematical algorithms. Algorithms are repeatable in nature, and as such, the generated numbers are pseudorandom.

A lot of research has gone into pseudorandom number theory, most modern algorithms for generating them are so good that the numbers look exactly like they were truly random. Pseudorandom numbers have the characteristic that they are predictable, meaning they can be repeated if known where in the sequence the first number is taken from. For some purposes in simulation studies however, this predictability is a quality instead of a flaw.

Ideally, the sequence of pseudorandom numbers used in any Monte Carlo simulation should possess the following properties:

Uniformity - The sequence of pseudorandom numbers should be uniform and unbiased. This property of a pseudorandom number generator is expressed as its order of equidistribution. The higher the order of equidistribution, the better the generator in terms of uniformity. 
Long Period - The generator should be of long period. That is, repetition of the same sequence of pseudorandom numbers should occur as late as possible in the algorithm. The period typically is expressed as a power of 2 .

Uncorrelated sequences - Sequences of pseudorandom numbers should be serially uncorrelated: any sequence of pseudorandom numbers should not be correlated with any other sequence generated with the same generator. (All n-tuples of pseudorandom numbers generated should be mutually independent.)

Efficiency and speed - In order not to run the risk of significantly slowing down the actual simulation, the pseudorandom number generator should be fast (computation time) and efficient (use of memory).

In all versions of the EA algorithms, the random number generation is based on the Mersenne Twister algorithm.

From Wikipedia: The Mersenne twister is a pseudorandom number generator developed by Matsumoto and Nishimura (1998). It provides for fast generation of very high quality random numbers, having been designed specifically to rectify many of the flaws found in older algorithms.

There are at least two common variants of the algorithm, differing only in the size of the Mersenne primes used. The newer and more commonly used one is the Mersenne Twister MT 19937.

MT 19937 has the following desirable properties:

1. It was designed to have a colossal period of $2^{19937}-1$ (the creators of the algorithm proved this property). This period explains the origin of the name: it is a Mersenne prime, and some of the guarantees of the algorithm depend on internal use of Mersenne primes. In practice, there is little reason to use larger ones.

2. It has a very high order of dimensional equidistribution. Note that this means, by default, that there is negligible serial correlation between successive values in the output sequence.

3. It is faster than all but the most statistically unsound generators. 
4. It is statistically random in all the bits of its output, and passes the stringent Diehard tests (a battery of statistical tests for measuring the quality of a set of random numbers, developed by George Marsaglia).

How the algorithm works: The algorithm itself is a twisted generalized feedback shift register or TGFSR for short. The "twist" is a transformation which assures equidistribution of the generated numbers in 623 dimensions (linear congruential generators can at best manage reasonable distribution in 5 dimensions).

Linear congruential generators (LCGs) represent one of the oldest and best-known pseudorandom number generator algorithms. The theory behind them is easy to understand, and they are easily implemented and fast. It is, however, known that the properties of this class of generator are not ideal.

LCGs are defined by the recurrence relation:

$$
V_{i+1}=A \cdot V_{i}+B \bmod M
$$

Where $V_{n}$ is the sequence of random values and $A, B$ and $M$ are generatorspecific integer constants.

The period of a general LCG is at most $M$, and in most cases less than that. The LCG will have a full period if:

1. $B$ and $M$ are relatively prime

2. $A-1$ is divisible by all prime factors of $M$

3. $A-1$ is a multiple of 4 if $M$ is a multiple of 4

4. $M>\max \left(A, B, V_{0}\right)$

5. $A>0, B>0$

Today, with the advent of the Mersenne twister, which both runs faster than and generates higher-quality deviates than almost any LCG, only LCGs with $M$ equal to a power of 2 , most often $M=2^{32}$ or $M=$ $2^{64}$, make sense at all. These are the fastest-evaluated of all random number generators; a common Mersenne twister implementation uses it to generate seed data. 
Nevertheless, LCGs may be the only option in some cases. For instance, in an embedded system, the amount of memory available is often very severely limited.

In the simulation tool presented in 4.6 , the random numbers used are generated through an LCG with $M=2^{32}$. 


\section{Appendix C}

\section{computational complexity theory: some definitions}

The definitions used are taken from the NIST (National Institute of Standards and Technology) Dictionary of Algorithms and Data Structures:

http://www.nist.gov/dads/

and from the Computational Complexity Theory section of the Wikipedia encyclopedia:

http://en.wikipedia.org/wiki/Computational_complexity_theory

Definition C.1 (big- $\mathcal{O}$ notation). A theoretical measure of the execution of an algorithm, usually the time or memory needed, given the problem size $n$, which is usually the number of items.

Informally, saying some equation $f(n)=\mathcal{O}(g(n))$ means it is less than some constant multiple of $g(n)$.

Formally: $f(n)=\mathcal{O}(g(n))$ means there are positive constants $c$ and $k$, such that $0 \leq f(n) \leq c g(n), \forall n \geq k$. The values of $c$ and $k$ must be fixed for the function $f$ and must not depend on $n$.

Definition C.2 ( $\Theta$ notation). A theoretical measure of the execution of an algorithm, usually the time or memory needed, given the problem size $n$, which is usually the number of items.

Informally, saying some equation $f(n)=\Theta(g(n))$ means it is within a constant multiple of $g(n)$ 
Formally: $f(n)=\Theta(g(n))$ means there are positive constants $c_{1}, c_{2}$, and $k$, such that $0 \leq c_{1} g(n) \leq f(n) \leq c_{2} g(n), \forall n \geq k$. The values of $c_{1}$, $c_{2}$, and $k$ must be fixed for the function $f$ and must not depend on $n$.

Note: As an example, $n^{2}+3 n+4$ is $\mathcal{O}\left(n^{2}\right)$, since $n^{2}+3 n+4<$ $2 n^{2}, \forall n>10$. Strictly speaking, $3 n+4$ is $\mathcal{O}\left(n^{2}\right)$, too, but big- $\mathcal{O}$ is often misused to mean "equal" to rather than "less than". The notion of "equal to" is expressed by $\Theta(n)$.

The importance of this measure can be seen in trying to decide whether an algorithm is adequate, but may just need a better implementation, or the algorithm will always be too slow on a big enough input. For instance, the quicksort algorithm (see e.g. Knuth (1998)), which is $\mathcal{O}(n \log n)$ on average, running on a small desktop computer can beat the bubble sort algorithm (see e.g. Knuth (1998)), which is $\mathcal{O}\left(n^{2}\right)$, running on a supercomputer if there are a lot of numbers to sort. To sort $1,000,000$ numbers, the quicksort takes 20,000,000 steps on average, while the bubble sort takes 1,000,000,000,000 steps!

Any measure of execution must implicitly or explicitly refer to some computation model. Usually this is some notion of the limiting factor. For one problem or machine, the number of floating point multiplications may be the limiting factor, while for another, it may be the number of messages passed across a network. Other measures which may be important are compares, item moves, disk accesses, memory used, or elapsed ("wall clock") time.

Knuth (1998, p.107) uses $|f(n)| \leq c|g(n)|$. But in computational complexity theory only positive functions are considered, so the absolute value bars may be left out (definition of big- $\mathcal{O}$ notation after Cormen et al. (1990, p.26)).

Definition C.3 $(\mathcal{N P})$. The complexity class of decision problems for which answers can be checked by an algorithm whose run time is polynomial in the size of the input. Note that this doesn't require or imply that an answer can be found quickly, only that any claimed solution can be verified quickly. " $\mathcal{N} \mathcal{P}$ " is the class that a $\mathcal{N}$ ondeterministic Turing 
machine accepts in $\mathcal{P}$ olynomial time. (Also known as Nondeterministic Polynomial time.)

Definition C.4 ( $\mathcal{N P}$-complete). The complexity class of decision problems for which answers can be checked for correctness, given a certificate, by an algorithm whose run time is polynomial in the size of the input (that is, it is $\mathcal{N} \mathcal{P}$ ) and no other $\mathcal{N} \mathcal{P}$ problem is more than a polynomial factor harder. Informally, a problem is $\mathcal{N} \mathcal{P}$-complete if answers can be verified quickly, and a quick algorithm to solve this problem can be used to solve all other $\mathcal{N} \mathcal{P}$ problems quickly.

Definition C.5 ( $\mathcal{N P}$-hard). The complexity class of decision problems that are intrinsically harder than those that can be solved by a nondeterministic Turing machine in polynomial time. When a decision version of a combinatorial optimization problem is proved to belong to the class of $\mathcal{N} \mathcal{P}$-complete problems, then the optimization version is $\mathcal{N} \mathcal{P}$-hard.

Definition C.6 (strongly $\mathcal{N} \mathcal{P}$-hard). The complexity class of decision problems which are still $\mathcal{N} \mathcal{P}$-hard even when all numbers in the input are bounded by some polynomial in the length of the input.

Definition C.7 (polynomial time). When the execution time of a computation, $m(n)$, is no more than a polynomial function of the problem size, $n$. More formally $m(n)=\mathcal{O}(n k)$ where $k$ is a constant.

Definition C.8 (complexity class). Any of a set of computational problems with the same bounds $(\Theta(n))$ on time and space, for deterministic and nondeterministic machines.

Definition C.9 (decision problem). A problem with a "yes" or "no" answer. Equivalently, a function whose range is two values, such as $\{0,1\}$.

Definition C.10 (nondeterministic Turing machine). A Turing machine which has more than one next state for some combinations of contents of the current cell and current state. An input is accepted if any move sequence leads to acceptance.

Definition C.11 (Turing machine). A model of computation consisting of a finite state machine controller, a read-write head, and an 
unbounded sequential tape. Depending on the current state and symbol read on the tape, the machine can change its state and move the head to the left or right. Unless otherwise specified, a Turing machine is deterministic.

Definition C.12 (model of computation). A formal, abstract definition of a computer. Using a model one can more easily analyze the intrinsic execution time or memory space of an algorithm while ignoring many implementation issues. There are many models of computation which differ in computing power (that is, some models can perform computations impossible for other models) and the cost of various operations.

Definition C.13 (state). The condition of a finite state machine or Turing machine at a certain time. Informally, the content of memory. 


\section{Bibliography}

Acton, F. S. (1990). Numerical Methods that Usually Work, chapter 17. The Mathematical Association of America, Washington, D. C.

Angell, L. C. and Chandra, M. (2001). "Performance Implications of Investments in Continuous Quality Improvement". International Journal of Quality and Reliability Management, 21(1/2), pp. 108-125.

Arnheiter, E. and Giglio, R. J. (1998). "A Quality Cost Model to Determine Optimal Policies for Purchased Components". Quality Management Journal, 5(3), pp. 54-64.

Bai, D. S. and Yun, H. J. (1996). "Optimal Allocation of Inspection Effort in a Serial Multi-Stage Production System". Computers and Industrial Engineering, 30(3), pp. 387-396.

Ballou, D. P. and Pazer, H. L. (1982). "The Impact of Inspector Fallibility on the Inspection Policy in Serial Production Systems". Management Science, 28(4), pp. 387-399.

Barad, M. and Braha, D. (1996). "Control Limits for Multi-Stage Manufacturing Processes with Binomial Yield (Single and Multiple Production Runs)". Journal of the Operational Research Society, 47, pp. 98-112.

Barber, P., Graves, A., Hall, M., Sheath, D., and Tomkins, C. (2000). "Quality Failure Costs in Civil Engineering Projects". International Journal of Quality and Reliability Management, 17(4/5), pp. 479-492.

Bennett, G. and Gupta, L. C. (1969). "Least-cost Tolerances - I". International Journal of Production Research, 8(1), pp. 65-73. 
Bennett, G. and Gupta, L. C. (1970). "Least-cost Tolerances - II". International Journal of Production Research, 8(2), pp. 169-184.

Britney, R. R. (1972). "Optimal Screening Plans for Nonserial Production Systems". Management Science, 18(9), pp. 550-559.

Burgess, T. F. (1996). "Modelling Quality Cost Dynamics". International Journal of Quality and Reliability Management, 8(3), pp. 8-26.

Campanella, J. and the ASQC Quality Costs Committee (1990). Principles of Quality Costs. ASQC Quality Press, Milwaukee.

Cayer, C. and Puddicombe, S. (2000). "Economics of Quality in a Contract Pharmaceutical Organization". Managing Service Quality, 10(5), pp. 269-277.

Chan, L. K., Cheng, S. W., and Spiring, F. A. (1988). "A New Measure of Process Capability: Cpm". Journal of Quality Technology, 20, pp. 162-175.

Chandra, M. J. (2001). Statistical Quality Control. CRC Press.

Chen, K. S., Huang, M. L., and Li, R. K. (2001). "Process Capability Analysis for an Entire Product". International Journal of Production Research, 39(17), pp. 4077-4087.

Chen, T. J. (1999). "Quantitative Selection of Inspection Plans for Variation Risk Management". Master's thesis, Massachusetts Institute of Technology.

Clark, H. J. and Tannock, J. D. T. (1999). "The Development and Implementation of a Simulation Tool for the Assessment of Quality Economics Within a Cell-Based Manufacturing Company". International Journal of Production Research, 37(5), pp. 979-995.

Clark, K. B. and Wheelwright, S. C. (1993). Managing New Product and Process Development - text and cases. The Free Press.

Computational Science Education Project (1996). Mathematical Optimization. http://csep1.phy.ornl.gov/. 
Cormen, T. H., Leiserson, C. E., and Rivest, R. L. (1990). Introduction to Algorithms. MIT Press.

Curkovic, S., Vickery, S. K., and Droge, C. (2000). "An Empirical Analysis of the Competitive Dimensions of Quality Performance in the Automotive Supply Industry". International Journal of Quality and Reliability Management, 20(3), pp. 386-403.

Czuchry, A. J., Yasin, M. M., and Little, G. S. (1999). "A Practical, Systematic Approach to Understanding Cost of Quality: A Field Study". Industrial Management \& Data Systems, 8, pp. 362-366.

Dale, B. and Plunkett, J. J. (1991). Quality Costing. Chapman \& Hall, first edition.

Dale, B. G. and Plunkett, J. J. e. (1990). Managing Quality. Philip Allan.

De Jong, K. A. (1975). An Analysis of the Behaviour of a Class of Genetic Adaptive Systems. Ph.D. thesis, University of Michigan Press.

Del Castillo, E. and Hurwitz, A. M. (1997). "Run-to-Run Process Control: Literature Review and Extensions". Journal of Quality Technology, 29(2), pp. 184-195.

Demeulemeester, E. and Callewier, D. (1997). Integrale Kwaliteitszorg: Concepten, Methoden en Technieken. Lannoo.

Dennis Jr, J. E. and Schnabel, R. B. (1983). Numerical Methods for Unconstrained Optimization and Nonlinear Equations. Prentice-Hall, New Jersey.

Duncan, A. J. (1986). Quality Control and Industrial Statistics. Irwin, Illinois, fifth edition.

Emmons, H. E. and Rabinowitz, G. (2002). "Inspection Allocation for Multistage Deteriorating Production Systems". IIE Transactions, 34, pp. 1031-1041. 
English, J. R. and Taylor, G. D. (1993). "Process Capability Analysis - a Robustness Study". International Journal of Production Research, 31, pp. 1621-1635.

Eppen, G. D. and Hurst, Jr., E. G. (1974). "Optimal Location of Inspection Stations in a Multistage Production Process". Management Science, 20(8), pp. 1194-1200.

Feigenbaum, A. V. (1956). "Total Quality Control". Harvard Business Review, 34(6), pp. 93-101.

Fraticelli, B. P., Lehtihet, E. A., and Cavalier, T. M. (1997). "Sequential Tolerance Control in Discrete Parts Manufacturing". International Journal of Production Research, 35(5), pp. 1305-1319.

Garvin, D. (1984). "What does "Product Quality" really mean?". Sloan Management Review, 26(1), pp. 25-33.

Gerth, R. J. and Pfeifer, T. (2000). "Minimum Cost Tolerancing under Uncertain Cost Estimates". IIE Transactions, 32(6), pp. 493-504.

Gill, P. E., Murray, W., and Wright, M. (1983). Practical Optimization. Academic Press, New York.

Glover, F. (1986). "Future Paths for Integer Programming and Links to Artificial Intelligence". Computers and Operations Research, 13, pp. $533-549$.

Goldberg, D. (1989). Genetic Algorithms in Search, Optimization, and Machine Learning. Addison Wesley, NY.

Golhar, D. Y. and Pollock, S. M. (1988). "Determination of the Optimal Process Mean and the Upper Limit for a Canning Problem". Journal of Quality Technology, 20, pp. 188-192.

Grant, E. L. and Leavenworth, R. S. (1972). Statistical Quality Control. McGraw-Hill, New York.

Hansen, P. (1986). "The Steepest Ascent Mildest Descent Heuristic for Combinatorial Programming". Capri, Italy, Congress on Numerical Methods in Combinatorial Optimization. 
Hauser, J. R. and Clausing, D. (1988). "The House of Quality". Harvard Business Review, pages 63-73.

Holland, J. H. (1975). Adaptation in Natural and Artificial Systems. University of Michigan Press.

Hwang, G.-H. and Aspinwall, E. M. (1999). "The Development of a Quality Cost Model in a Telecommunications Company". Total Quality Management, 10(7), pp. 949-965.

Johnson, N. and Kotz, S. (1970). Continuous Univariate Distributions - 1. John Wiley \& Sons, Inc., Salt Lake City, Utah.

Juran, J. (1980). Quality Planning and Analysis. McGraw Hill.

Juran, J. M. and Gryna, F. M. (1993). Quality Planning and Analysis. McGraw-Hill, third edition.

Kapur, K. C. and Cho, B.-R. (1994). "Economic Design and Development of Specifications". Quality Engineering, 6(3), pp. 401-417.

Keats, J. B., Del Castillo, E., Von Collani, E., and Saniga, E. M. (1997). "Economic Modeling for Statistical Process Control". Journal of Quality Technology, 29(2), pp. 144-147.

Kirkpatrick, S., Gelatt, C. D., and Vecchi, M. P. (1983). "Optimization by Simulated Annealing". Science, 220, pp. 671-680.

Knuth, D. E. (1998). The Art of Computer Programming. AddisonWesley.

Krishnan, S. K., Agus, A., and Husain, N. (2000). "Cost of Quality: The Hidden Costs". Total Quality Management, 11(4/5/6), pp. S844-S848.

Kros, J. F. and Mastrangelo, C. M. (1998). "Impact of Nonquadratic Loss in the Taguchi Design Methodology". Quality Engineering, 10(3), pp. 509-519.

Law, A. M. and Kelton, W. D. (1982). Simulation Modeling and Analysis. McGraw-Hill, New York. 
Lee, H.-H., Chandra, M. J., and Deleveaux, V. J. (1997). "Optimal Batch Size and Investment in Multistage Production Systems with Scrap". Production Planning \& Control, 8(6), pp. 586-596.

Lindsay, G. F. and Bishop, A. B. (1964). "Allocation of Screening Inspection Effort - a Dynamic Programming Approach". Management Science, 10(2), pp. 342-352.

Maghsoodloo, S. and Huang, L.-H. (1997). "Quality Loss Functions and Performance Measures for a Mixed Bivariate Response". Benchmarking for Quality Management \& Technology, 4(2), pp. 121-147.

Maghsoodloo, S. and Li, M.-H. C. (2000). "Optimal Asymmetric Tolerance Design". IIE Transactions, 32(12), pp. 1127-1138.

Matsumoto, M. and Nishimura, T. (1998). "Mersenne twister: A 623dimensionally Equidistributed Uniform Pseudorandom Number Generator". ACM Transactions on Modeling and Computer Simulations.

Menipaz, E. (1978). "A Taxonomy of Economically Based Quality Control Procedures". International Journal of Production Research, 16(2), pp. $153-167$.

Michaelewicz, Z. and Fogel, D. B. (2000). How to Solve It: Modern Heuristics. Springer-Verlag, Berlin.

Moen, R. M. (1998). "New Quality Cost Model Used as a Top Management Tool". The TQM Magazine, 10(5), pp. 334-341.

Montgomery, D. (1991). Introduction to Statistical Quality Control. John Wiley \& sons.

Montgomery, D. C., Keats, J., Runger, G. C., and Messina, W. S. (1994). "Integrating Statistical Process Control and Engineering Process Control". Journal of Quality Technology, 26(2), pp. 79-87.

Morris, R. A. and Watson, E. F. (1997). "Determining Process Capability in a Chemical Batch Process". Quality Engineering, 10(2), pp. 389-396. 
Moskowitz, H., Plante, R., and Duffy, J. (2001). "Multivariate Tolerance Design Using Quality Loss". IIE Transactions, 33, pp. 437-448.

Osyczka, A. (2002). Evolutionary Algorithms for Single and Multicriteria Design Optimization. Physica-Verlag, Heidelberg.

Ovretveit, J. (2000). "The Economics of Quality - a Practical Approach". International Journal of Health Care Quality Assurance, 13(5), pp. 200-207.

Plante, R. D. (2001). "Process Capability: A Criterion for Optimizing Multiple Response Product and Process Design". IIE Transactions, 33, pp. 497-509.

Porter, L. J. and Rayner, P. (1992). "Quality Costing for Total Quality Management". International Journal of Production Economics, 27, pp. 69-81.

Rabinowitz, G. and Yahalom, O. (2001). "Imperfect Inspection of a Multi-Attribute Deteriorating Production System - a Continuous Time Model". Quality and Reliability Engineering International, 17, pp. 407418.

Reeves, C. R. (1993). Modern Heuristic Techniques for Combinatorial Problems. Blackwell Scientific Publications.

Sandoval-Chavez, D. A. and Beruvides, M. A. (1998). "Using Opportunity Costs to Determine the Cost of Quality: A Case Study in a Continuous-Process Industry". The Engineering Economist, 43(2), pp. $107-124$.

Silver, E. (2004). "An Overview of Heuristic Solution Methods". Journal of the Operational Research Society, 55, pp. 936-956.

Sörensen, K. (2003). A Framework for Robust and Flexible Optimisation Using Metaheuristics. PhD thesis, University of Antwerp.

Tagaras, G. (1996). "Dynamic Control Charts for Finite Production Runs". European Journal of Operational Research, 91, pp. 38-55. 
Tagaras, G. (1998). "A Survey of Recent Developments in the Design of Adaptive Control Charts". Journal of Quality Technology, 30(3), pp. 212-231.

Taguchi, G., Elsayed, E., and Hsiang, T. (1989). Quality Engineering in Production Systems. Mc-Graw-Hill, New York.

Tang, C. S. (1991). "Designing an Optimal Production System with Inspection". European Journal of Operations Research, 52, pp. 45-54.

Tannock, J. D. T. (1995). "Choice of Inspection Strategy Using Quality Simulation". International Journal of Quality and Reliability Management, 12(5), pp. 75-84.

Tannock, J. D. T. (1997). "An Economic Comparison of Inspection and Control Charting Using Simulation". International Journal of Quality and Reliability Management, 14(7), pp. 687-699.

Troutt, M. D., Ambrose, P. J., and Chan, C. K. (2001). "Optimal Throughput for Multistage Input-Output Processes". International Journal of Operations and Production Management, 21(1/2), pp. 148158.

Van Volsem, S. (2002). "Optimizing Inspection Strategies for MultiStage Process Chains: A Case Study". 16th triennial IFORS conference, International Federation of Operational Research Societies.

Van Volsem, S., Dullaert, W., and Van Landeghem, H. (2006). "An Evolutionary Algorithm and Discrete Event Simulation for Optimizing Inspection Strategies for Multi-Stage Processes". European Journal of Operational Research.

Van Volsem, S. and Van Landeghem, R. (2003). "Optimizing Inspection Strategies for Multi-Stage Processes: An Exploratory Modelling Framework and Simulation". 5th international QUALITA conference, Institut de Sûreté Industrielle.

Villalobos, J. R., Foster, J. W., and Disney, R. L. (1993). "Flexible Inspection Systems for Serial Multi-Stage Production Systems". IIE Transactions, 25(3), pp. 16-26. 
Wasserman, G. S. (1996). "A Case Study Illustrating the Existence of Dynamics in Traditional Cost-of-Quality Models". Quality Engineering, 9(1), pp. 119-128.

Wasserman, G. S. and Lindland, J. L. (1994). "Minimizing the Cost of Quality over Time: A Dynamic Quality Cost Model". 48th Annual ASQC Quality Congress Transactions, Las Vegas, Nevada.

Wei, C.-C., Lee, Y.-H., and Chang, C.-L. (1999). "Maximum Conformance Rate-Based Tolerance Design". Integrated Manufacturing Systems, 10(5), pp. 284-288.

White, L. S. (1969). "Shortest Route Models for the Allocation of Inspection Effort on a Production Line". Management Science, 15(5), pp. 249-259.

Winston, W. L. (1991). Introduction to Mathematical Programming Applications and Algorithms. PWS-Kent Publishing Company.

Wonnacott, T. and Wonnacott, R. (1990). Introductory Statistics for Business and Economics. John Wiley \& sons.

Zhang, H. C. and Huq, M. (1992). "Tolerancing Techniques: The Stateof-the-Art". International Journal of Production Research, 30(9), pp. 2111-2135. 